Data de Depósito:

Assinatura:

\title{
Minimal hyperlinking HyTime documents: especificação e apresentação de estruturas clássicas de hipertexto ${ }^{1}$
}

\author{
Ciro Cirne Trindade
}

Orientadora: Profa. Dra. Maria da Graça Campos Pimentel

\author{
Dissertação apresentada ao Instituto de Ciências \\ Matemáticas e de Computação - ICMC-USP - como parte \\ dos requisitos para a obtenção do título de Mestre em \\ Ciências da Computação e Matemática Computacional. \\ USP - São Carlos \\ Fevereiro/1997
}

${ }^{1}$ Este trabalho contou com o apoio financeiro da Capes. 
Minimal hyperlinking HyTime documents: especificação e apresentação de estruturas clássicas de hipertexto

Ciro Cirne Trindade 
Aos meus pais,

Ivo Trindade e

Maria de Lourdes Cirne Trindade 


\section{Agradecimentos}

À Prof ${ }^{\mathrm{a}}$. Dr ${ }^{\mathrm{a}}$. Maria da Graça Campos Pimentel, pela orientação, dedicação, paciência e ensinamentos sem os quais esse trabalho não teria sido concluído.

Aos meus pais, Ivo Trindade e Maria de Lourdes Cirne Trindade, pelo enorme apoio, compreensão, educação, paciência e carinho a mim dedicados durante toda a vida e em especial nesse período em não pudemos estar juntos. Sem vocês eu nada seria.

À Shirley, pelo incentivo, paciência, companhia e carinho a mim dispensados, fundamentais no decorrer desse trabalho.

À Lloyd Rutledge, pelas sugestões dadas durante a elaboração do DTD CHTS.

Aos colegas envolvidos no projeto SMmD: Richard, Chorfi, Gustavo, Chaves, Willie, Fabiano, Laércio, Laura e Vinícius, pela colaboração.

Aos colegas do Intermídia, pela camaradagem e pelos churrascos.

Ao pessoal do Telemídia da PUC-Rio, em especial a Luiz Fernando, Guido Lemos e ao velho amigo dos tempos de UFRN, Fábio Costa, pela oportunidade do convívio e pelos conhecimentos adquiridos sobre o NCM.

Aos colegas de sala: Victor, Rogério, Sarita e Rudnei, e aos amigos de república: Miguel, Emanoel (vulgo Chicão), Gilson e Márcio, pela amizade, companheirismo, apóio e paciência.

Aos técnicos do LDCC: Sônia, Ângelo, Luciano e Rogério, pela atenção dispensada.

Às jovens da secretaria da Pós: Beth, Laura e Marília, e da biblioteca: Silvana, Gislene, Maria, Sandra, Rose e Giselda, pela atenção, simpatia e prestatividade sempre demonstradas.

À CAPES, pelo apoio financeiro. 


\section{RESUMO}

Os hiperdocumentos manipulados pelos sistemas hipertexto clássicos não podem ser utilizados em outro sistema ou plataforma. O padrão HyTime, uma extensão de SGML, constitui um esforço para permitir que documentos hipermídia e multimídia possam ser descritos em termos de sua estrutura e conteúdo e, desse modo, ser utilizados por quaisquer sistemas conformantes. Esse trabalho investiga os recursos para especificação de hiperdocumentos hipermídia de HyTime, em particular, aqueles providos por um Minimal hyperlinking HyTime document, uma classe de documentos definida pelo padrão.

Como resultado deste trabalho, algumas estruturas tradicionais da literatura sobre hipertexto foram especificadas em um DTD através de construtores HyTime, um sistema básico hipermídia para autoria e apresentação dessas estruturas foi modelado, e a codificação da apresentação dessas estruturas através de applets Java foi implementada para que elas possam ser utilizadas no ambiente da WWW.

\section{Abstract}

Classic Hypertext Systems have defined their documents so that they cannot be interchanged between systems or platforms. HyTime is an ISO standard, built as an extension of SGML, defined so as to allow the specification of multimedia and hypermedia documents to be made in terms of their stucture and contents - as a result hyperdocuments can be interchanged among any HyTime conforming systems. The work reported in this dissertation investigates what sort of documents are those conforming to Minimal hyperlinking HyTime documents.

As a result, the work presents (a) the specification of a DTD that allows constructors supported in several classic hypertext systems, (b) the architecure of a conforming hypermedia environment and (c) a Java implementation for the constructors specified — so that the underlying classic hypertext structure can be made available in a open distributed hypermedia system such the WWW. 


\section{CONTEÚDo}



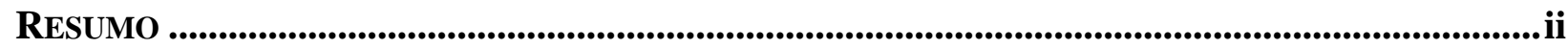

ABSTRACT .................................................................................................................................................

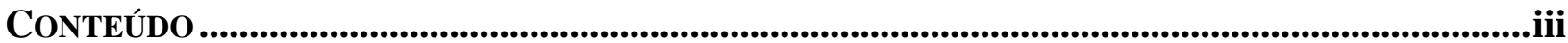

ÍNDICE DE FIGURAS ......................................................................................................................vii

LISTA DE ABREVIATURAS .....................................................................................................................

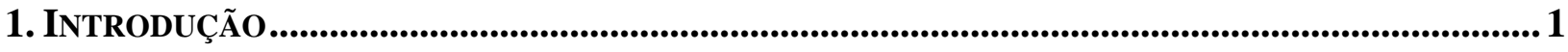

2. DOCUMENTOS ESTRUTURADOS ....................................................................................................

2.1 Considerações Iniciais ..................................................................................................

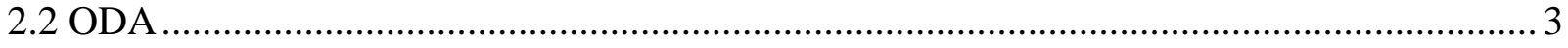

2.2.1 Estruturas Específicas de ODA ……………………..............................................

2.2.2 Arquiteturas Genéricas de ODA.................................................................................. 5

2.2.3 O Processo de Layout de ODA.................................................................................. 7

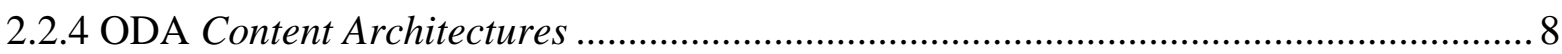

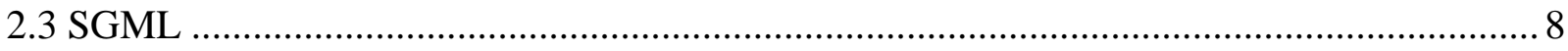

2.3.1 DTD



2.3.3 Atributos ………………………………………………………………………. 11

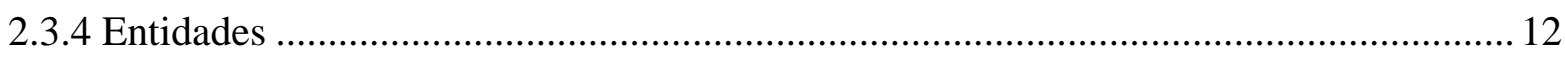

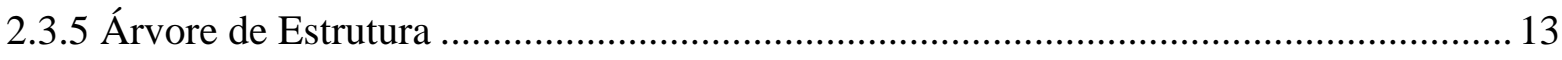

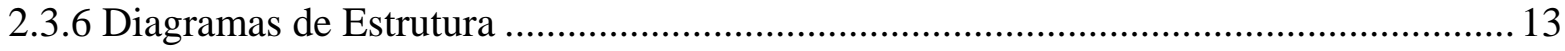

2.3.7 SGML Parser ..................................................................................................... 15

2.3.8 Declarações de Marcação ........................................................................................... 15 


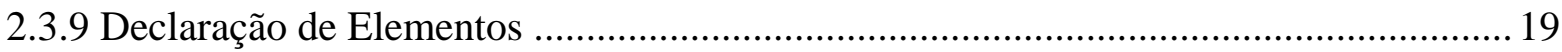



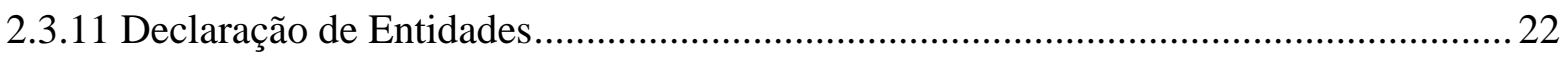

2.3.12 Instância de um Documento SGML ........................................................................ 24

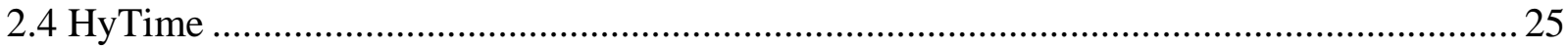

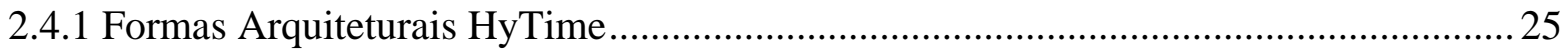

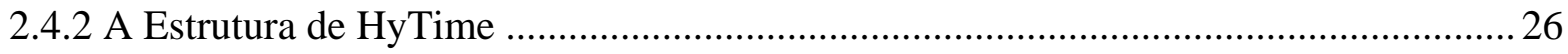

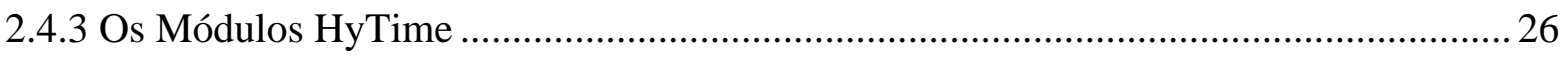

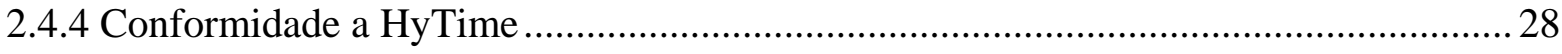



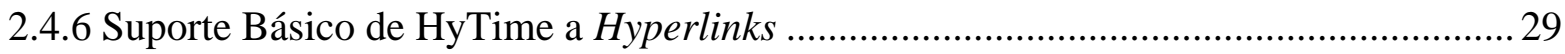



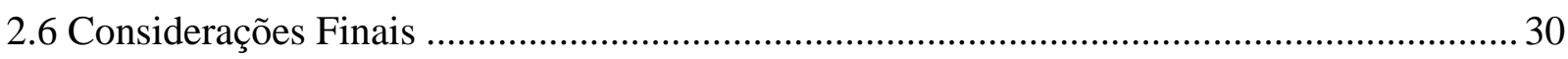

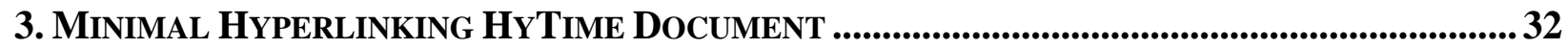



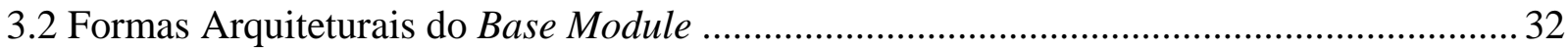

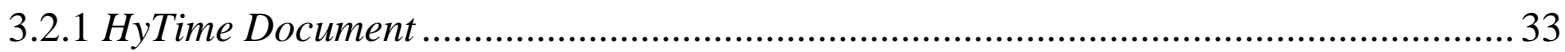

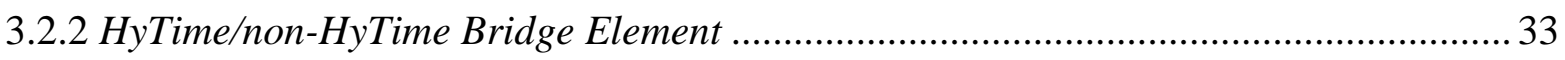

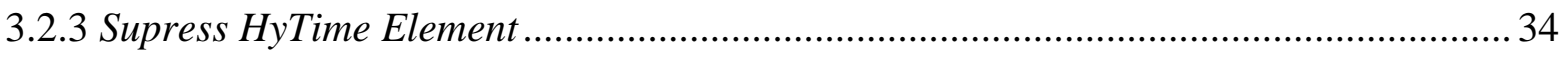

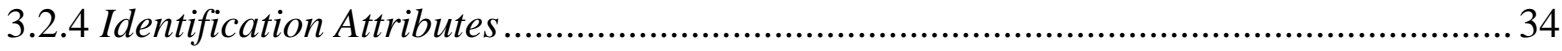

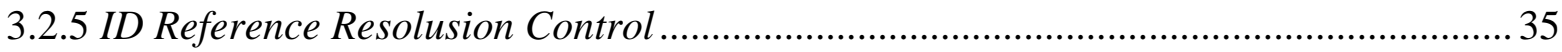

3.3 Formas Arquiteturais do Location Address Module ........................................................... 35

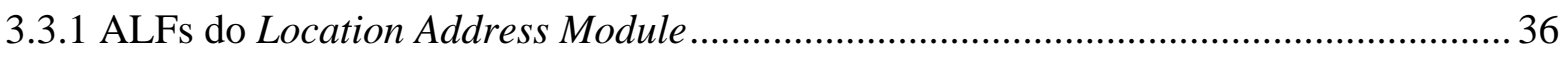

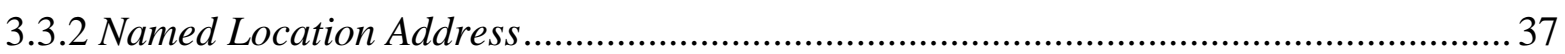

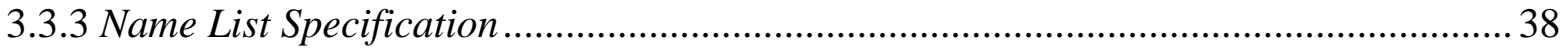

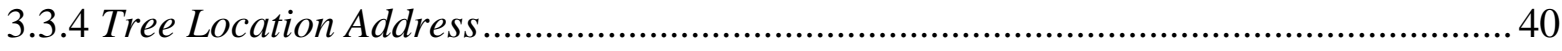

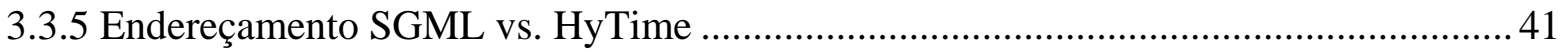

3.4 Formas Arquiteturais do Hyperlinks Module .................................................................... 43



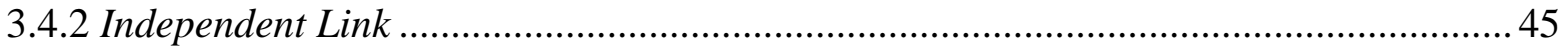




4. MOdELOS E SISTEMAS HIPERMÍDIA .................................................................................................. 47

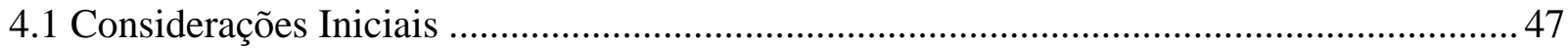

4.2 Modelos Hipermídia para a Estruturação de Hiperdocumentos .......................................... 47

4.2.1 Dexter Hypertext Reference Model.............................................................................. 47

4.2.2 NCM - Nested Context Model............................................................................... 49

4.3 Modelos Hipermídia para a Estruturação de Aplicações ..................................................... 50

4.3.1 HDM - Hypertext Design Model ................................................................................ 50

4.3.2 AHM - Amsterdam Hypermedia Model................................................................... 51

4.3.3 RMM - Relationship Management Methodology .................................................... 53

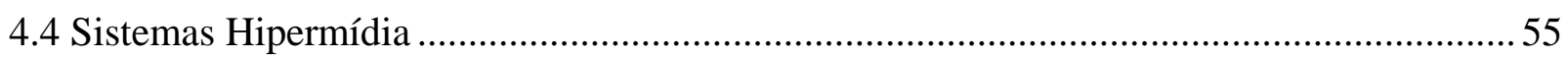



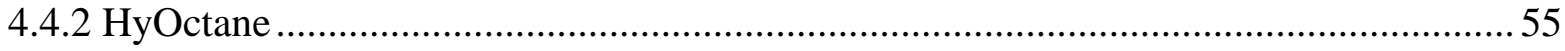

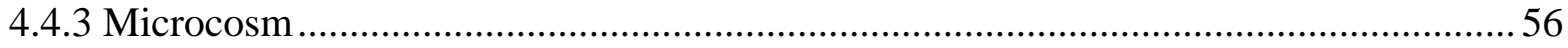

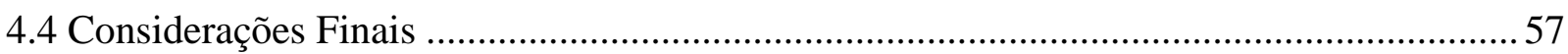

5. CHTS: CLASSIC HYPERTEXT STRUCTURES EM HYTIME................................................58



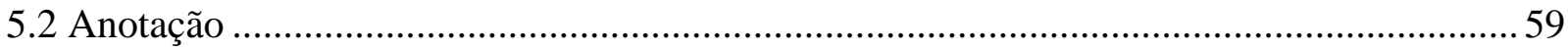

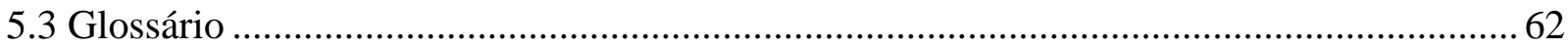

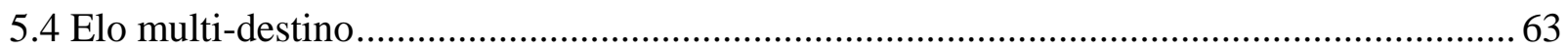

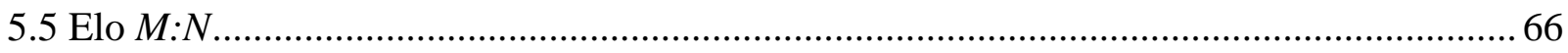

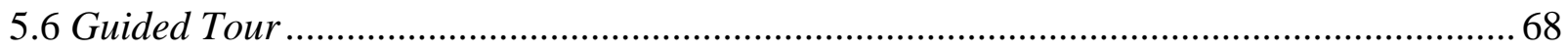

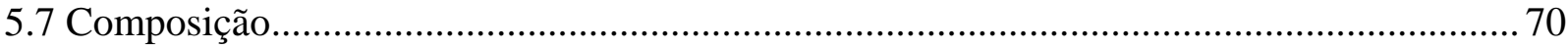

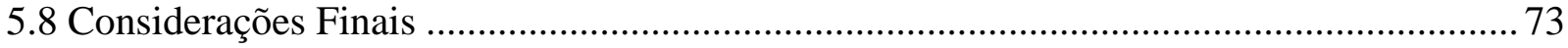

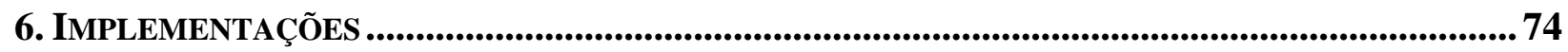





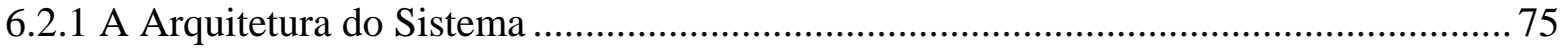

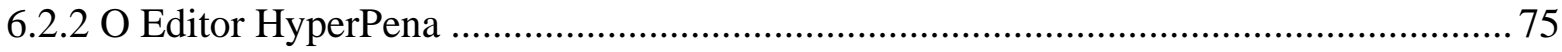

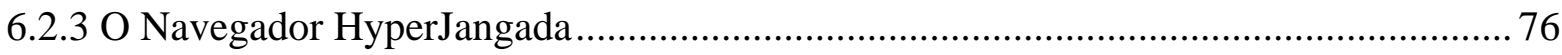

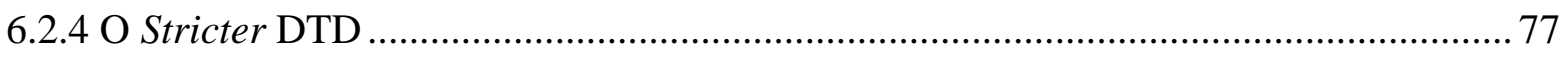






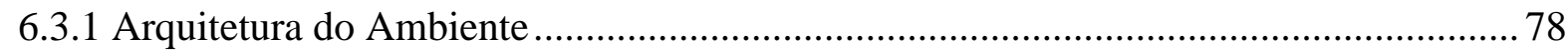

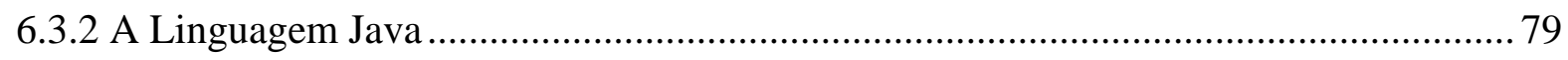

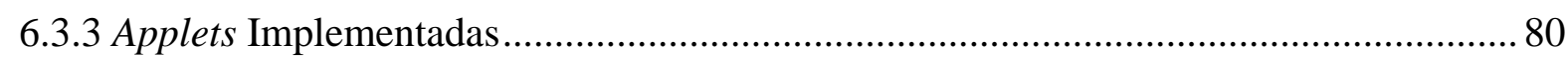

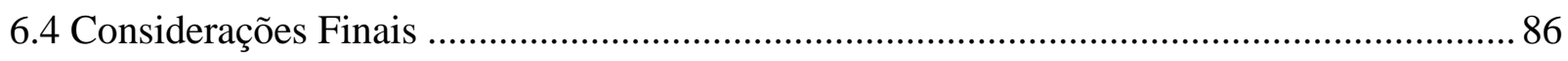

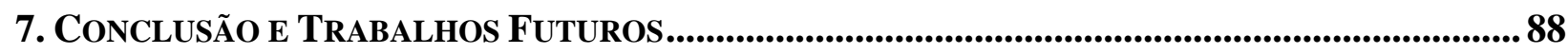

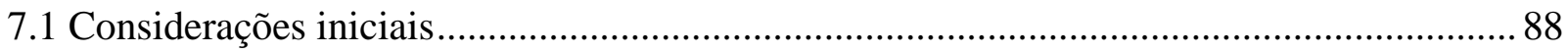





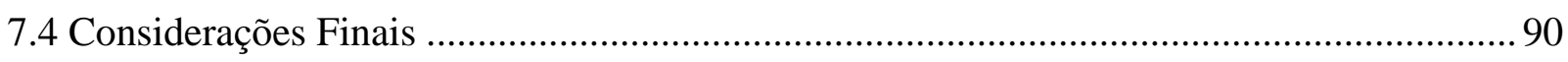

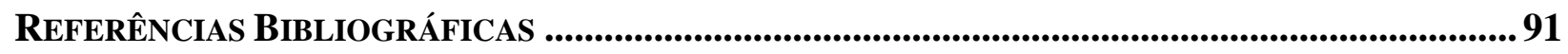

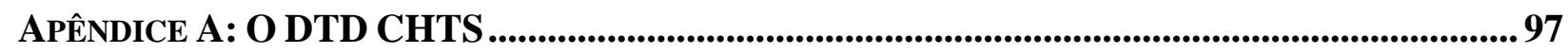

APÊNDICE B: TELAS DO HYPERPENA E HYPERJANGADA...................................................... 102

APÊNDICE C: SCREEN DUMPS DAS APPLETS IMPLEMENTADAS.......................................... 107 


\section{ÍNDICE DE FIGURAS}

Figura 2.1: Estruturas lógica e de layout (Brown 89a) ................................................................ 4

Figura 2.2: Layout do documento nas páginas (Brown 89a).................................................. 5

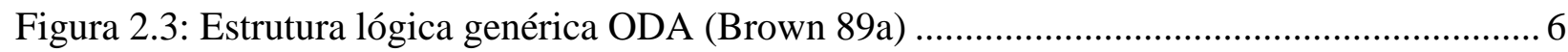

Figura 2.4: Instância do “Conjunto de páginas para parte” (Brown 89a) ..................................... 6

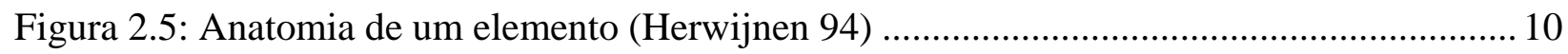

Figura 2.6: Exemplo de um documento SGML .................................................................. 11

Figura 2.7: Árvore de estrutura para uma Dissertação........................................................... 13

Figura 2.8: Sete tipos de diagramas de estrutura (Herwijnen 94) ............................................ 14

Figura 2.9: Diagrama de estrutura para um elemento terminal (Herwijnen 94) .......................... 14

Figura 2.10: Diagramas de estrutura para uma Dissertação .................................................... 15

Figura 2.11: DTD para uma dissertação........................................................................ 16

Figura 2.12: Correspondência entre diagramas de estrutura e model groups (Herwijnen 94)...... 18

Figura 2.13: Interdependência dos módulos HyTime (Rutledge 95) ........................................ 26

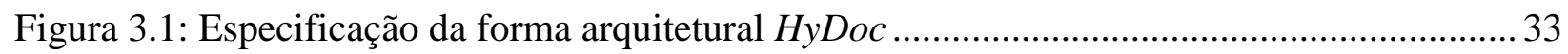

Figura 3.2: Especificação da forma arquitetural HyBrid......................................................... 33

Figura 3.3: Especificação da forma arquitetural sHyTime ..................................................... 34

Figura 3.4: Especificação da forma arquitetural all-id............................................................... 34

Figura 3.5: Especificação da forma arquitetural all-ref .......................................................... 35

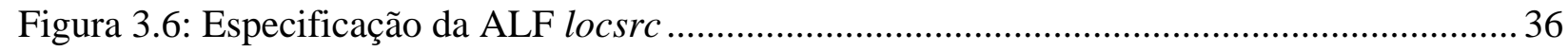

Figura 3.7: Especificação da forma arquitetural multloc ..................................................... 37

Figura 3.8: Especificação da forma arquitetural nameloc........................................................ 38

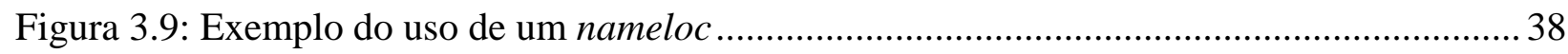


Figura 3.10: Especificação da forma arquitetural nmlist......................................................... 38





Figura 3.13: Exemplo de uma árvore de documento (DeRose \& Duran 94) .............................. 40

Figura 3.14: Especificação da forma arquitetural clink .......................................................... 44

Figura 3.15: Um clink HyTime e sua conversão HTML (Rutledge 96a) ................................... 44

Figura 3.16: Especificação da forma arquitetural ilink ......................................................... 45

Figura 3.17: Tipos de elo a partir de uma âncora aggtrav (Rutledge 95).................................. 45

Figura 4.1: Hierarquia das classes NCM (Soares et al. 95b)................................................... 49

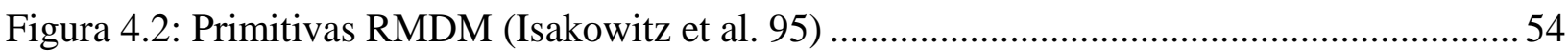

Figura 5.1: Relacionamento entre os arquivos de uma anotação .............................................. 59

Figura 5.2: Definição do elemento annot (annotation) …....................................................... 59

Figura 5.3: Instância de um arquivo do tipo web of links para anotações................................... 60

Figura 5.4: Árvore de estruturas do documento index.html................................................... 61

Figura 5.5: Documento com as anotações (annot.sgml) ........................................................... 61

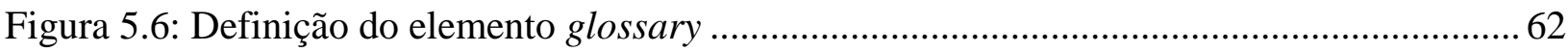



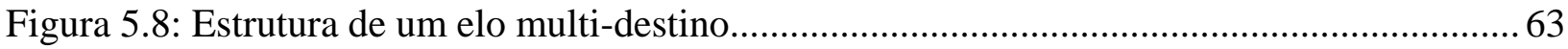

Figura 5.9: Definiç̧ão do elemento mtarglnk ............................................................................ 64

Figura 5.10: Trecho de um documento HTML (index.html) ................................................. 64

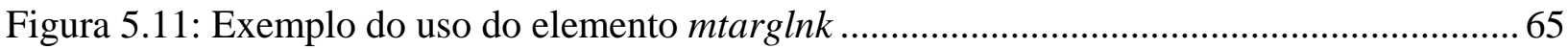

Figura 5.12: Apresentação de um elo multi-destino ................................................................66

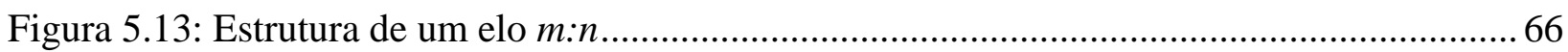

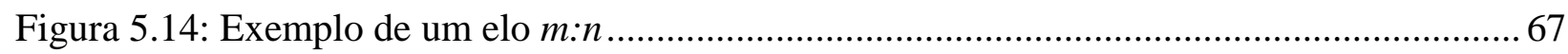

Figura 5.15: Instância de um web of links contendo um elemento m-nlnk ............................... 68

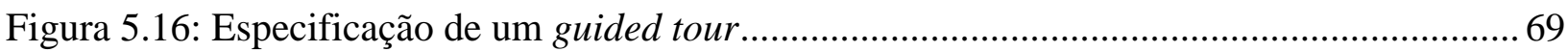




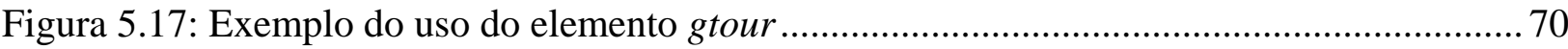

Figura 5.18: Especificação do elemento composit ..................................................................... 71

Figura 5.19: Ilustração de um nó de composição ....................................................................... 72

Figura 5.20: Especificação do nó de composição mostrado na Figura 5.19 ............................... 72



Figura 6.2: Arquitetura do ambiente baseado em applets Java ................................................. 78

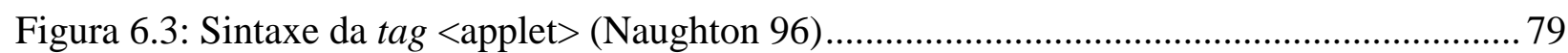

Figura 6.4: Inclusão da applet para anotações em um documento HTML ................................. 81

Figura 6.5: Elemento annot alterado para a apresentação através de uma applet........................ 81



Figura 6.7: Inclusão da applet para glossários em um documento HTML ................................ 82

Figura 6.8: Inclusão da applet para elos multi-destino em um documento HTML ..................... 83

Figura 6.9: Exemplo de um documento com o elemento mtarglnk ........................................ 84

Figura 6.10: Inclusão da applet para guided tours em um documento HTML ............................ 85

Figura 6.11: Exemplo de um arquivo contento o elemento $g$-tour ............................................ 85

Figura 6.12: Inclusão da applet para composições em um documento HTML ...........................86

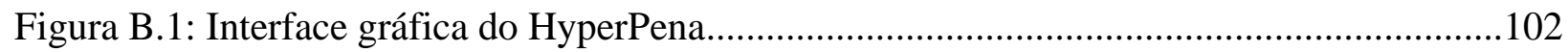

Figura B.2: Sensibilidade a contexto no HyperPena ................................................................. 103

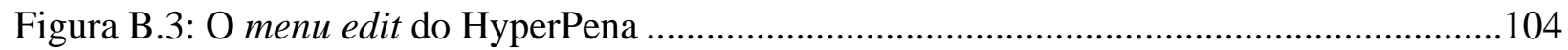

Figura B.4: Tratamento dos caracteres acentuados no HyperPena .........................................104

Figura B.5: Validação de um hiperdocumento no HyperPena .................................................. 105

Figura B.6: Interface gráfica do HyperJangada ..................................................................... 106

Figura C.1: Interface gráfica da applet para anotações ........................................................ 107

Figura C.2: Interface gráfica da applet para glossários....................................................... 108

Figura C.3: Interface gráfica da applet para elos multi-destino ............................................. 109

Figura C.4: Interface gráfica da applet para guided tours................................................... 110 


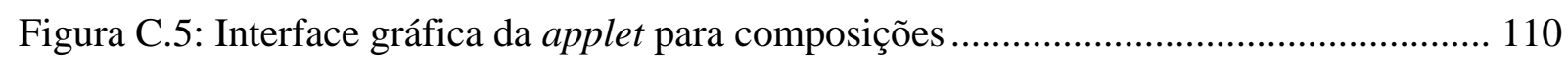




\section{Lista DE ABREVIATURAS}

$\mathrm{AF}$ Architectural Form

ALF Attribute List Form

CHTS. Classic Hypertext Structures

DTD .Document Type Definition

ETF Element Type Form

HTML Hypertext Markup Language

HyTime Hypermedia/Time-Based Structuring Language

ICMSC .Instituto de Ciências Matemáticas de São Carlos

ISO International Organization for Stardadization ODA Office Document Architecture SGML Standard Generalized Markup Language

URL Uniform Resource Locator WWW Word-Wide Web 


\section{INTRODUÇÃO}

Os sistemas hipertexto clássicos desenvolvidos nos anos 80 evoluíram de modo independente, e essa independência se refletiu nos hiperdocumentos por eles manipulados. Como conseqüência, os hiperdocumentos gerados por um sistema não podem ser utilizados em outro sistema ou plataforma. O Dexter Reference Model (Halasz \& Schwartz 90) foi proposto ao final dos anos 80 como parte de um esforço para permitir a reutilização do conteúdo e da estrutura de hiperdocumentos por sistemas distintos. Dexter tem evoluído lentamente (Halasz \& Schwartz 94) (Hardman et al. 94) (Grøbæk 94) (Garzotto et al. 94) e ainda é objeto de pesquisa.

O padrão HyTime (Hypermedia/Time-Based Structuring Language) (Newcomb et al. 91) (ISO 92) foi desenvolvido pela ISO num esforço paralelo ao Dexter, com o objetivo de permitir que hiperdocumentos hipermídia possam ser descritos em termos de sua estrutura e conteúdo e, desse modo, possam ser utilizados por quaisquer sistemas conformantes. HyTime foi proposto como uma extensão do padrão SGML (Standard Generalized Markup Language) (ISO 86) (Goldfard 95) e, similarmente a SGML, prevê que o conteúdo de um documento seja definido independentemente da forma de apresentação. HyTime permite a formalização de estruturas hipertexto e hipermídia complexas e, assim como o Dexter, tem sido explorado basicamente em pesquisas (Buford et al. 94a) (Buford et al. 94b) (Buford et al. 94c) (Pimentel 95) (Pimentel et al. 96), e de modo limitado, devido principalmente à sua complexidade (Buford 96).

Atualmente muito mais popular que HyTime, a linguagem HTML (Hypertext Markup Language) é um formato para hipertextos bastante simples e largamente utilizado (Berners-Lee et al. 94). Essa linguagem é formalmente definida por SGML e é o principal formato para a informação disponível na WWW (World-Wide Web) — um ambiente distribuído para hipertextos construído na Internet que recebeu grande aceitação e adoção. Porém, devido à sua simplicidade, HTML não provê várias estruturas disponíveis em sistemas hipermídia clássicos.

Explorando a relação entre HyTime e HTML, foram feitas propostas para tornar HTML conformante a HyTime (Rutledge et al. 95) (DeRose \& Duran 94) e para permitir a apresentação de documentos HyTime na WWW (Rutledge 96a). Apesar da aplicação de HyTime a HTML, e vice-versa, ser facilitada pela relação de ambos com SGML, essas propostas são limitadas uma vez que impõem a simplicidade de HTML ao mesmo tempo que não exploram a flexibilidade de HyTime.

Portanto, identifica-se um desequilíbrio entre HyTime e HTML. Enquanto o primeiro permite a especificação de estruturas complexas e flexíveis, sua complexidade o torna pouco difundido. Já o segundo tem sua popularidade favorecida pela sua simplicidade — apesar dessa simplicidade se estender à estrutura suportada. 
Surge, deste modo, a oportunidade de investigar como o padrão HyTime pode ser utilizado na especificação de hiperdocumentos que (a) admitem estruturas clássicas e (b) são manipulados por aplicações similares àquelas encontradas hoje na WWW.

Nesse sentido, os objetivos do trabalho reportado nesta dissertação são:

- investigar o padrão HyTime, principalmente seu subconjunto Minimal hyperlinking HyTime document;

- demonstrar o contexto de HyTime dentro de outros modelos da literatura de hipertexto;

- demonstrar como uma classe de hiperdocumentos que suporte as estruturas clássicas da tecnologia hipermídia pode ser especificada em HyTime;

- determinar como documentos conformantes com a classe especificada podem ser apresentados em um ambiente dedicado e também na WWW.

Faz parte da proposta de alguns sistemas em desenvolvimento (Soares et al. 95a) (Teixeira et al. 95) (Moreira et al. 95), em cujo contexto esta dissertação está inserida, a investigação de padrões como SGML e HyTime e a conformância aos mesmos. Mais especificamente, no âmbito deste trabalho, estão previstas a modelagem de um ambiente que permita a manipulação de documentos conformantes com esses padrões e a investigação de mecanismos para disponibilização desses documentos na WWW.

Uma alternativa viável para a disponibilização de estruturas complexas na WWW é o uso de applets - pequenos programas Java que podem ser ativados a partir de documentos HTML quando este é apresentado por uma aplicação que contenha a Java Virtual Machine (Sun 97) (Naughton 96). Devido à sua portabilidade e larga adoção, uma apresentação codificada em Java pode ser visualizada praticamente em toda WWW. Conseqüentemente, uma classe de documentos HyTime torna-se mais disponível se uma aplicação tomar qualquer documento dessa classe e gerar uma apresentação codificada em Java (Rutledge 96b).

Os demais capítulos desse trabalho estão assim organizados: o próximo capítulo apresenta uma visão geral dos padrões ODA, SGML e HyTime, além de uma breve discussão sobre HTML; o Capítulo 3 descreve as principais formas arquiteturais do Minimal hyperlinking HyTime document, um subconjunto de HyTime; o Capítulo 4 expõe alguns sistemas e modelos hipermídia reportados na literatura atual do ponto de vista da modelagem de hiperdocumentos e de aplicações hipermídia; o Capítulo 5 apresenta a descrição das estruturas formalizadas no DTD CHTS (Classic Hypertext Structures) proposto neste trabalho; o Capítulo 6 trata da modelagem de dois ambientes que permitem a manipulação de documentos conformantes com o DTD CHTS; e o último capítulo apresenta as conclusões e as propostas de continuidade deste trabalho. 


\section{DOCUMENTOS ESTRUTURADOS}

\subsection{Considerações Iniciais}

Este capítulo apresenta três padrões internacionais que propõem a representação e o intercâmbio de documentos estruturados: ODA, SGML e HyTime. Discute ainda HTML, uma linguagem definida por um DTD SGML que é, atualmente, o padrão adotado na WWW para a representação de hiperdocumentos.

Diferentemente de SGML e HyTime, ODA é um padrão que especifica a forma de apresentação dos documentos, e é apresentado para dar uma visão completa sobre essas duas classes de padrões.

\subsection{ODA}

O padrão ODA (Office Document Architecture) (ISO 89) é discutido por Heather Brown em (Brown 89a). ODA é um modelo para documentos hierárquico e orientado a objetos. Objetos representam os componentes do documento, e atributos provêem informações a respeito dos objetos. Um documento pode ser visto como uma árvore, na qual a estrutura do documento é definida pelo formato da árvore e o conteúdo é armazenado nas folhas da árvore. Essa separação entre conteúdo e estrutura é fundamental para a representação de documentos multimídia. Cada objeto folha possui um atributo que define o tipo de seu conteúdo associado. As regras para manipulação de diferentes tipos de conteúdo são conhecidas por content architectures.

As próximas sessões introduzem as principais características das estruturas de documentos ODA, dão um esboço do processo de layout de ODA e uma breve revisão das content architectures.

\subsubsection{Estruturas Específicas de ODA}

Um documento ODA é descrito por uma estrutura lógica e uma estrutura de layout. A estrutura lógica divide o documento em itens, enquanto a estrutura de layout divide a representação visível do documento em áreas retangulares.

Objetos lógicos podem representar itens genéricos como títulos e parágrafos, ou itens mais especializados como legendas de figuras e referências bibliográficas. Objetos de layout, por sua vez, representam conjuntos de páginas, páginas e áreas retangulares dentro de páginas. Essas áreas retangulares podem ser aninhadas. Por definição, áreas com outras áreas definidas dentro 
delas são chamadas de quadros (frames), enquanto as áreas de mais baixo nível são chamadas de blocos. Um quadro pode ser usado para representar uma coluna de texto, por exemplo, com blocos aninhados representando as áreas usadas por parágrafos dentro da coluna.

O conteúdo do documento é claramente comum às duas estruturas e provê a ligação entre elas. Para ilustrar essas estruturas será usado como exemplo um documento técnico dividido em Partes e Sessões. Cada "Parte" tem um título seguido por uma ou mais "Sessões", que por sua vez possui um subtítulo seguido por um ou mais parágrafos. Na Figura 2.1 são mostradas as estruturas lógica e de layout de um fragmento desse documento extraído do início de uma nova "Parte”. Nesse exemplo é assumido que uma nova "Parte” começa em uma nova página.



Figura 2.1: Estruturas lógica e de layout (Brown 89a)

A estrutura lógica mostra que o fragmento de documento da Figura 2.1 consiste no título da Parte e no início da primeira Seção, incluindo o subtítulo e três parágrafos. Somente as folhas da estrutura lógica — os títulos e parágrafos — têm conteúdo associado. A estrutura de layout mostra que só há espaço para os dois primeiros parágrafos na primeira página. Novamente, somente as folhas — os blocos — têm conteúdo associado a elas. A Figura 2.2 ilustra como o fragmento do documento seria apresentado no papel. 




Figura 2.2: Layout do documento nas páginas (Brown 89a)

\subsubsection{Arquiteturas Genéricas de ODA}

As arquiteturas genéricas de ODA provêem um meio para definir classes de documentos ou estilos. Eles consistem em dois conjuntos de descrições de classes de objetos (uma para objetos lógicos e outra para objetos de layout) que definem os tipos e combinações de objetos permitidas. Em particular, a descrição de classe de cada objeto não-folha inclui um atributo chamado gerador de subordinados que define como um objeto pode ser formado por objetos subordinados. Esse atributo especifica que um subordinado pode ser:

- opcional (OPT: 0 ou 1 ocorrência)

- requerido (REQ: exatamente 1 ocorrência)

- repetitivo (REP: 1 ou mais ocorrências)

- opcional e repetitivo (OPT REP: 0, 1 ou mais ocorrências)

Adicionalmente, grupos de subordinados podem ser expressos como:

- uma seqüência (SEQ: ocorrem na ordem especificada)

- um agregado (AGG: ocorrem em qualquer ordem)

- uma escolha (CHO: somente um dos grupos ocorre)

Uma estrutura genérica para uma "Parte" no documento tomado como exemplo seria definida como ilustrado na Figura 2.3. É assumido que todos os objetos são requeridos (REQ), a não ser que seja indicado o contrário. Desse modo, isto indica que uma "Parte" começa por um título requerido, seguido opcionalmente pelo nome do autor, seguido por uma ou mais sessões. Cada "Seção" começa por um subtítulo requerido e depois consiste em uma mistura de parágrafos, diagramas e listas. REP CHO indica uma série de um ou mais itens que ocorrem em qualquer ordem. Diagramas, por sua vez, consistem em uma figura e uma legenda (em qualquer 
ordem), e listas consistem em um ou mais itens. As palavras em itálico que aparecem na Figura 2.3 são relativas ao layout e serão explicadas posteriormente.

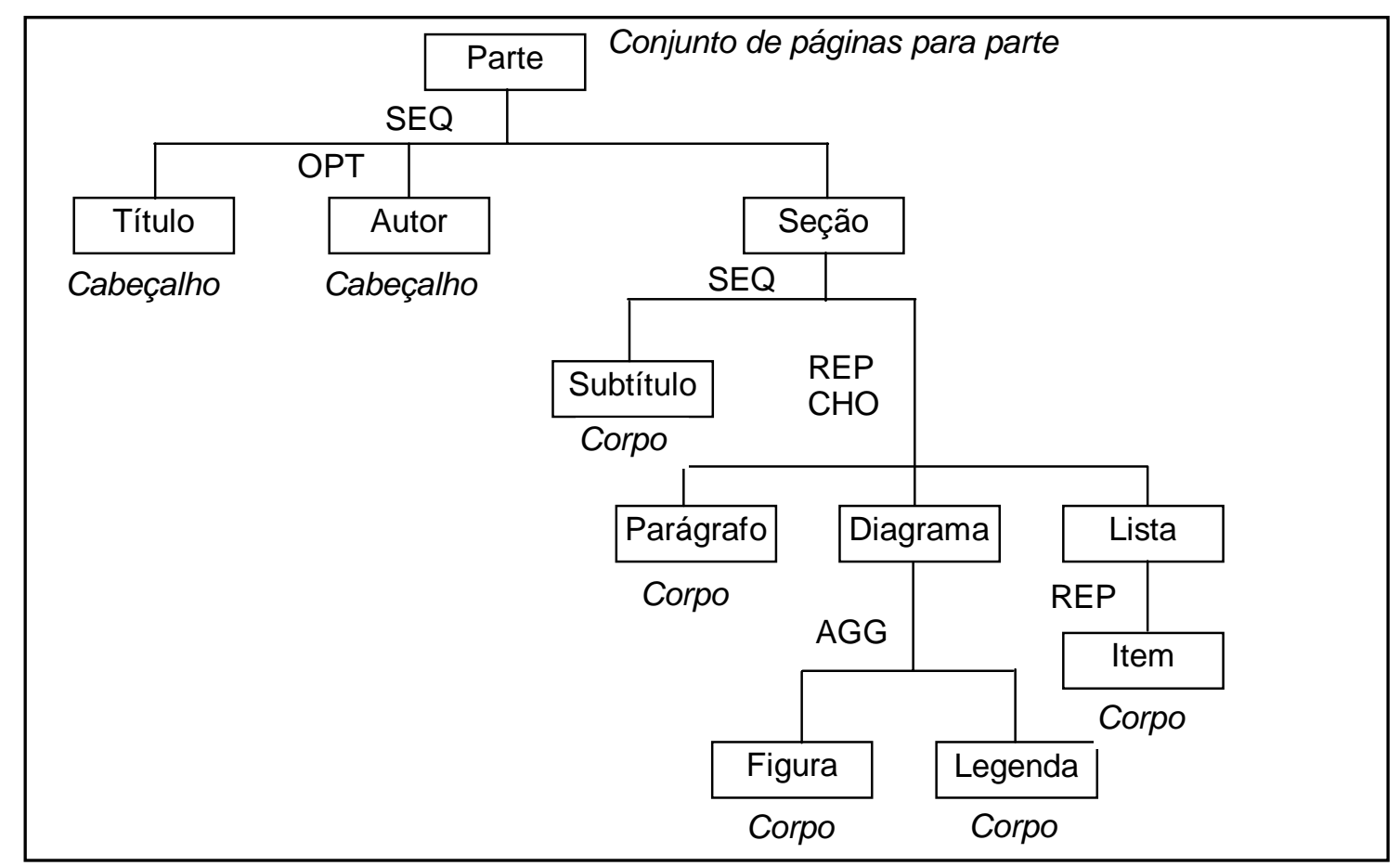

Figura 2.3: Estrutura lógica genérica ODA (Brown 89a)

Uma estrutura de layout genérica correspondente deve definir um conjunto de páginas, por exemplo, “Conjunto de páginas para parte”, contendo uma "Página de título” requerida, seguida por zero ou mais "Páginas de continuação”. A Figura 2.4 ilustra uma instância simples de um conjunto de páginas com uma única página de continuação. Os quadros mostrados dentro das páginas representam as áreas para armazenar informações do título e do corpo do texto. Blocos não são incluídos na estrutura de layout genérica. Ao invés disso, eles são atribuídos a páginas e quadros durante o processo de layout, como descrito na próxima seção.

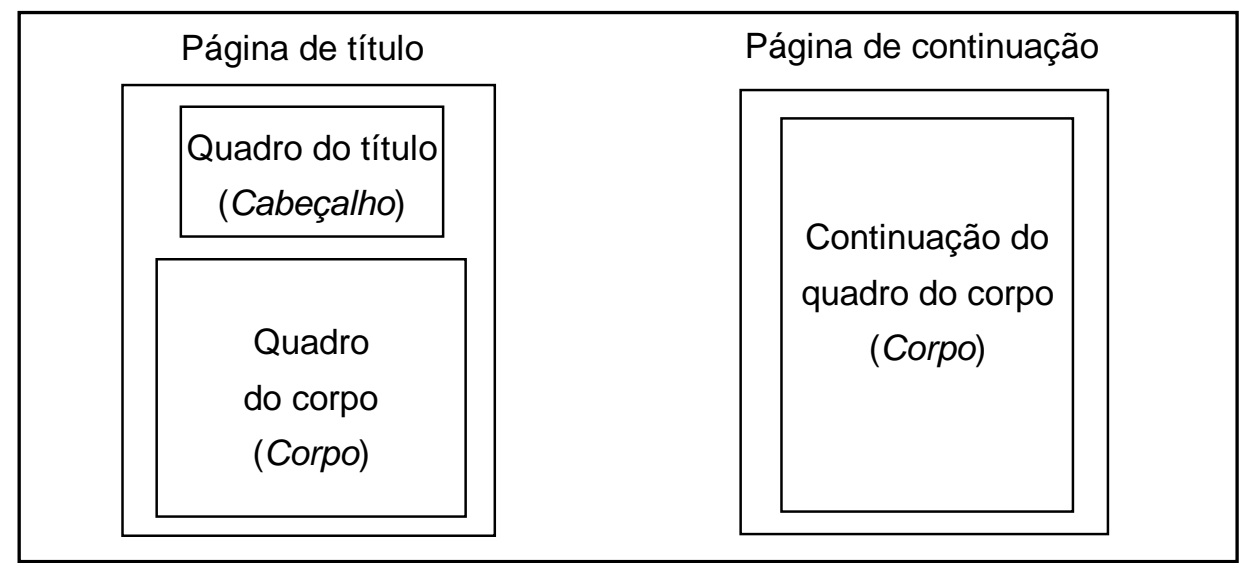

Figura 2.4: Instância do “Conjunto de páginas para parte” (Brown 89a) 


\subsubsection{O Processo de Layout de ODA}

O processo de layout de ODA determina onde e como cada item do documento será alocado. Ele usa a estrutura lógica específica, as estruturas genéricas e as content architectures para criar a estrutura de layout específica do documento. O processo de layout de ODA trabalha em dois níveis:

- Layout do conteúdo: organiza porções do conteúdo em blocos. Esse estágio é dependente das content architectures envolvidas e de um conjunto de atributos conhecido por presentation style. Esse nível trata de detalhes sutis como o posicionamento de caracteres ou pixels dentro dos blocos.

- Layout do documento: especifica limitações para os blocos criados pelo processo de layout do conteúdo (por exemplo, tamanho máximo) e aloca esses blocos em páginas e quadros apropriados. Esse estágio é dependente de um conjunto de atributos conhecido por layout styles. As principais características desse estágio são descritas a seguir.

Um passo crucial no processo de layout é a determinação de quais classes de objetos de layout devem ser usadas para um determinado objeto lógico. Três atributos são usados para tomar essa decisão: layout object class, layout category e permitted categories. Duas delas, layout object class e permitted categories, se aplicam a objetos lógicos e são parte do conjunto de atributos conhecido por layout styles. O terceiro, permitted categories, se aplica a quadros. Os itens representados em itálico nas Figuras 2.3 e 2.4 se referem aos valores desses atributos.

A layout object class é usada para indicar que o objeto lógico completo (com todos os seus subordinados) deve ser organizado em uma única instância de um determinado objeto de layout. Nenhuma outra parte do documento deve compartilhar o mesmo objeto de layout. Com isso, é possível dividir logicamente o documento em páginas ou conjuntos de páginas. No exemplo da Figura 2.4, "Parte" tem sua layout object class definida como "Conjunto de páginas para parte" e cada "Parte" é, portanto, organizada em uma instância separada do conjunto de páginas, com uma única "página de título" e quantas "páginas de continuação" forem necessárias.

A layout category e as permitted categories são fornecidas para associar objetos lógicos folha a quadros. A layout category associa um nome a um objeto lógico folha. Dessa forma, o conteúdo do objeto pode ser organizado somente em um quadro que tenha o mesmo nome especificado como uma de suas permitted categories. Nos exemplos apresentados anteriormente, é mantido um relacionamento simples entre objetos lógicos folha e quadros, e são usados somente dois nomes de categorias, "Cabeçalho" e "Corpo", como pode ser visto nas Figuras 2.3 e 2.4 .

Portanto, quando o processo de layout do documento começa uma nova "Parte", ele cria um novo "Conjunto de páginas para parte" consistindo inicialmente de uma única "página de título". Os nomes de categorias, então, dirigem o "título" e o "autor" (se presentes) para o "quadro de título", e itens subseqüentes para o "quadro do corpo" na "página de título". Se o "quadro do corpo" ficar cheio, o processo de layout cria uma "página de continuação" e dirige os 
itens para a "continuação do quadro do corpo". Isto é repetido, se necessário, até que a "Parte” tenha sido completamente processada.

\subsubsection{ODA Content Architectures}

A discussão acima praticamente não mencionou nada a respeito do conteúdo do documento. Isto foi possível porque ODA separa claramente a estrutura do conteúdo. Nessa seção será dada uma breve descrição das três content architectures existentes.

- Character Content Architecture: é formada por caracteres gráficos e de controle. A forma e posicionamento dos caracteres é controlada por vários atributos bem como pelos caracteres de controle.

- Raster Graphics Content Architecture: representa uma imagem bidimensional na forma de um vetor retangular bidimensional de elementos de figura. Como no caso do character content, um grande conjunto de atributos é usado para controlar a apresentação do conteúdo. As imagens podem ser representadas em várias orientações, e podem ser redimensionadas e ajustadas para que caibam na área útil do bloco.

- Geometric Graphics Content Architecture: é inteiramente baseada no padrão CGM (Computer Graphics Metafile) (ISO 87). Dessa forma, os objetos gráficos primitivos são marcadores, linhas, áreas preenchidas e texto.

Essa seção encerra a apresentação do padrão ODA. A próxima apresenta o padrão SGML.

\subsection{SGML}

O padrão SGML (Standard Generalized Markup Language) (ISO 86) foi proposto para permitir que documentos armazenados eletronicamente pudessem ser definidos conforme seu conteúdo e sua estrutura (Brown 89a), independentemente de sua forma de apresentação. SGML é uma linguagem genérica para a descrição da estrutura lógica de documentos. A linguagem SGML é genérica porque permite a definição de linguagens específicas, sendo que essas últimas definem a estrutura hierárquica de uma classe de documentos. SGML tem flexibilidade para definir um conjunto ilimitado de linguagens específicas, por exemplo, uma para memorandos, uma para artigos, uma para livros, etc. (Herwijnen 94).

Portanto, cada documento SGML está associado a uma linguagem específica que o define. Essa definição é feita através da criação de um DTD (Document Type Definition). Desse modo, a linguagem definida em um DTD especifica uma classe de documentos, por exemplo, livro, jornal, revista, a qual é compartilhada por muitas instâncias de documentos.

A estrutura lógica de um documento, definida pelo DTD, é descrita através de marcas padronizadas (markup). Essas marcas identificam o início e o fim de cada item lógico, chamado 
elemento SGML, e permitem a especificação de seus atributos. É possível atribuir um identificador único a um elemento SGML, de forma que ele possa ser referenciado em qualquer ponto de um documento. Essa característica tem sido utilizada para a especificação de ligações hipertexto.

\subsubsection{DTD}

Um DTD define as regras para a especificação de uma classe de documentos. Desse modo, um DTD declara:

- que tipos de elementos podem existir em um documento; por exemplo, um livro pode conter capítulos, seções, subseções, etc.;

- que atributos esses elementos podem ter; por exemplo, o número de versão e data da última revisão; e

- como as instâncias desses elementos estão hierarquicamente relacionadas; por exemplo, um livro contém capítulos, os quais contém seções, as quais podem conter subseções, etc.

A estrutura especificada em um DTD, segundo sua definição no padrão SGML, possui uma propriedade importante: apenas a estrutura lógica de um documento é descrita, não sendo fornecida informação alguma sobre a semântica de apresentação do documento (Brown 89a). Desse modo, para um livro, por exemplo, é dada a estrutura de seus capítulos e seções, mas nada é definido a respeito do formato de apresentação das páginas e colunas, ou qual a fonte utilizada para os caracteres.

Isso significa que uma aplicação que processa um documento SGML é responsável por especificar como as instâncias dos elementos devem ser visualizadas no documento final. Isso é feito normalmente através do uso de style sheets, as quais armazenam os atributos relativos à apresentação. Essas style sheets estão, naturalmente, fora do escopo do padrão. É possível, inclusive, que existam várias style sheets que controlam a apresentação de um mesmo documento de várias formas. Entretanto, tanto o conteúdo como a estrutura do documento são os mesmos em todos os casos. Uma outra alternativa para a especificação das características de apresentação de um documento SGML é o uso de DSSSL (Document Style Semantics and Specification Language) (ISO 96). DSSSL é um padrão ISO recente para a definição das propriedades de apresentação de um documento SGML. Até o momento, DSSSL não foi implementado em nenhum sistema comercial.

Um DTD define três tipos de comandos para marcação: elementos, atributos e entidades. Marcar um documento SGML significa classificar seus elementos, atributos e entidades conforme a árvore de estrutura genérica formalmente descrita pelo DTD (Herwijnen 94). As sessões seguintes descrevem como usar esses três tipos de marcação. A seção 2.3.5 apresenta uma árvore de estrutura e a seção 2.3.8 define como são feitas as declarações de marcação em um DTD. 


\subsubsection{Elementos}

Um elemento (element) é delimitado por símbolos chamados start-tag e end-tag. Em sua forma mais simples, um start-tag SGML consiste do delimitador de abertura de start-tag $(<)$ seguido pelo identificador genérico (GI), isto é, o nome do elemento definido pelo DTD, seguido pelo delimitador de fechamento do tag (>). Um identificador genérico não é, por default, case sensitive (Herwijnen 94). A Figura 2.5 mostra as partes de tags e elementos.

Um exemplo de start-tag é <TITLE>. Nesse exemplo, TITLE é o identificador genérico, a ocorrência desse start-tag em um documento indica o início do elemento TITLE.

Um end-tag tem o mesmo identificador genérico do start-tag, mas é precedido pelo delimitador de início de end-tag (</): </TITLE>.

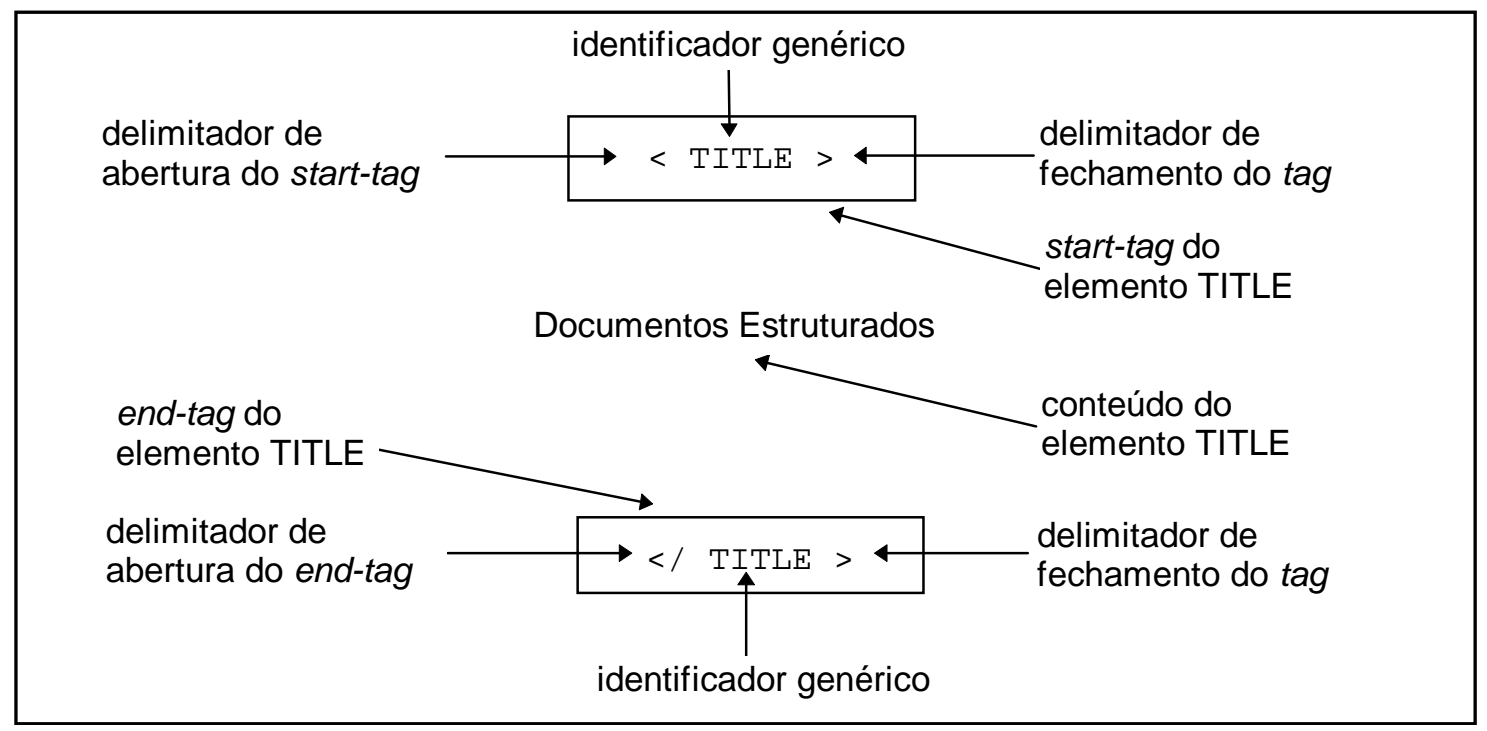

Figura 2.5: Anatomia de um elemento (Herwijnen 94)

Elementos SGML podem ser aninhados, o que ocorre quando o conteúdo de um elemento contém outros tags.

A Figura 2.6 é uma versão SGML de um fragmento desta dissertação.

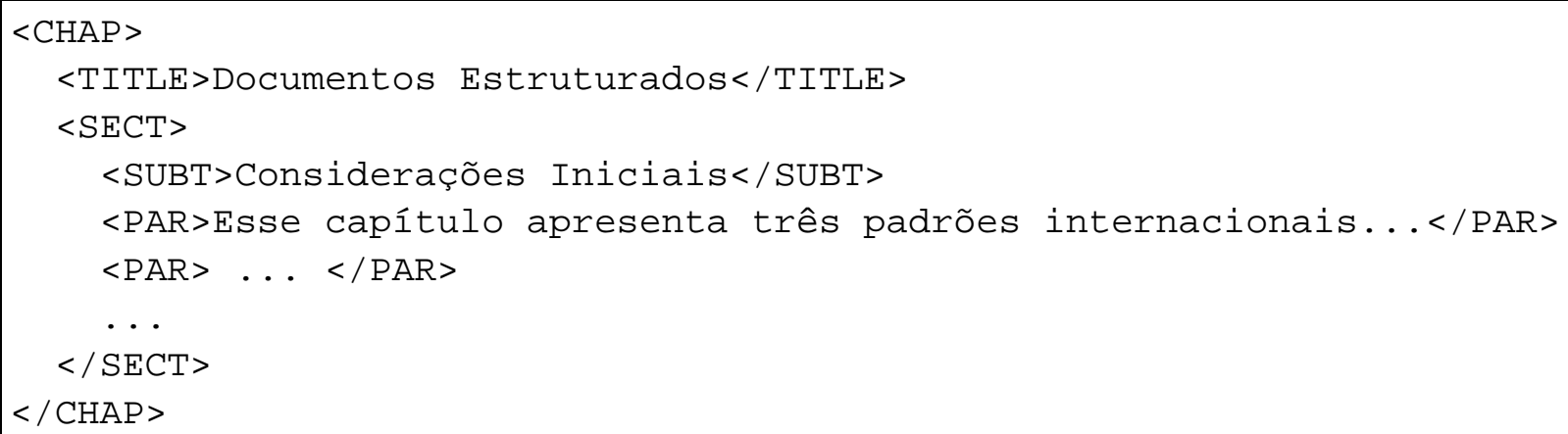


Figura 2.6: Exemplo de um documento SGML

No exemplo acima, o título (TITLE) do capítulo (CHAP) não tem elementos aninhados e consiste do texto “Documentos Estruturados”. Já a seção (SECT) consiste de itens aninhados representando o subtítulo (SUBT) e os parágrafos (PAR). Ainda, o próprio capítulo aninha os elementos TITLE e SECT.

Na seção 2.3.9 é apresentado como se faz a declaração de elementos no DTD.

\subsubsection{Atributos}

Um atributo (attribute) é um qualificador que indica uma propriedade de um elemento, e desse modo, um atributo é definido por um tipo (que é dado por um identificador genérico) e seu conteúdo (que é delimitado pelos start-tags e end-tags). Como, por exemplo, os atributos FORMAT e STATUS do elemento TITLE abaixo:

\section{<TITLE FORMAT="standard" STATUS="public"> Documentos ...}

Um atributo consiste em um nome de atributo (FORMAT, STATUS), um sinal de igualdade (=), e um valor (standard, public). Os nomes de atributos não são case sensitive, porém seus valores o são (Herwijnen 94).

Atributos são alocados nos start-tags de definição de um elemento, e podem indicar identificadores de referência, confidencialidade, informação de formatação, e assim por diante (Herwijnen 94).

Em sua forma mais completa, um start-tag de um elemento SGML pode consistir em delimitador de início de start-tag, identificador genérico, uma lista de atributos, um delimitador de fechamento de tag.

Desse modo, atributos podem ter valores com significado especial. Um atributo pode ser usado para permitir a um elemento se referir a outro por meio de tipos de atributos especiais: identificadores únicos (ID) e referência a identificadores únicos (IDREF). Um atributo do tipo ID pode ser usado para distinguir um elemento de todos os outros; assim esse elemento poderá ser referenciado por outros elementos que possuam atributos do tipo IDREF (Goldfard 90). Por exemplo, na seguinte lista de referências bibliográficas (<REFER>):

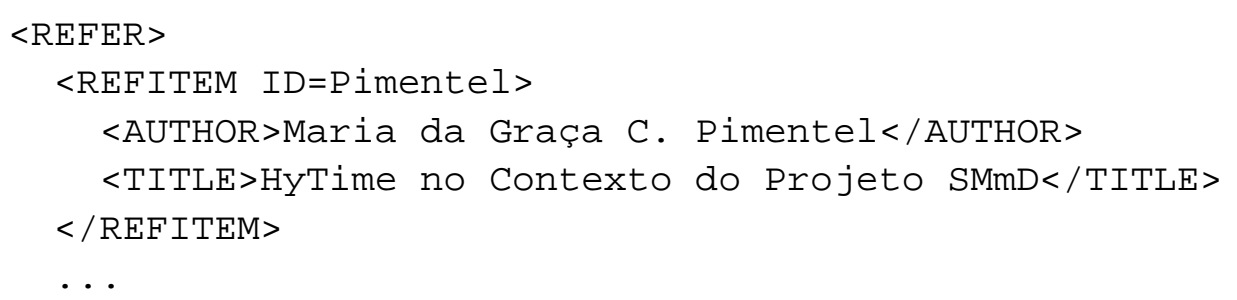


$</$ REFER $>$

foi atribuído um atributo identificador único (ID) ao item da lista de referências bibliográficas $(<$ REFITEM $>$ ) que pode ser referenciado em qualquer ponto do documento. Uma referência ao elemento com atributo ID=Pimentel pode ser feita usando-se um elemento que contenha um atributo do tipo IDREF (por exemplo, <BIBREF>):

Em HyTime no contexto do Projeto SMmD <BIBREF RID=Pimentel>...

O atributo RID é um atributo de referência a um identificador único (IDREF).

Na seção 2.2.10 formaliza-se como se faz declarações de atributos no DTD.

\subsubsection{Entidades}

Documentos podem conter, por exemplo, caracteres ou símbolos que não constam no teclado. Também é desejável que se possa incluir imagens, desenhos, fotos ou texto de um outro documento. Em todos esses casos o SGML usa referência a uma entidade (entity); isto é representado por uma cadeia de caracteres (string) inserida no ponto do texto onde o material externo precisa ser encontrado.

As entidades são usadas:

- para abreviar uma string (entidades gerais);

- para codificar caracteres especiais, acentos, símbolos (entidades caracter);

- para incluir arquivos externos (entidades externas);

- como variáveis em um DTD (entidades parâmetro).

As partes de uma referência à entidade são as seguintes: delimitador de abertura de referência a entidade (\&), nome da entidade, e delimitador de fechamento da referência a entidade (;). Por exemplo: \&SGML ; . No caso de entidades parâmetro, o delimitador de abertura é o \% (Herwijnen 94). Dessa forma, para definir que o texto "Standard Generalized Markup Language" substitui a entidade "SGML”, faz-se o seguinte:

<!ENTITY SGML "Standard Generalized Markup Language">

Dessa forma, um texto que tivesse a seguinte forma:

“0 padrão \&SGML; foi proposto para..."

Seria interpretado por um SGML parser exatamente como: 
“O padrão Standard Generalized Markup Language foi proposto para..."

Na seção 2.3.11 formaliza-se a declaração de entidades no DTD.

\subsection{5 Árvore de Estrutura}

A definição de uma classe de documentos requer não apenas que os elementos sejam definidos, mas também o relacionamento entre eles. Elementos podem conter outros elementos, esse aninhamento pode ser graficamente expresso através de uma árvore (Herwijnen 94). A Figura 2.7 apresenta um exemplo de estrutura de uma dissertação. Uma dissertação poderia possuir outros elementos, por exemplo, um parágrafo (PAR) poderia conter figuras, tabelas, notas de rodapé, etc.

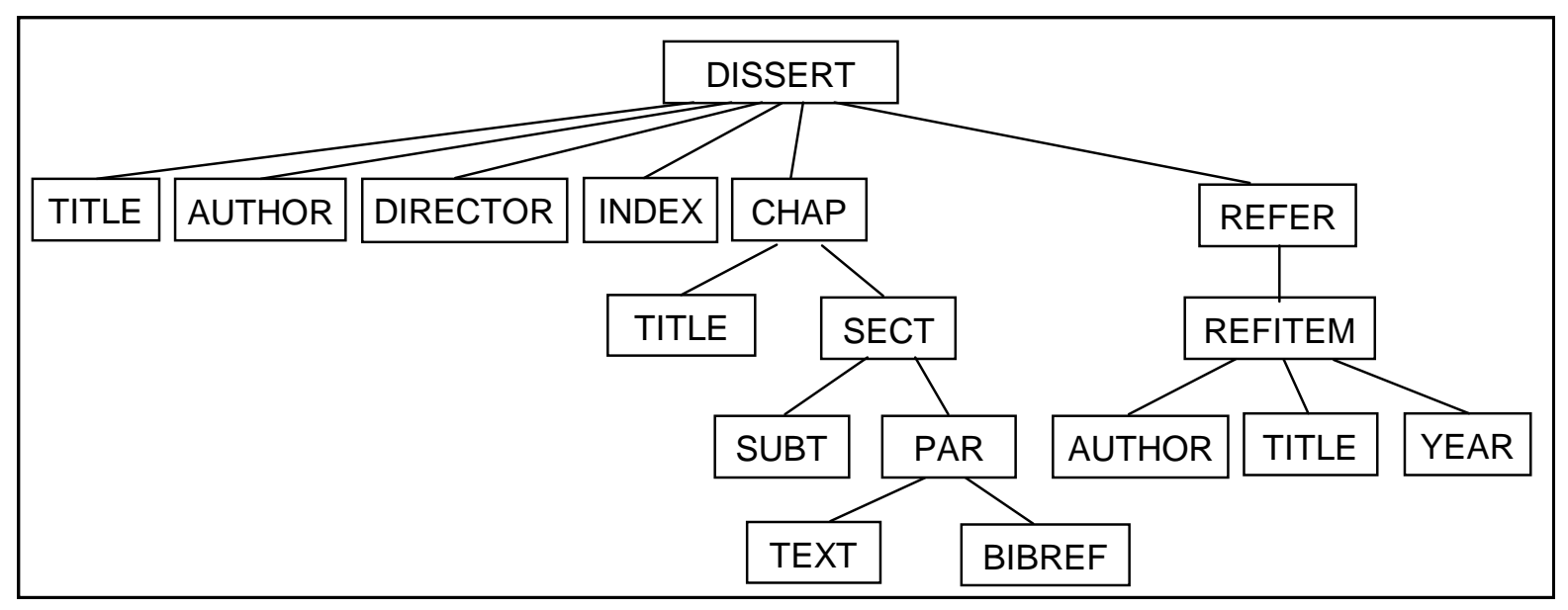

Figura 2.7: Árvore de estrutura para uma Dissertação

A árvore de estrutura, entretanto, não formaliza a ordem ou a freqüência de ocorrência dos elementos. Essas informações são descritas pelos diagramas de estrutura (Herwijnen 94), apresentados a seguir.

\subsubsection{Diagramas de Estrutura}

O diagrama de estrutura é uma notação alternativa para representar a estrutura de uma classe de documentos, e, de acordo com (Herwijnen 94), pode ser facilmente traduzido nas declarações de um DTD.

Existem sete tipos básicos de diagramas de estrutura, mostrados na Figura 2.8. 


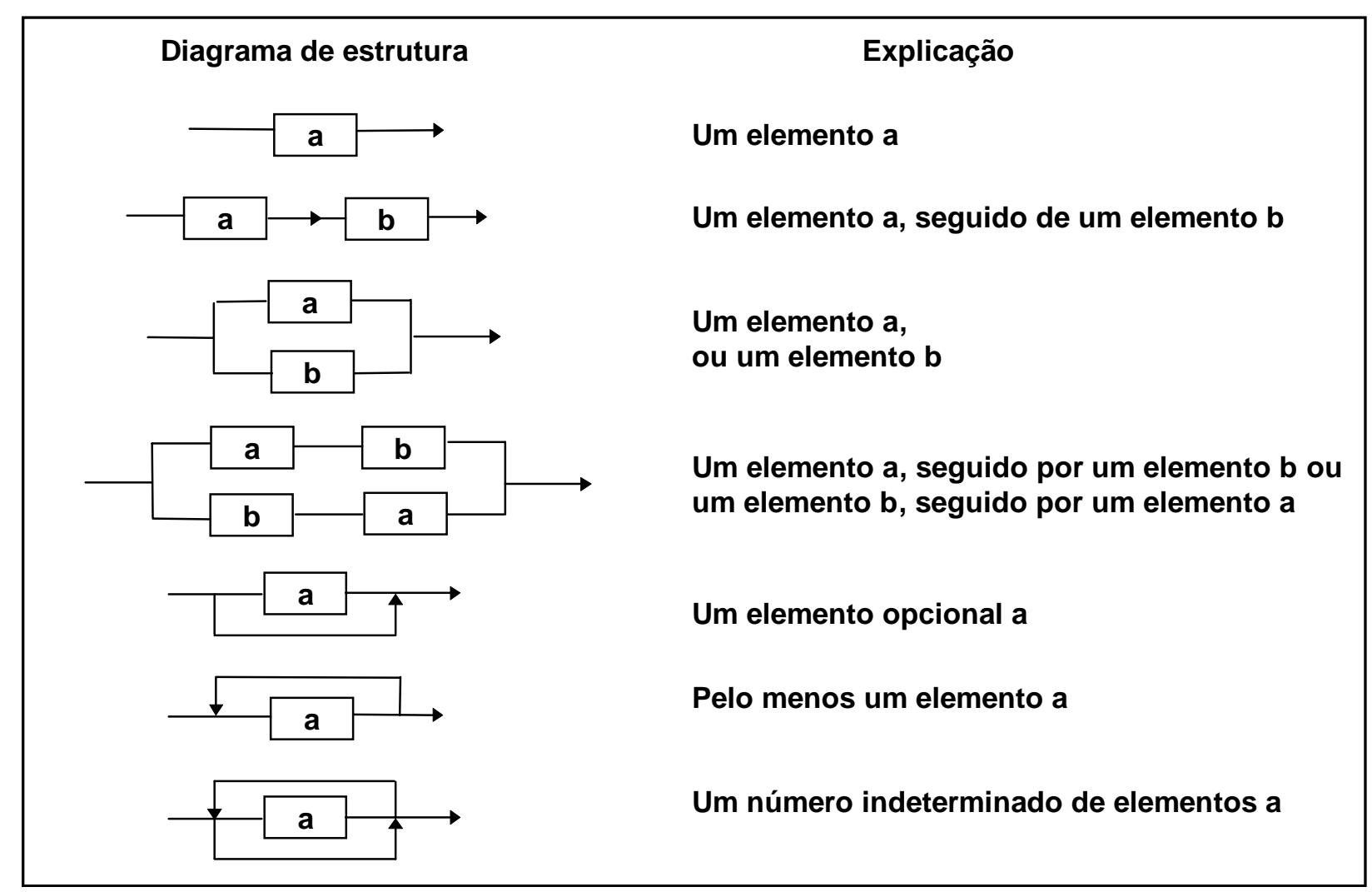

Figura 2.8: Sete tipos de diagramas de estrutura (Herwijnen 94)

Um nó que não contém outros nós é chamado elemento terminal. O diagrama de estrutura para um elemento terminal possui um triângulo no canto inferior direito, como mostrado na Figura 2.9.

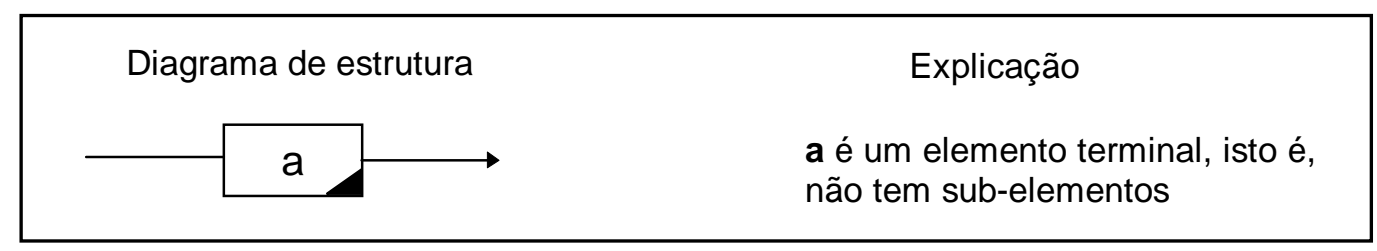

Figura 2.9: Diagrama de estrutura para um elemento terminal (Herwijnen 94)

A Figura 2.10 apresenta uma possível configuração dos diagramas de estrutura para a árvore de estrutura da Figura 2.7. Pode-se observar nessa figura que a notação de diagramas de estrutura permite apresentar mais informações que a árvore de estrutura, por exemplo, que a dissertação deve ter pelo menos um capítulo e que o capítulo pode conter um título e várias sessões. 


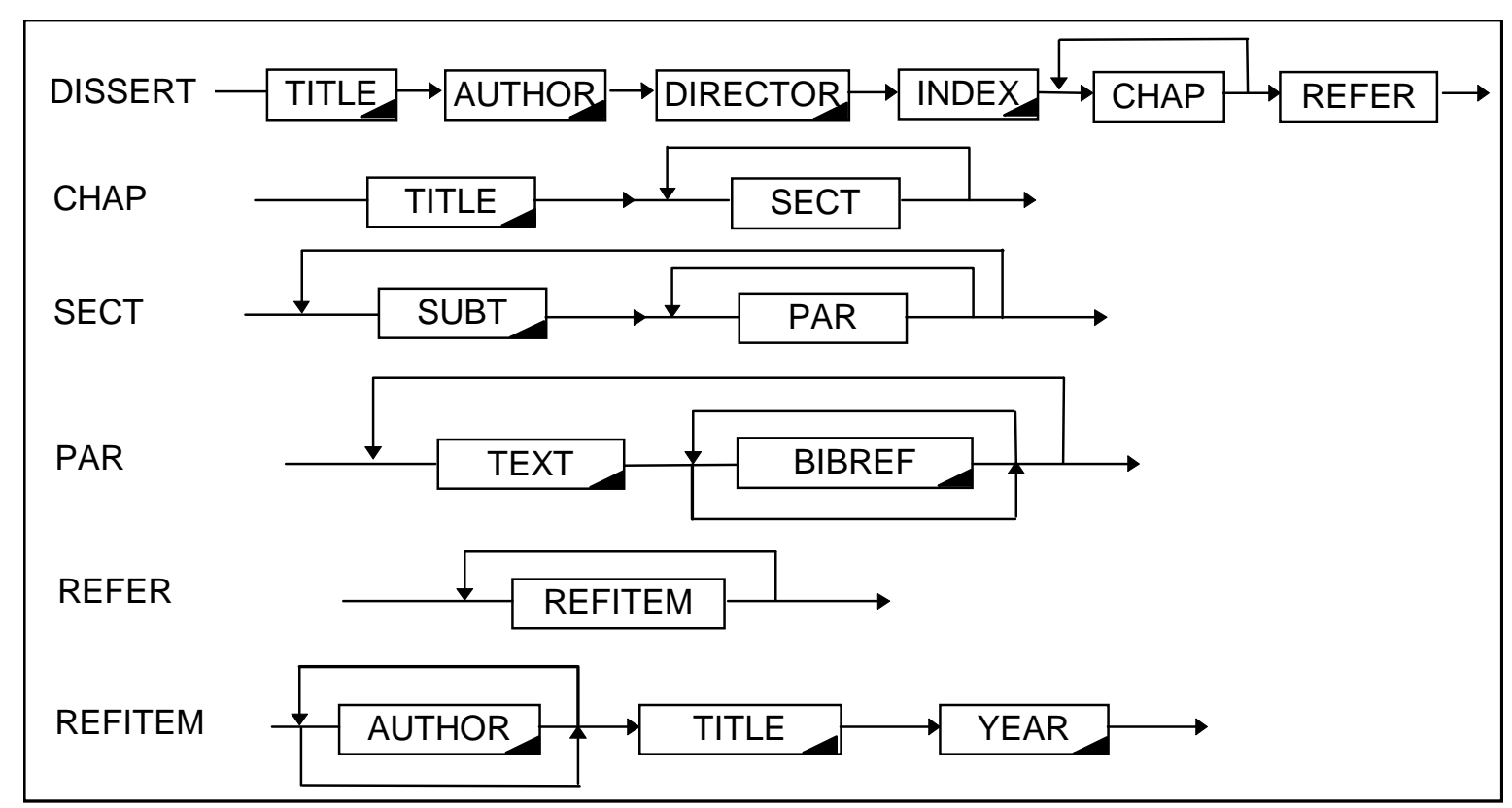

Figura 2.10: Diagramas de estrutura para uma Dissertação

Em SGML, dados do tipo caracter são indicados pela palavra reservada \#PCDATA. O símbolo \# precedendo PCDATA é um indicador de palavra reservada. PCDATA significa parsed caracter data (Herwijnen 94).

\subsubsection{SGML Parser}

Para assegurar que a marcação de um documento SGML seja consistente, livre de erros, e interpretada corretamente, todo sistema conformante deve conter um programa que reconhece a marcação em documentos SGML. Esse programa é chamado de SGML parser. O SGML parser checa:

- se um DTD de um documento é conformante a SGML;

- se a instância do documento é conformante ao DTD.

Parsers estão freqüentemente incluídos em um editor SGML, mas eles também podem ser independentes. Parsers ajudam a prevenir erros e o mau uso de marcação.

\subsubsection{Declarações de Marcação}

Essa seção descreve como definir as declarações de marcação e como construí-las a partir dos diagramas de estrutura. Observe o DTD da Figura 2.11. 


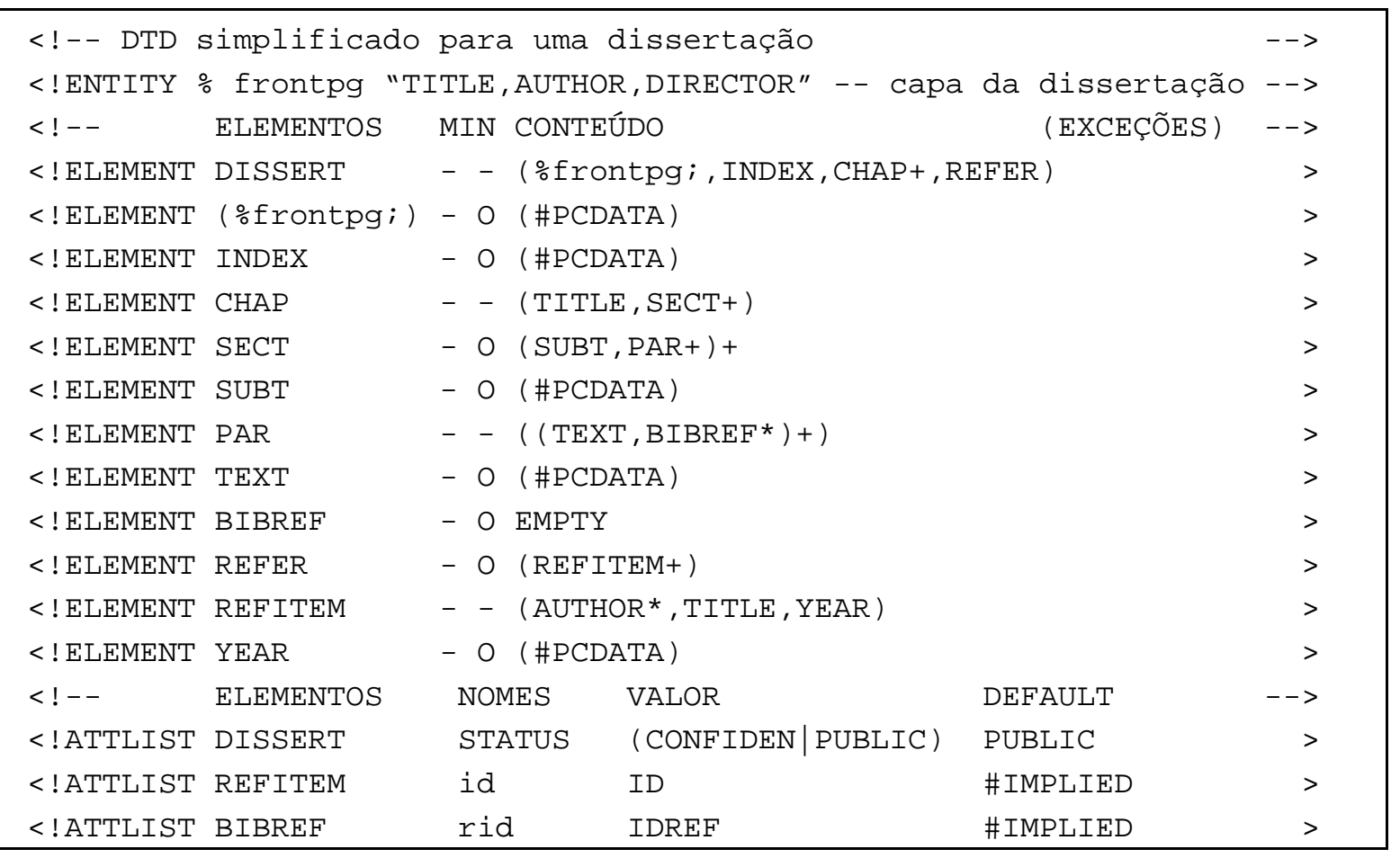

Figura 2.11: DTD para uma dissertação

Esse DTD ilustra as características da maioria dos DTDs:

- todas as linhas em um DTD começam com “<! ”; elas são declarações de marcação;

- as três ocorrências mais freqüentes são: elementos (ELEMENT), atributos (ATTLIST) e entidades (ENTITY);

- elementos, atributos e entidades têm nomes (identificadores genéricos);

- as expressões entre parênteses são grupos formados por seqüência de elementos;

- elementos são seguidos por indicadores de ocorrência (“+”, “?” ou “*”) e sequenciados dentro de grupos por conectores (“|”, “, ” ou “\&”);

- Comentários são indicados por “<! - -”.

As expressões contendo um símbolo de percentagem (\%) são apenas para ilustrar como funcionam as entidades parâmetro. Nesse exemplo, frontpg é uma entidade parâmetro cujo conteúdo é “TITLE, AUTHOR, DIRECTOR”. Uma referência a \%frontpg; é na verdade uma referência ao seu conteúdo.

Esse DTD define um tipo de documento para dissertações, declarando os elementos DISSERT, TITLE, AUTHOR, DIRECTOR, INDEX, CHAP, SECT, SUBT, PAR, TEXT, BIBREF, REFER, REFITEM, YEAR. As declarações de marcação controlam a forma com que a marcação deve ser interpretada, isto é, DISSERT é o elemento mais externo e contém todos os outros na ordem e freqüência determinados; TITLE é um elemento do tipo \#PCDATA, e assim por diante. 
Formalmente, a estrutura de uma declaração de marcação é a seguinte: delimitador de abertura da declaração de marcação (<!); uma palavra-chave (ELEMENT, ATTLIST ou ENTITY) dependendo do tipo de declaração; o conteúdo da declaração; e o delimitador de fechamento da declaração de marcação (>).

Os comentários em uma declaração de marcação aparecem entre “--”. Se uma declaração de marcação começa com um comentário, não há espaços entre o delimitador de abertura da declaração (<!) e o delimitador de abertura do comentário (--).

Podem haver várias palavras-chave em uma declaração de marcação. Essas palavraschave são freqüentemente palavras reservadas, por exemplo, ELEMENT, que tem um significado especial para o SGML parser . Não há espaços em branco entre o delimitador de abertura da declaração de marcação e a palavra-chave (Herwijnen 94).

Os blocos que fazem parte de uma declaração de marcação são: grupos, conectores, indicadores de ocorrência e nomes. Esses conceitos são definidos nos próximos parágrafos.

Os nomes SGML têm no máximo oito caracteres (“a-Z”, “0-9”, “.”, “-”). Um nome deve começar sempre por uma letra (“a-Z”). Name tokens são semelhantes a nomes, exceto pelo fato de que eles não necessariamente começam por uma letra.

Há três tipos de grupos que podem aparecer em uma declaração de marcação:

1. model groups: uma lista de elementos;

2. name groups: uma lista de nomes;

3. name token groups: uma lista de name tokens;

O conteúdo de um grupo consiste em tokens, por exemplo, CONFIDEN, PUBLIC. Model groups podem ser aninhados e os objetos que compõem o grupo são relacionados através de conectores.

Model groups são usados dentro das declarações de elementos para definir os possíveis conteúdos de um elemento.

Um name group deve possuir pelo menos um nome válido dentre seus delimitadores de grupo seguido por um número arbitrário de outros nomes com conectores entre eles. Somente um tipo de conector deve ser usado dentro de um name group, por exemplo: (TO \& FROM) ou (CONFIDEN | PUBLIC). Eles podem ser usados em todo tipo de declaração de marcação.

Se os tokens de um name group forem identificadores genéricos, como em (TO \& FROM), um name group é também um model group (Herwijnen 94).

Semelhantemente aos name groups, name token groups devem possuir pelo menos um name token válido entre seus delimitadores, seguido por um número arbitrário de outros com conectores entre eles. Somente um tipo de conector deve ser usado em um name token group. Por exemplo, (1KEY, 2KEY) ou (CHI -1211) são todos name token groups válidos. Eles podem ser usados em todos os tipos de declaração de marcação. Nomes também são name tokens válidos (Herwijnen 94). 
Conectores indicam o relacionamento entre os elementos. Existem vários tipos de conectores, porém apenas um deve aparecer no mesmo model group. Há uma correspondência direta entre os diagramas de estrutura e os conectores dos model groups.

1. Conectores de seqüência: são representados por vírgulas (“,”). Os elementos ou model groups que aparecem dos dois lados do conector de seqüência devem figurar na mesma ordem.

2. Conectores E: são representados pelo símbolo "\&”. Os elementos ou model groups que aparecem em ambos os lados de um conector "e" devem aparecer em qualquer ordem, mas ambos devem aparecer no documento.

3. Conectores OU: são representados por barras verticais (“|”). Se o elemento ou model group do lado direito do conector "ou" aparecer, o elemento ou model group do lado esquerdo não deve aparecer, e vice-versa.

Indicadores de ocorrência determinam a freqüência com que os elementos ou model groups ocorrem no documento. Os indicadores de ocorrência são:

1. +: indica a ocorrência de pelo menos um elemento;

2. *: indica a ocorrência de nenhum ou vários elementos;

3. ?: indica a ocorrência opcional de um elemento.

Indicadores de ocorrência têm prioridade sobre os conectores (Herwijnen 94). A lista completa de correspondências entre os conectores e indicadores de ocorrência em model groups e os diagramas de estrutura é mostrada na Figura 2.12.

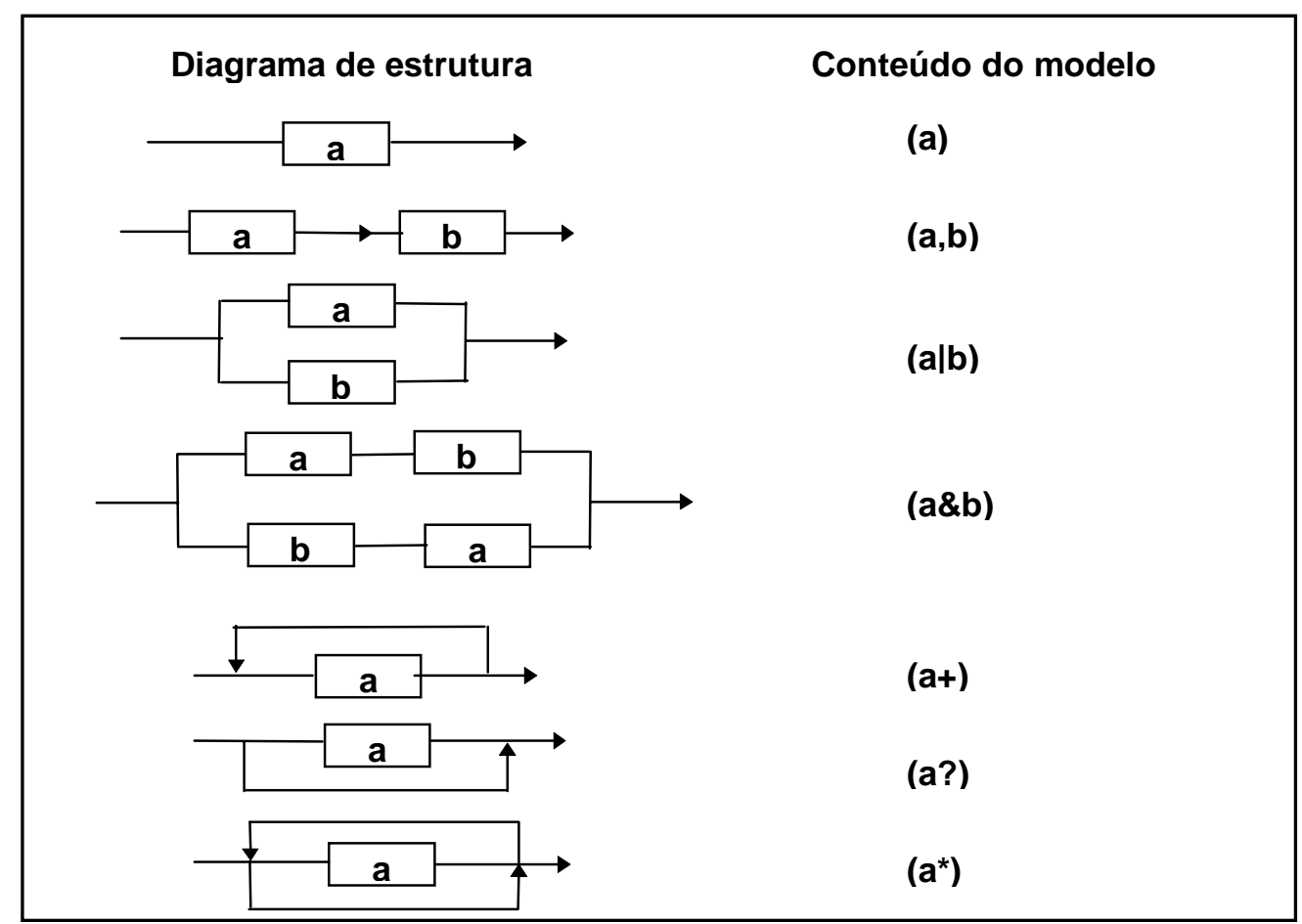

Figura 2.12: Correspondência entre diagramas de estrutura e model groups (Herwijnen 94) 


\subsubsection{Declaração de Elementos}

As declarações de elementos são construídas introduzindo-se conectores de seqüência e indicadores de ocorrência em model groups. Cada nó da árvore e cada diagrama de estrutura corresponde à declaração de um elemento no DTD.

A sintaxe para a declaração de um elemento é a seguinte:

<!ELEMENT nome omitted-tag-minimization conteúdo>

A omitted tag minimization determina se o start- e end-tags devem estar presentes em todas as ocorrências do elemento. Ela consiste de dois caracteres separados por um espaço em branco, um para o start-tag e outro para o end-tag. A letra $\mathrm{O}$ indica que o tag pode ser omitido e o sinal “-” indica que ele deve estar presente.

É possível que um elemento possa ocorrer em todos os sub-elementos de um determinado elemento. Por exemplo, um elemento nota de rodapé (FN) pode aparecer em qualquer lugar dentro do elemento DISSERT. Incluir FN em todos os model groups seria repetitivo. O mesmo efeito pode ser obtido incluindo-se elementos que não fazem parte da estrutura hierárquica do documento (Herwijnen 94):

$$
<\text { !ELEMENT nome minimization (modelgroup) +(inclusão)> }
$$

O sinal “+” é o delimitador de inclusão. Por exemplo, a declaração:

<!ELEMENT DISSERT - - (TITLE, AUTHOR, DIRECTOR, INDEX, CHAP+, REFER $)+($ FN $)>$

especifica que o elemento FN pode ocorrer em qualquer lugar em DISSERT (um número ilimitado de vezes, inclusive em qualquer de seus sub-elementos).

Pode acontecer, também, que um elemento não deva aparecer em todos os sub-elementos de um certo elemento. Um exemplo é a nota de rodapé, que deve ser impedida de ocorrer dentro dela mesma. Isto é garantido declarando-se uma exclusão, a qual é definida por:

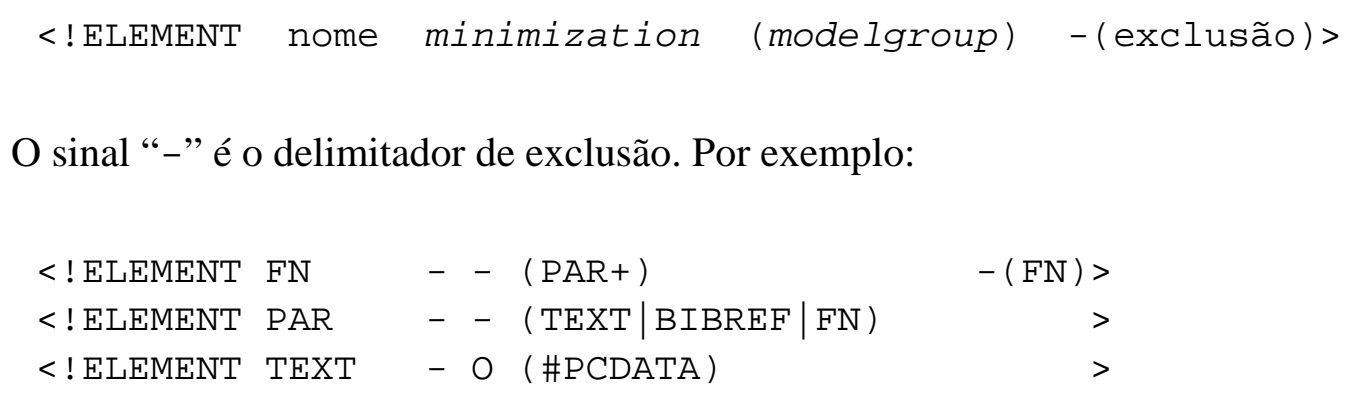


Às vezes um texto possui elementos que devem receber um tratamento diferenciado por parte do SGML parser. Por exemplo, em um livro sobre SGML, podem ocorrer vários exemplos com tags que não devem ser processados. O parser dá tratamento diferenciado aos diferentes tipos de dado.

Alguns exemplos desses tipos de dados são:

1. fórmulas matemáticas e gráficos;

2. texto formatado;

3. texto com marcação.

Em todos esses casos deve ser possível impedir que o parser interprete caracteres ou seqüências especiais de bits como delimitadores de marcação. Isto pode ser obtido fornecendo-se ao elemento um conteúdo declarado (Herwijnen 94).

Há quatro tipos possíveis de conteúdo declarado, cada um indicado por uma palavra reservada. Quando usados na declaração de um elemento, eles indicam o conteúdo declarado do elemento:

- CDATA (character data): os elementos devem conter somente caracteres SGML. Todos os caracteres ou delimitadores de marcação são ignorados, exceto os delimitadores para abertura



$<\mathrm{a}>=\langle\mathrm{p} \quad \mathrm{c} /|\mathrm{E}|>$

um parser detectaria um erro, caso esse texto fosse tratado como \#PCDATA. Para que essa notação seja aceita em documento SGML, deve-se fazer a seguinte declaração no DTD (Herwijnen 94):

$<$ !ELEMENT Expvalue - - CDATA >

Feito isso, é possível escrever:

$<$ Expvalue $><$ a $>=\langle p \quad c /|$ E $\mid></$ Expvalue $>$

- RCDATA (replaceable character data): semelhante ao CDATA, exceto pelo fato de que referências a entidades, bem como referências a caracteres, são reconhecidas (Herwijnen 94).

- EMPTY: se o elemento não contém texto ou outros elementos, seu conteúdo deve ser declarado como EMPTY. Por exemplo, um tag <DATE> poderia informar ao sistema de processamento que a data é requerida em algum ponto no documento (Herwijnen 94):

$<$ !ELEMENT DATE - O EMPTY > 
- ANY: significa que o elemento pode conter qualquer mistura de texto e outros elementos declarados no DTD (DeRose \& Duran 94).

\subsubsection{Declaração de Atributos}

Os atributos permitidos para um elemento são declarados todos de uma só vez no DTD usando-se uma lista de declaração de atributos. Cada atributo tem um nome pelo qual ele é referenciado, um tipo que determina que tipo de valor ele pode ter (identificador SGML, número, etc.), e um valor default para ser usado quando o atributo não for especificado (DeRose \& Duran 94).

As partes de uma declaração de atributos são: delimitador de abertura de declaração de marcação (“<!”); palavra-chave de declaração de lista de atributos (ATTLIST); nome do elemento ao qual a lista pertence; nome do atributo; possíveis valores do atributo ou palavrachave; valor default do atributo, ou palavra-chave; e delimitador de fechamento de declaração de marcação. Por exemplo:

$\begin{array}{lllll}<\text { !ATTLIST DISSERT } & \text { TYPE } & \text { (CONFIDEN|PUBLIC) } & \text { PUBLIC } & > \\ <\text { !ATTLIST REFITEM } & \text { id } & \text { ID } & \text { \#IMPLIED } & >\end{array}$

Nesse exemplo, o elemento DISSERT possui um atributo chamado TYPE com dois valores possíveis, CONFIDEN ou PUBLIC, e o valor default é PUBLIC. Já o elemento REFITEM possui o atributo id, cujo valor é a palavra-chave ID. O Valor default de REFITEM é a palavrachave \#IMPLIED, o que significa que o valor não precisa ser informado; a aplicação determina como a ausência do atributo é tratada.

Os nomes de atributos devem obedecer às regras dos nomes SGML. Assim como os nomes de elementos, os de atributo não são case sensitive. É possível definir tantos atributos quanto se queira. O tamanho dos tokens que definem os valores dos atributos não pode ser maior que 8. Os valores possíveis das palavras-chave são apresentados na Tabela 2.1: 


\begin{tabular}{|c|c|c|}
\hline Palavra-chave & \begin{tabular}{|l|} 
Atributo \\
\end{tabular} & \begin{tabular}{|l|} 
Tipo \\
\end{tabular} \\
\hline CDATA & caracter & CDATA \\
\hline ENTITY & nome de entidade geral & nome SGML \\
\hline ENTITIES & lista de nomes de entidades gerais & nome SGML \\
\hline ID & identificador & nome único \\
\hline IDREF & referência a identificador & nome \\
\hline IDREFS & lista de referências a identificador & nomes \\
\hline NAME & nome & nome \\
\hline NAMES & lista de nomes & nomes separados por espaços \\
\hline NMTOKEN & token para nome & token para nome \\
\hline NMTOKENS & lista de tokens para nome & tokens para nomes \\
\hline NOTATION & nome de notação & \\
\hline NUMBER & número & dígito \\
\hline NUMBERS & lista de números & dígitos \\
\hline NUTOKEN & token para número & menos que 9 caracteres \\
\hline NUTOKENS & lista de tokens para número & tokens p/ números com espaços \\
\hline
\end{tabular}

Tabela 2.1: Palavras-chave possíveis para atributos (Herwijnen 94)

Uma das palavras-chave listadas na Tabela 2.2 abaixo pode ser adotada como valor default de um atributo.

\begin{tabular}{|l|l|}
\hline \#FIXED & $\begin{array}{l}\text { a palavra-chave é seguida pelo valor do atributo, que será sempre o } \\
\text { mesmo }\end{array}$ \\
\hline \#REQUIRED & um valor deve sempre ser especificado \\
\hline \#CURRENT & valor mais recentemente especificado é usado \\
\hline \#CONREF & valor para referência cruzada \\
\hline \#IMPLIED & $\begin{array}{l}\text { o valor não precisa ser informado; a aplicação determina como a } \\
\text { ausência do atributo é tratada }\end{array}$ \\
\hline
\end{tabular}

Tabela 2.2: Valores defaults dos atributos (Herwijnen 94)

\subsubsection{Declaração de Entidades}

Entidades são definidas por uma declaração de entidade. Existem dois tipos de entidades: entidades gerais e entidades parâmetros (Herwijnen 94).

O conteúdo de uma entidade geral pode ser:

1. Um parâmetro literal. Esse é o caso mais comum.

2. A especificação de uma entidade externa. Possibilita a inclusão de arquivos externos ao documento. 
3. Texto para dado. A facilidade menos usada.

4. Bracketed text. Permite definir entidades cujo texto será substituído por marcação.

A sintaxe de uma declaração de entidade cuja entidade é um parâmetro literal é a seguinte: delimitador de abertura da declaração de marcação (“<!”); palavra-chave de declaração de entidade (ENTITY); nome da entidade; delimitador do conteúdo da entidade (" ou '); conteúdo do parâmetro literal; delimitador do conteúdo (” ou '); delimitador de fechamento da declaração de marcação (">”). Por exemplo:

\section{<!ENTITY CALS "Computer-aided Acquisition an Logistics Support">}

Nesse exemplo, o nome da entidade é CALS e o conteúdo do parâmetro literal é Computer-aided Acquisition and Logistics Support.

Se o conteúdo do parâmetro literal possuir aspas duplas, deve-se usar aspas simples como delimitador do conteúdo da entidade e vice-versa.

Entidades externas são locais ou públicas. Uma entidade local geralmente não é conhecida fora do sistema onde ela está instalada, enquanto uma entidade pública está registrada de uma forma padrão e está disponível a todos. A sintaxe de uma declaração de entidade externa é a seguinte: delimitador de abertura da declaração de marcação (“<!”); palavra-chave de declaração de entidade (ENTITY); nome da entidade; identificador de sistema ou público; delimitador de fechamento da declaração de marcação (">”).

Para entidades locais, é requerido um identificador de sistema. As partes de um identificador de sistema são: palavra-chave de identificador de sistema (SYSTEM); delimitador de string (“ ou '); um identificador de sistema; delimitador de string (” ou '). Por exemplo:

<!ENTITY chap SYSTEM "/home/SD/ciro/chap.sgm">

As partes de um identificador público são as seguintes: palavra-chave de identificador público (PUBLIC); delimitador de string (“ ou '); um identificador do proprietário do texto público; delimitador de string (” ou '); novo delimitador de string (“ ou '); um identificador de sistema; delimitador de string (" ou '). Por exemplo:

$<$ !ENTITY \% ISOnum PUBLIC “ISO 8879-1986//ENTITIES Numeric and Special Graphic//EN" "C: \a.ent">

Há três tipos de entidade de texto para dado, cada uma indicada por uma palavra-chave que precede o parâmetro literal na declaração de entidade genérica:

1. CDATA: o texto substituto é do tipo caracter.

2. SDATA: o texto substituto é do tipo caracter específico. 
3. PI: o texto substituto contém uma instrução de processamento.

Um exemplo de uma entidade de texto para dado do tipo SDATA é a representação de símbolos especiais em uma forma específica requerida por um processador de texto. A entidade Omega poderia ser substituída pelo comando $\mathrm{T}_{\mathrm{E}} \mathrm{X} \backslash$ Omega:

$$
<\text { !ENTITY Omega SDATA “\Omega"> }
$$

Entidades para processamento de texto para dados são uma forma conveniente para a definição de instruções de processamento.

$$
<\text { !ENTITY CC PI ".CC 5"> }
$$

Instruções de processamento definidas dessa forma podem ser facilmente alteradas quando o documento é transportado para um sistema diferente (Herwijnen 94).

Bracketed text permite a definição de entidades cujo texto substituto é uma marcação. Por exemplo:

$$
<\text { !ENTITY formula MS "RCDATA }[<a>=<p c /|E|>] \text { " }>
$$

onde a palavra-chave MS indica que a entidade contém uma seção marcada (marked section), ou seja, ela é precedida e sucedida pelos delimitadores de abertura (“<![”) e fechamento ("]]>”) de seção marcada respectivamente. Outras palavras-chave são: MD para texto precedido por delimitadores de abertura (“<!”) e sucedidos por delimitadores de fechamento de declaração de marcação (“>”); STARTTAG para o texto precedido por um delimitador de abertura de start-tag (“<”) e sucedido por um delimitador de fechamento de tag (“>”); ENDTAG para o texto precedido por um delimitador de abertura de end-tag (“</”) e sucedido por um delimitador de fechamento de $\operatorname{tag}$ (">”).

Entidades parâmetro só podem ser usadas dentro de declarações de marcação. As entidades parâmetro são delimitadas pelo caracter “\%” ao invés do símbolo "\&”. As declarações de entidades parâmetros são semelhantes às das entidades gerais, porém é inserido um sinal de porcentagem entre a palavra-chave ENTITY e o nome da entidade.

\subsubsection{Instância de um Documento SGML}

Todo documento SGML deve conter um DTD ou uma referência a um DTD. A referência a um DTD é feita através de uma declaração no início de um documento SGML chamada document type declaration. O exemplo abaixo mostra que uma document type declaration 
começa com a palavra-chave DOCTYPE, seguida pelo nome do documento, a palavra reservada SYSTEM e o nome ou path do DTD.

$<$ !DOCTYPE DISSERT SYSTEM “dissert.dtd">

Quando o DTD é armazenado fora do documento, é fácil de mantê-lo e ele pode ser compartilhado entre diferentes documentos. Entretando, se for preciso enviar o documento para um sistema diferente, pode ser preciso adicionar o DTD a uma parte do documento chamada document type declaration subset. A DOCTYPE declaration subset é o local para adicionar-se declarações privadas, tanto na forma de um DTD completo, ou como um complemento de um DTD externo. Essas declarações aparecem entre colchetes. O exemplo abaixo ilustra o uso da document type declaration subset.

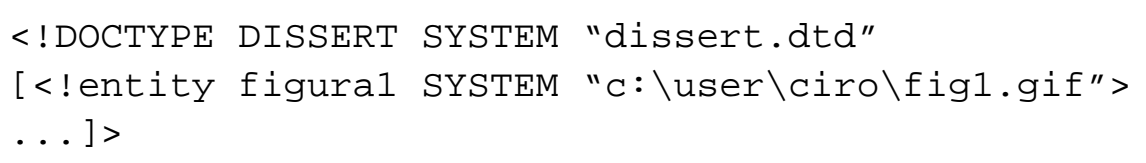

\subsection{HyTime}

O padrão HyTime (Hypermedia/Time-Based Structuring Language) (ISO 92), pode ser visto como uma extensão ou uma aplicação de SGML, e define como um DTD pode ser usado para descrever a estrutura de documentos multimídia e hipermídia. Desse modo, HyTime é uma meta-linguagem para representação de ligações hipertexto (hiper-elos), bem como o escalonamento e a sincronização de eventos no espaço e no tempo. Para isso, são fornecidos mecanismos e modelos para identificação, localização e ligação desses objetos de informação.

\subsubsection{Formas Arquiteturais HyTime}

O HyTime é definido formalmente por um conjunto de regras, chamadas formas arquiteturais (AFs), que os projetistas de aplicação podem aplicar aos seus DTDs (ISO 92). Cada forma arquitetural especifica como um elemento SGML pode ser definido em um DTD cujas instâncias contêm informações com relação a certos conceitos ou grupos de conceitos HyTime (Rutledge 93).

Há dois tipos de formas arquiteturais: ETF (element type form) e ALF (attribute list form). Um ETF é definido por uma declaração de elemento em conjunto com uma declaração de atributos. Um ALF é definido somente por um declaração de atributos (ISO 92). 


\subsubsection{A Estrutura de HyTime}

HyTime é estruturado como um conjunto de módulos que são incluídos quando necessários a uma aplicação particular. Cada módulo suporta um conjunto de formas arquiteturais HyTime. O conjunto de formas arquiteturais suportadas por um módulo determina as facilidades providas por esse módulo (Fujitsu \& TechnoTeacher 95). A interdependência entre os módulos HyTime é mostrada na Figura 2.13.

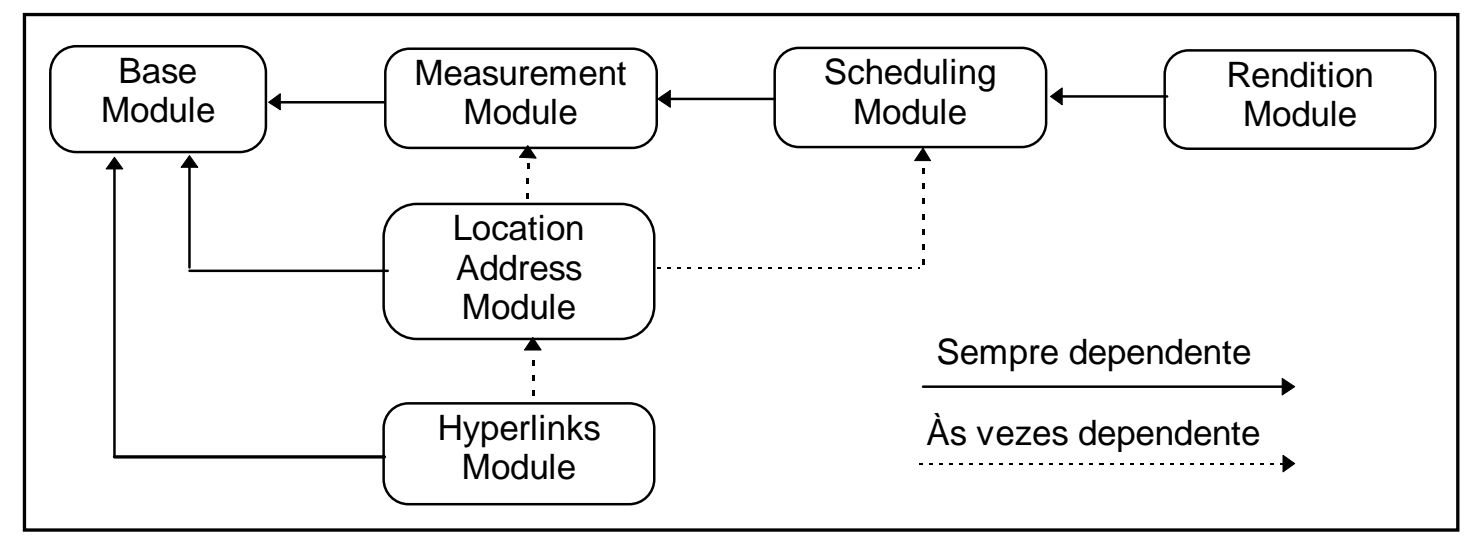

Figura 2.13: Interdependência dos módulos HyTime (Rutledge 95)

\subsubsection{Os Módulos HyTime}

Os seis módulos HyTime são brevemente descritos a seguir:

1. Base Module: é formado por AFs de caráter independente, algumas delas obrigatórias e outras opcionais. As AFs obrigatórias dão suporte ao gerenciamento do hiperdocumento (usando SGML) e a identificação de propriedades HyTime. As AFs opcionais fornecem facilidades para, por exemplo, a definição de valores de atributos e acesso direto otimizado a partes dos documentos (ISO 92).

Esse módulo é obrigatório, e nele estão definidos muitos atributos necessários a todos os outros módulos.

2. Measurement Module: as AFs desse módulo fornecem mecanismos para a especificação da posição e dimensão de objetos, usando unidades de medida definidas pela aplicação (ISO 92) (Fujitsu \& TechnoTeacher 95). É possível, por exemplo, definir dimensões que utilizam determinadas unidades de medida, e objetos podem ser posicionados dentro dessas dimensões em uma posição particular que é especificada por essas unidades de medida (Rutledge 93).

3. Location Address Module: as AFs desse módulo estendem as formas de endereçamento possíveis em SGML ao permitir que identificadores sejam associados a objetos em posições 
arbitrárias, e permitem a identificação de objetos localizados em documentos externos. Isto significa que é possível localizar padrões de caracteres, identificar porções de elementos, identificar elementos com determinadas propriedades e especificar um grupo de objetos como um único elemento (Rutledge 93).

4. Hyperlinks Module: esse módulo permite que sejam especificadas conexões (hiper-elos) entre objetos (ISO 92), independente da hierarquia do documento. Quando utilizado em conjunto com o location address module, é possível estabelecer ligações entre objetos de informações arbitrários.

5. Scheduling Module: esse módulo permite que eventos (ocorrências de objetos) sejam escalonados em eixos de coordenadas de finite coordinate spaces (fcs) de tal forma que a posição desses objetos pode ser expressa em relação a esses eixos (ISO 92).

Esse módulo é dependente do measurement module por utilizar as facilidades de dimensão e posicionamento, entre outras, fornecidas pelas AFs daquele módulo.

6. Rendition Module: esse módulo é dependente do scheduling module e, de fato, estende as funções oferecidas por ele. As AFs desses módulos especificam como eventos em um finite coordinate space podem ser mapeados em outro (Rutledge 93), por exemplo, como eventos em um espaço de coordenadas virtual podem ser mapeados em um real.

Nem todos os seis módulos são necessários a todas as aplicações. Apenas o base module é obrigatório, os demais são opcionais. Uma aplicação HyTime pode incorporar apenas os módulos que contenham as formas arquiteturais necessárias a seus hiperdocumentos e omitir o resto.

Dentre os inúmeros tipos de hiperdocumentos que podem ser formalizados através do HyTime, duas classes de documentos são definidas no padrão: a classe Minimal Hyperlinking, baseada no hyperlinks module e no location address module, que permite a definição de hiperdocumentos de estrutura elaborada; e a classe Minimal Scheduling, baseada no scheduling module e measurement module, cujas AFs permitem a formalização da estrutura de documentos multimídia.

Desse modo, as classes Minimal Hyperlinking e Minimal Scheduling fornecem suporte, respectivamente, para a especificação da estrutura necessária para hiperdocumentos e elementos multimídia, e ilustram o fato do HyTime ser definido com Hypermedia/Time-based Structuring Language. 


\subsubsection{Conformidade a HyTime}

Todo hiperdocumento HyTime especifica em sua declaração quais módulos e opções são necessárias ao seu processamento. Dentre as inúmeras possibilidades, cinco são explicitamente definidas pelo padrão:

1. Basic hyperlinking HyTime document: utiliza o base module acrescido de algumas AFs opcionais, o location address module também acrescido de AFs opcionais e o hyperlinks module.

2. Basic scheduling HyTime document: utiliza todos os seis módulos HyTime, sendo que os seguintes módulos são acrescidos de AFs opcionais: base, measurement, location address, scheduling e rendition.

3. Minimal HyTime document: declara somente o base module.

4. Minimal hyperlinking HyTime document: declara o base module, o location address module acrescido de uma AF opcional (multloc) e o hyperlinks module. As principais AFs desse subconjunto de HyTime são descritas no próximo capítulo.

5. Minimal scheduling HyTime document: utiliza o base module acrescido de uma AF opcional, o measurement module e o scheduling module ambos também acrescidos de uma AF opcional.

O trabalho reportado nessa dissertação refere-se à definição de um DTD que utiliza as facilidades correspondentes à classe Minimal hyperlinking HyTime document, e é parcialmente reportado em (Trindade \& Pimentel 97). No contexto no qual essa dissertação está inserida, a classe Minimal scheduling HyTime document também está sendo investigada, conforme descrito em (Pimentel et al. 97c).

O padrão HyTime define ainda aplicações, sistemas e engines conformantes a HyTime. Uma aplicação conformante a HyTime deve ser conformante a SGML, manipular documentos conformantes a HyTime e possuir documentação também conformante a HyTime (o que implica possuir uma declaração do padrão) (ISO 92).

Um sistema conformante a HyTime deve ser um sistema conformante a SGML e deve possuir documentação e declarações conformantes a HyTime. Além disso, o sistema deve ser capaz de processar um documento HyTime Minimal, como definido acima (ISO 92).

A próxima seção discute o papel do HyTime engine.

\subsubsection{O HyTime Engine}

Um SGML parser traduz a marcação e o texto de um arquivo SGML para uma representação interna que especifica as instâncias de elementos do documento, seu conteúdo e atributos. Um HyTime engine interage com o SGML parser, reconhece as formas arquiteturais HyTime e executa o processamento específico do HyTime. Esse processamento inclui a 
checagem de erros, a extração de atributos específicos de HyTime e a resolução de certos tipos de endereços. A informação gerada pelo HyTime engine é colocada à disposição da aplicação. O papel principal do HyTime engine é dar suporte à composição de informações hipermídia, inclusive resolução de elos, endereçamento de objetos e a representação de sistemas de coordenadas (Buford et al. 94a).

\subsubsection{Suporte Básico de HyTime a Hyperlinks}

Uma das mais importantes características de HyTime é o seu suporte a endereçamento indireto, adicionalmente ao mecanismo de endereçamento direto fornecido por SGML (Fujitsu \& TechnoTeacher 95).

O suporte que SGML dá à criação de hiper-elos é baseado em endereçamento direto. Elos em um documento são definidos pela atribuição de um ID (unique identifier) a um elemento, e a referência a esse elemento é feita através de seu ID (Fujitsu \& TechnoTeacher 95).

A capacidade de suporte a hyperlinking de SGML pode ser resumida da seguinte forma (Fujitsu \& TechnoTeacher 95):

- Referências só podem ser feitas a IDs de elementos no mesmo documento, ou seja, dentro do mesmo parsing context.

- SGML não é capaz de conectar algo que não seja um elemento, ou um elemento que não tenha um ID.

- As referências não podem ser feitas a um sub-documento.

Os mecanismos de endereçamento indireto de HyTime permitem a declaração de elementos de elo em documentos separados dos documentos cuja informação eles apontam. Essa capacidade suporta (Fujitsu \& TechnoTeacher 95):

- A criação de um ou mais documentos externos contendo um web of links para outros documentos, incluindo documentos aos quais o usuário não tem acesso a escrita.

- A separação da tarefa de escrita da tarefa de criação de elos, de tal forma que essa última pode ser feita por um especialista em documentação on-line depois que o documento foi escrito.

- Manutenção simplificada de elos, através da concentração dos elementos de elo em uma única posição ao invés de espalhá-los pelo documento.

O uso de documentos externos que contêm elementos de elo oferece um meio alternativo a métodos tais como URLs (Uniform Resource Locators) utilizados na WWW para a manutenção de elos através de corpos complexos de informação (Fujitsu \& TechnoTeacher 95).

HyTime é discutido com mais detalhes no próximo capítulo. 


\subsection{HTML}

O padrão HTML (Hypertext Markup Language) (Berners-Lee et al. 94) tornou-se amplamente utilizado como formato para hiperdocumentos disponibilizados na WWW, formato esse reconhecido pelos browsers existentes. HTML é formalmente definido por um DTD SGML e, desse modo, define como um conjunto de elementos deve ser estruturado para compor um documento. HTML define, entre seus elementos, elos hipertexto e inclusão de outras mídias.

Apesar de HTML estar formalmente definido por um DTD SGML, a maioria dos documentos existentes hoje na WWW não é totalmente conformante a esse DTD. Isso ocorre porque os browsers atualmente em uso na WWW processam documentos HTML com flexibilidade e sem utilizar todas as características de validação oferecidas por um SGML parser.

Isso significa que os browsers em uso na WWW possuem, embutidos, um parser encarregado de reconhecer elementos HTML, parser esse que processa uma estrutura menos rígida que a definida pelo DTD HTML.

O comportamento interativo dos documentos HTML é definido pelos elementos âncora $a$ HTML que têm um atributo href associado. O conteúdo de tais elementos é considerado hotspot: eles são apresentados de maneira distinta, e sua ativação por parte do usuário provoca a apresentação de outro documento ou porção do documento. Esse relacionamento entre um hotspot e a apresentação provocada por sua ativação é típico de hipertextos. Os elos em HTML são unidirecionais: a seleção de um elo trás outro segmento de documento, mas esse segmento não age como um elo de volta para a posição original. Além disso, cada âncora só faz ligações para um único objeto.

Embora HTML use SGML, ele não usa os identificadores únicos SGML para referenciar porções do documento. O HTML utiliza a notação URL (Uniform Resource Locator) para especificar a posição de documentos na WWW (Berners-Lee et al. 94). Isto provê um modo comum e unificado de acesso a arquivos e informações através da WWW.

Porém, como sugerido em (Rutledge et al. 95), HTML não satisfaz todos os requisitos necessários para atender à nova geração de documentos hipermídia integrados e abertos, os quais são preocupação de trabalhos inseridos no contexto desta dissertação (Teixeira et al. 95) (Soares et al. 95). SGML e HyTime satisfazem muitos desses requisitos. Por isso, é interessante que os documentos HTML possam suportar construtores HyTime, como discutido em (Rutledge et al. 95).

\subsection{Considerações Finais}

O padrão ODA especifica tanto a estrutura lógica quanto a estrutura de apresentação do conteúdo de documentos. Vários mecanismos e atributos de apresentação estão disponíveis para a modelagem da apresentação desses documentos. Enquanto isso, SGML e HyTime só tratam da estrutura lógica dos documentos através da inserção de uma marcação padronizada — a 
especificação da apresentação está fora do escopo desses padrões. Dessa forma, a tarefa de autoria fica bastante simplificada, pois os detalhes de apresentação são deixados a cargo da aplicação que manipula tais documentos.

O material aqui apresentado deve ser de grande utilidade para aqueles que desejam iniciar-se nos padrões para hiperdocumentos SGML e HyTime. Parte desse material foi, ainda, disponibilizado à comunidade científica (Pimentel et al. 96).

O próximo capítulo apresenta a estrutura das principais formas arquiteturais do Minimal hyperlinking HyTime document. 


\section{Minimal HyperLinKING HyTime Document}

\subsection{Considerações Iniciais}

Nesse capítulo são descritas as principais formas arquiteturais dos módulos base, location address e hyperlinks de HyTime. Esses módulos compõem o Minimal hyperlinking HyTime document — um subconjunto de HyTime.

Um documento conformante com HyTime é um Minimal hyperlinking HyTime document se suas declarações HyTime forem as seguintes (ISO 92):

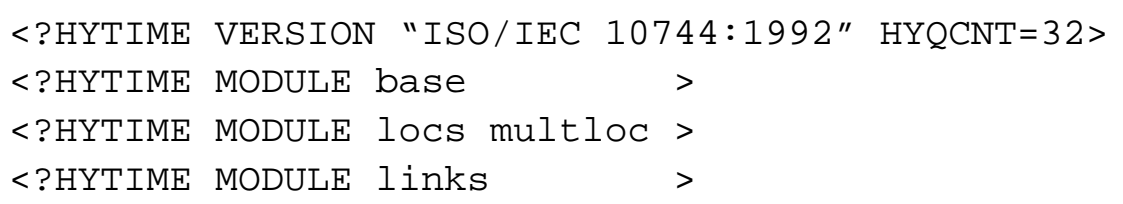

A declaração da versão do padrão HyTime usado deve ser a primeira declaração HyTime em um documento. O parâmetro HYQCNT (highest quantum count) declara um limite que não pode ser excedido por nenhum quantum count no documento. O número especificado para HYQCNT deve ser uma potência de dois (ISO 92).

Logo após a declaração da versão, são declarados os módulos HyTime aos quais deve ser oferecido suporte. No caso do Minimal hyperlinking HyTime document são declarados o base module (base), o location address module (locs) acrescido de um AF opcional (multloc) e, naturalmente, o hyperlinks module (links). As AFs mais significativas desses módulos e as que foram utilizadas na formalização das estruturas presentes no DTD CHTS são descritas nas próximas seções.

\subsection{Formas Arquiteturais do Base Module}

O objetivo principal do base module engloba: estabelecer que porções do documento são processáveis por HyTime; prover construtores primários usados na definição de construtores em outros módulos; e definir atributos comuns que podem ser usados em qualquer elemento HyTime. Nas próximas seções são apresentadas as principais formas arquiteturais do base module. 


\subsubsection{HyTime Document}

O ETF HyDoc (HyTime Document) representa o elemento de mais alto nível na estrutura de elementos de um documento HyTime (vide Figura 3.1). Seu conteúdo, juntamente com o daqueles de outros tipos de elementos, compreendem um meta-DTD com o qual todas as instâncias de documentos conformantes a HyTime devem conformar. As definições de atributo em todas as listas de atributo HyTime também são parte do meta-DTD (ISO 92).

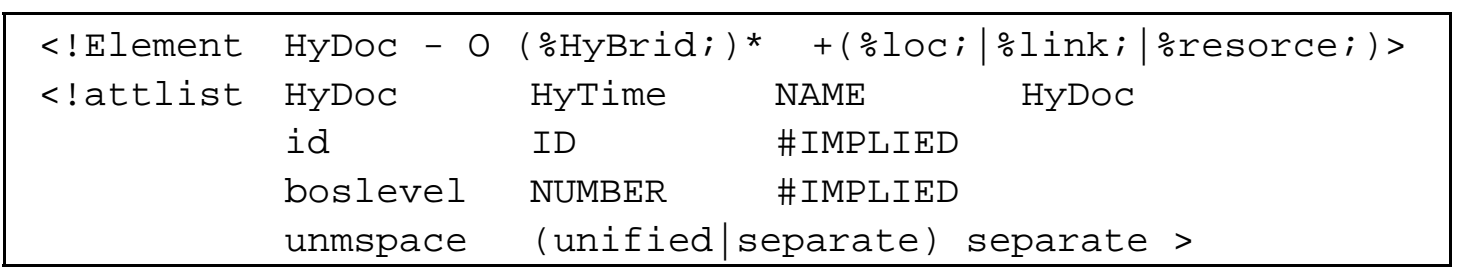

Figura 3.1: Especificação da forma arquitetural $H y D o c$

O atributo HyTime (HyTime Architectural Form) identifica a forma arquitetural de um elemento. Seu valor é o nome do elemento da forma arquitetural com a qual o elemento conforma (ISO 92).

O atributo boslevel (bounding object set level) especifica o nível de limitação do HyTime BOS ${ }^{2}$ (Bounded Object Set) que é determinado quando o documento é designado como um hub document ${ }^{3}$. Se não for especificado, a aplicação determina o seu próprio BOS (ISO 92).

O atributo unmspace (unified name space) indica se entidades e identificadores únicos compartilham um único name space (unified) ou não (separate) (ISO 92).

\subsubsection{HyTime/non-HyTime Bridge Element}

Um elemento que não possui uma semântica HyTime específica, mas requer o uso de alguns atributos HyTime comuns pode ser declarado como sendo da AF HyBrid (vide Figura 3.2). No entanto, o termo "HyBrid" também é usado como um modelo de conteúdo, que pode ser aplicado para definir um elemento que pode conter qualquer disposição de sub-elementos HyTime e não-HyTime. Esse uso é expresso pelo uso da entidade parâmetro \%HyBrid; (DeRose \& Duran 94).

\begin{tabular}{|lll|}
\hline$<$ !element & HyBrid - O (\%HyBid; $)^{*}$ & $>$ \\
$<$ !attlist & HyBrid HyTime NAME HyBrid $>$ \\
\hline
\end{tabular}

Figura 3.2: Especificação da forma arquitetural HyBrid

\footnotetext{
${ }^{2} \mathrm{O}$ assunto que uma aplicação HyTime processa: um conjunto de um ou mais documentos e outros objetos de informação (ISO 92).

${ }^{3} \mathrm{O}$ documento pelo qual o acesso a um hiperdocumento HyTime começa.
} 


\subsubsection{Supress HyTime Element}

Para os elementos da forma sHyTime (vide Figura 3.3) e todos os seus sub-elementos, um processador HyTime ignora todos os atributos HyTime que ocorrerem em seu conteúdo. Elementos sHyTime podem possuir qualquer content model (DeRose \& Duran 94).

$\begin{array}{lll}<\text { !element } & \text { sHyTime }- \text { O ANY } & > \\ <\text { !attlist } & \text { sHyTime } & \text { HyTime } \\ \text { NAME } & \text { SHyTime }>\end{array}$

Figura 3.3: Especificação da forma arquitetural sHyTime

\subsubsection{Identification Attributes}

O ALF all-id (identification attributes) consiste em atributos comuns que identificam um elemento, seu conteúdo e seus atributos (vide Figura 3.4). Esses atributos comuns podem ser usados individualmente na lista de definições de atributos; cada um é considerado uma facilidade independente do ponto de vista da determinação de sua obrigatoriedade ou não (ISO 92).

\begin{tabular}{|llll|}
\hline$<$ !attlist & all-id & & \\
& id & ID & \#IMPLIED \\
notation & NAME & \#IMPLIED \\
delims & CDATA & \#IMPLIED \\
conloc & IDREFS & \#CONFREF \\
& context & (context |ncontext) ncontext \\
& HyNames & CDATA & \#FIXED " $">$ \\
\hline
\end{tabular}

Figura 3.4: Especificação da forma arquitetural all-id

$\mathrm{O}$ atributo id (unique identifier) identifica um elemento no documento. Todo elemento HyTime deve declarar e usar um atributo ID SGML.

O atributo notation (data content notation) identifica a notação na qual o conteúdo de um elemento é representado. O atributo é processado da mesma forma que um SGML parser trata os atributos NOTATION (ISO 92).

$\mathrm{O}$ atributo delims (notation delimiter set) tem significado somente em conjunto com o atributo notation. Se alguma notação em particular usa delimitadores similares aos de SGML, então esses delimitadores podem ser redefinidos através da especificação de uma lista de nomes e novos valores nesses atributos. Isto pode ser útil para evitar colisões com delimitadores SGML tais como "<” (DeRose \& Duran 94).

O atributo conloc (content location) identifica o conteúdo do elemento quando ele não está no conteúdo sintático, ou seja, entre o start-tag e o end-tag.

O atributo context (contextual content) indica se o conteúdo do elemento (se existir) deve ser válido no contexto em que o elemento ocorre, tanto no DTD quanto no meta-DTD. O atributo context requer o suporte da opção “context” (ISO 92). 
O atributo HyNames (HyTime attribute names) permite a renomeação de outros atributos HyTime.

\subsubsection{ID Reference Resolusion Control}

O ALF all-ref (ID reference resolution control) permite que um HyTime engine execute uma checagem especial no uso do atributo IDREF. Essa AF é mostrada na Figura 3.5. Ela requer o suporte à opção "refctl”. Há três tipos de controle, cada um expresso por um atributo de controle correspondente (DeRose \& Duran 94):

- refrange (ID reference attribute range): indica aonde o ID referenciado por um IDREF pode ser encontrado

- reflevel (ID reference resolution level): impõem um limite ao nível de referências indiretas

- reftype (ID reference element type): permite que se determine o elemento para o qual um IDREF pode apontar

\begin{tabular}{|llll|}
\hline$<$ !attlist & all-ref & & \\
& refrange & CDATA & \#FIXED "ALL I" \\
& reflevel & CDATA & \#IMPLIED \\
& reftype & CDATA & \#FIXED "ALL \#ANY" > \\
\hline
\end{tabular}

Figura 3.5: Especificação da forma arquitetural all-ref

\subsection{Formas Arquiteturais do Location Address Module}

A forma fundamental de posição é aquela que coincide com a forma fundamental de endereçamento; ou seja, um elemento em um documento que é identificado por um ID. Essa forma de posição é suportada pelo base module de HyTime e pode ser endereçada por atributos do tipo IDREF e IDREFS (ISO 92).

Entretanto, o base module não provê nenhuma forma de designar um ID a porções arbitrárias de dados, a elementos em documentos somente-leitura que não têm ID, a coleções de elementos e a outras posições arbitrárias (ISO 92).

O location address module do HyTime provê uma forma de referenciar objetos de dados específicos e porções ou posições dentro deles (DeRose \& Duran 94). Esse módulo fornece três formas para localização de objetos de dados:

- Posições endereçadas por um nome (name space locations): descreve algo através de seu nome formal, que deve ser único no contexto, por exemplo, uma entidade SGML ou ID. 
- Posições endereçadas por uma coordenada (coordinate locations): descreve algo através de sua posição em uma lista, por exemplo, “o terceiro item nessa lista”.

- Posições endereçadas por uma estrutura semântica (semantic location): descreve objetos através de alguma característica própria dos objetos, por exemplo, “o primeiro elemento com um atributo type cujo valor é 12”.

Na próxima subseção são apresentadas as ALFs locsrc e multloc; nas duas subsessões seguintes são apresentadas as ETFs nameloc e nmlist que especificam posições endereçadas por um nome; na subseção 3.3.4 é apresentada a ETF treeloc que especifica posições endereçadas por uma coordenada; e na subseção 3.3 .5 é descrito como se fazer endereçamentos robustos utilizando-se as AFs do location address module.

\subsubsection{ALFs do Location Address Module}

Há três ALFs (attribute lists forms) definidas para o location address module: location source (locsrc), multiple location (multloc) e span location (spanloc). As duas primeiras ALFs serão detalhadas nas próximas sessões, pois são utilizadas em especificações futuras.

Quando a opção spanloc é suportada, a ALF spanloc permite endereçar elementos e/ou porção de dados contínuos entre duas posições no mesmo documento SGML (ISO 92).

\subsubsection{Location source}

A ALF locsrc (location source) endereça uma posição com respeito a alguma outra posição, identificada pelo atributo locsrc. Se nenhuma location source for especificada, é usada a última especificada (ISO 92).

Locsrc pode ser usada como um atributo das AFs nameloc (seção 3.3.2) e treeloc (seção 3.3.4), por exemplo. Nas sessões 3.3.2 e 3.3.4 são dados exemplos do uso de locsrc. A definição dessa ALF pode ser vista na Figura 3.6.

\begin{tabular}{|lll|}
\hline$<$ lattlist & locsrc & \\
& locsrc IDREFS \#CURRENT > \\
\hline
\end{tabular}

Figura 3.6: Especificação da ALF locsrc

\subsubsection{Multiple location}

Às vezes é necessário criar um elo para várias unidades ao mesmo tempo, ou para um intervalo contínuo de itens. Aggregate locations são conjuntos de itens que uma aplicação deseja tratar como uma única entidade. Spans são intervalos contínuos de itens que estão linearmente organizados (DeRose \& Duran 94). 
Tanto aggregate locations quanto spans são tratados pelo HyTime como formas de múltipla posição (multiple location), e são legais somente se a opção HyTime multloc for setada (DeRose \& Duran 94), como ocorre na declaração do Minimal hyperlinking HyTime document.

A ALF multloc permite que as propriedades de ordenação, omissão de duplicidade e agregação sejam associadas a um elemento com endereço de múltipla posição (ISO 92), como mostrado na Figura 3.7.

\begin{tabular}{|llll|}
\hline$<$ !attlist & multloc & & \\
& ordering & (ordered|noorder) & noorder \\
& set & (set|notset) & notset \\
& aggloc & (aggloc|agglink|nagg) & nagg \\
id & ID & \#REQUIRED $>$ \\
\hline
\end{tabular}

Figura 3.7: Especificação da forma arquitetural multloc

Uma múltipla posição é inerentemente ordenada. O atributo ordenação de posição (ordering) indica se a ordem das múltiplas posições é significante para a aplicação (or dered) ou não (noorder) (ISO 92).

O atributo set diz a HyTime para descartar duplicações geradas pelo localizador. Os valores possíveis para set são set e o valor default notset. Portanto, se um nome é listado mais de uma vez em um nameloc (veja a próxima seção) e o elemento tem um atributo set cujo valor é set, então as instâncias duplicadas são ignoradas (DeRose \& Duran 94).

O atributo aggloc é usado para definir se uma múltipla posição deve ser tratada como um agregado. Seu valor pode ser aggloc, nagg ou agglink. Os valores especificam, respectivamente, que a múltipla posição deve ser tratada como uma única posição que tem vários componentes (um agregado), como uma lista de posições de componentes separados, ou como um elo hipertexto implícito entre seus componentes (DeRose \& Duran 94).

O valor agglink provê um meio para associar os componentes de uma posição múltipla como se eles fossem os destinos de um elo, sem que seja necessário codificar um elemento de elo. É possível a travessia bidirecional entre o agregado e cada um de seus membros, entre membros adjacentes e entre o primeiro e o último membro (ISO 92).

\subsubsection{Named Location Address}

HyTime provê uma forma de ligação para qualquer coisa que pode ser nomeada como uma entidade ou via um ID. A forma arquitetural usada, mostrada na Figura 3.8, para alcançar isto é chamada nameloc (named location address). Ela é um localizador cujo conteúdo consiste de um ou mais elementos nmlist (veja a próxima seção), cada um deles contendo um ou mais nomes de entidades ou IDs. Não é possível combinar nomes de entidades e IDs no mesmo nmlist - essa é uma das razões pelas quais um nameloc pode conter mais de um nmlist (DeRose \& Duran 94). 


\begin{tabular}{|llll|}
\hline$<$ !element & nameloc & - & O \\
$<$ !attlist & nameloc & & \\
& HyTime & NAME & nameloc \\
& id & ID & \#REQUIRED $>$ \\
\hline
\end{tabular}

Figura 3.8: Especificação da forma arquitetural nameloc

Uma referência a um elemento no documento livro5, que possui seu próprio atributo ID, considerando que o ID em questão é capitulo2 é ilustrada na Figura 3.9.

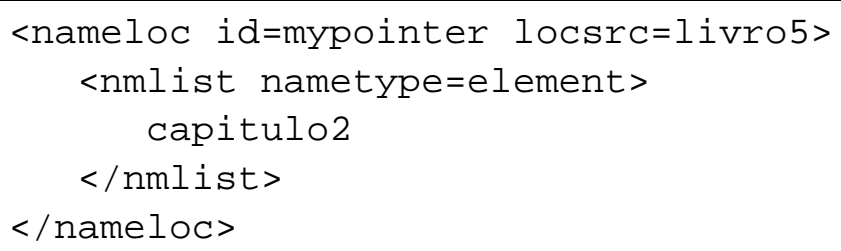

Figura 3.9: Exemplo do uso de um nameloc

\subsubsection{Name List Specification}

Um nmlist (name list specification) é simplesmente um recipiente do nome ou dos nomes que estão sendo referenciados (DeRose \& Duran 94) (vide Figura 3.10). Não há limites para o número de nomes.

\begin{tabular}{|c|c|c|c|}
\hline \multirow[t]{5}{*}{$\begin{array}{l}<\text { ! element } \\
<\text { !attlist }\end{array}$} & $\begin{array}{l}\mathrm{nmlist}- \\
\mathrm{nmlist}\end{array}$ & $0($ \#PCDATA $)>$ & \\
\hline & HyTime & NAME & nmlist \\
\hline & nametype & (entity|element |unified) & entity \\
\hline & docorsub & ENTITY & \#IMPLIED \\
\hline & dtdorlpd & NAMES & \#IMPLIED > \\
\hline
\end{tabular}

Figura 3.10: Especificação da forma arquitetural nmlist

O atributo nametype (name type) indica se os nomes da lista são nomes de entidades ou IDs de elementos, ou se o name space é unificado (ISO 92). No exemplo da Figura 3.9 esse atributo indica que o conteúdo da lista de nomes é um elemento.

$\mathrm{O}$ atributo obnames (object treated as names) provê outra maneira de controlar a interpretação das referências em um nmlist. Se ele possuir o valor obnames (ao invés de nobnames, que é o valor default e foi usado no exemplo da Figura 3.9), então o conteúdo do elemento referenciado é tratado como uma referência a ser seguida por HyTime.






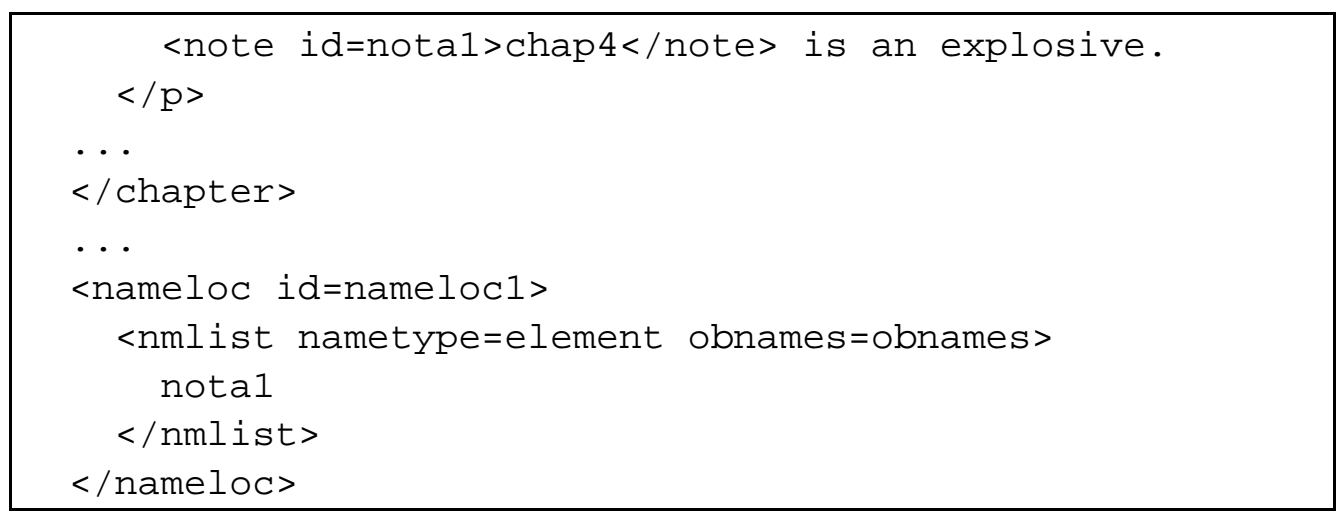

Figura 3.11: Exemplo do uso do atributo obnames

No exemplo da Figura 3.11, o nmlist parece apontar para o elemento note. Porém, como o atributo obnames tem o valor obnames e o conteúdo de note é “chap4”, que é um ID válido para o mesmo documento, HyTime irá resolver essa referência e a referência será para o elemento chapter, ao invés de note.

O atributo docorsub (SGML document or subdocument) deve ser adicionado a um nmlist se os nomes usados em seu conteúdo não são conhecidos no documento do nmlist e sim em outro documento. Nesse caso, docor sub irá especificar o nome da entidade que contém o documento no qual esses nomes são conhecidos. Se docorsub não for especificado, é assumido que os nomes foram definidos no mesmo documento do nmlist (DeRose \& Duran 94).

A Figura 3.12 apresenta um exemplo no qual dois nmlists no mesmo documento referenciam o mesmo elemento cujo ID é nota1, sendo que o segundo referencia esse elemento em um documento chamado livro5.

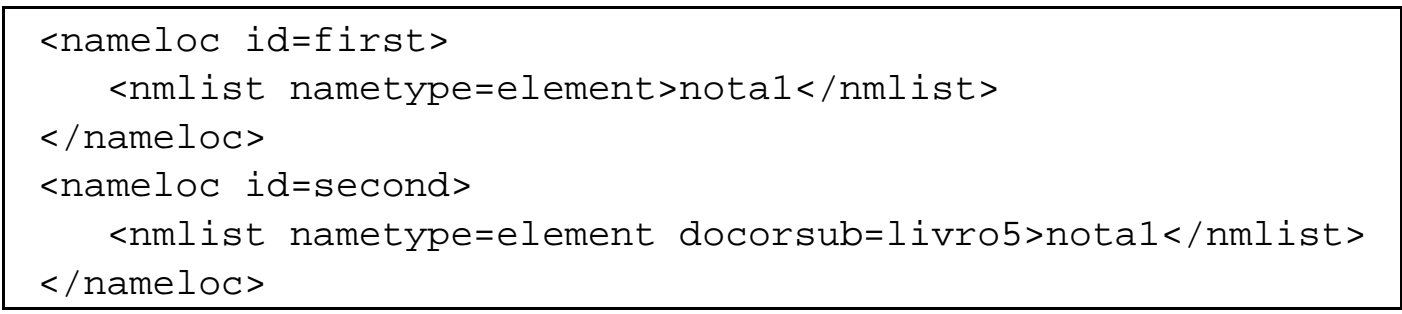

Figura 3.12: Exemplo do uso do atributo docorsub

O atributo dtdorltd (active DTDs or LTDs) especifica qual entre vários DTDs ou Link Process Definitions (LPDs) alternativos deve ser usado para mapear o documento (DeRose \& Duran 94). 


\subsubsection{Tree Location Address}

A AF treeloc (tree location address) provê uma forma conveniente de endereçar um nó de uma árvore. Treeloc pode endereçar qualquer tipo de árvore, não apenas documentos SGML (DeRose \& Duran 94).

Considerando o exemplo da Figura 3.13, treeloc seleciona um nó de tal árvore através da especificação de como alcançá-lo, passo a passo, desde a raiz. Por exemplo, para chegar, partindo da raiz, até o elemento item contendo "Human-readable representation", deve descer na árvore escolhendo:

- a raiz da árvore;

- o segundo filho da raiz (body);

- o primeiro filho desse nó (chapter 1);

- o segundo filho desse nó (section 1);

- o quarto filho desse nó (list);

- o quinto filho desse nó (o i tem desejado).

Isto é exatamente o que treeloc faz, a lista dos números necessários é inclusa em um elemento da forma marklist:
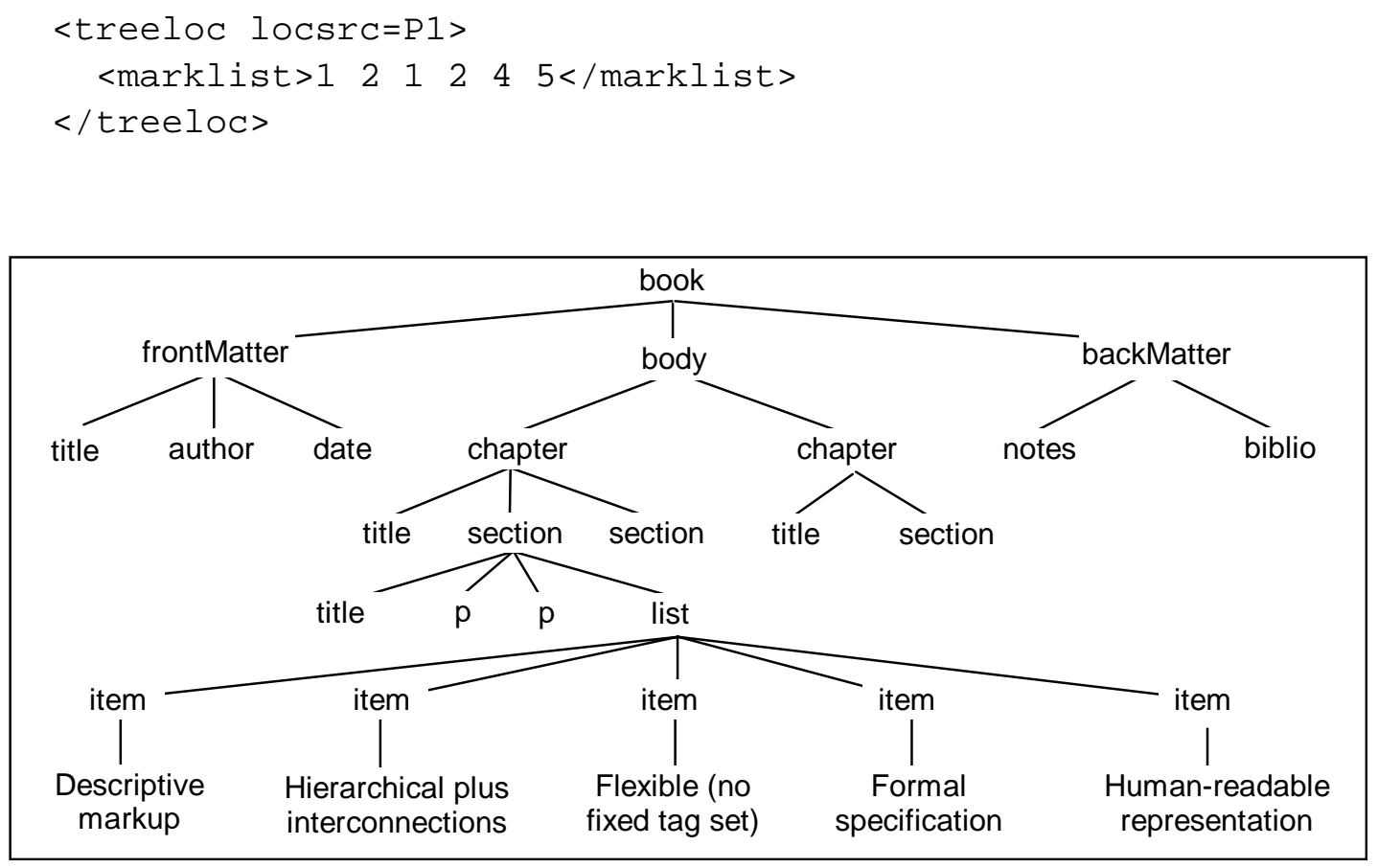

Figura 3.13: Exemplo de uma árvore de documento (DeRose \& Duran 94)

Deve ficar claro que qualquer nó em uma árvore pode ser alcançado a partir da raiz através de uma única lista de valores treeloc, e que qualquer uma dessas listas especifica um único nó (DeRose \& Duran 94). 


\subsubsection{Endereçamento SGML vs. HyTime}

Uma discussão interessante sobre a capacidade de endereçamento de SGML e HyTime é realizada por (DeRose \& Duran 94). Esses autores comentam que, embora o único mecanismo de endereçamento totalmente validado pelo SGML seja o mecanismo ID/IDREF, isto não quer dizer que outros mecanismos não possam ser utilizados. Contudo, um ID pode ser a melhor forma de referenciar um elemento em SGML porque:

- Um SGML parser checa automaticamente se todos os atributos ID em um documento são únicos e se todo IDREF aponta para um ID; essa checagem pode detectar vários erros do usuário.

- IDs são estáveis, geralmente não são modificados com o passar do tempo enquanto os documentos são editados ou revisados.

- Operações de edição comuns como a reorganização, inclusão ou exclusão de partes do documento não invalidam os IDs.

- Programas de autoria podem facilmente verificar a ausência de um ID, ao invés de levar o usuário a locais errados.

- HyTime trabalha na maioria das vezes convertendo outras formas de endereçamento para ID e IDREF; isto se torna trivial quando o destino desejado já possui um ID.

Dadas essas vantagens, (DeRose \& Duran 94) comentam que o uso desse mecanismo para todos os elementos SGML em todos os documentos traria vários benefícios especialmente para editores e para os usuários de hiperdocumentos e documentos que mudam freqüentemente. Como conseqüência, o uso de HyTime seria sensivelmente simplificado. Entretanto, os autores alertam que há várias razões para que muitos documentos não usem IDs deste modo:

- A geração de IDs únicos mnemônicos é difícil, especialmente em documentos muito grandes. A geração desses IDs poderia ser feita de forma automática, mas eles não teriam nenhum sentido para o usuário.

- Cada ID ocupa algum espaço e usuários de pequenos sistemas ou software que carregam o documento inteiro na memória poderiam ter limites práticos.

- Para a validação o parser deve manter uma lista de todos os IDs definidos (de outra maneira, ele não teria como saber se um novo ID é igual a um já existente). Isto pode diminuir a velocidade do parser mesmo em máquinas maiores e exceder a capacidade de máquinas pequenas.

Deste modo, (DeRose \& Duran 94) argumentam que o melhor compromisso seria colocar IDs em elementos estruturais maiores (por exemplo capítulos, sessões e listas) e então usar os endereçamentos do HyTime tais como treeloc para referências mais precisas dentro desses 
elementos. Tais endereçamentos envolvem tipicamente um nameloc e um treeloc. $\mathrm{O}$ nameloc aponta para o ancestral mais próximo que possua um ID SGML, e o treeloc desce na árvore tendo como location source o elemento nameloc. Esses elos são facilmente computados automaticamente. Por exemplo, se a primeira seção (section) na Figura 3.13 tivesse um ID=sec1, então seria possível especificar a posição do último item (item) da seguinte forma:



(DeRose \& Duran 94) defendem que essa convenção traz vários benefícios, mas um é primordial: a reorganização do documento em qualquer lugar fora do ancestral que possui o ID não causa nenhum efeito ao elo. Especificamente, o elo não é quebrado e dessa forma os leitores do documento terão poucos problemas. $O$ ancestral também pode ser movido sem que o elo seja quebrado. Logicamente, treeloc não protege o elo contra todo o tipo de edição do documento. Especificamente, mudanças dentro dos elementos identificados ainda podem causar problemas.

Como conclusão, (DeRose \& Duran 94) afirmam que não há uma solução definitiva para esse problema de modo geral, a não ser que a aplicação usada para fazer todas as modificações mantenha controle de todas as modificações. Portanto, sem um ambiente integrado de autoria muito avançado, um documento pode ser editado de tal forma que um elo poderá falhar. Entretanto, é possível criar elos relativamente robustos maximizando-se o uso dos IDs e usandose métodos simples como o treeloc para a navegação dentro de pequenas regiões selecionadas através do ID. 


\subsection{Formas Arquiteturais do Hyperlinks Module}

O HyTime define duas formas arquiteturais que uma aplicação pode usar para representar elos arbitrários (ISO 92):

- clink (contextual link) é simples; conta apenas com duas âncoras, uma delas é o conteúdo do elemento clink associado.

- ilink (independent link) é mais complexo; pode especificar um número indeterminado de link ends e suas âncoras podem estar em qualquer lugar, mesmo em objetos aos quais não se tem acesso para escrita.

\subsubsection{Contextual Link}

O ETF clink (contextual link), mostrado na Figura 3.14, permite que possa ser feita uma referência a uma posição no contexto (ISO 92); ou seja, uma âncora do elo é o conteúdo do próprio elemento clink, a outra é designada pelo atributo linkend, que é um IDREF para uma âncora ou para a posição do elemento que indica a âncora (DeRose \& Duran 94), como mostrado abaixo:



Nesse exemplo, a origem do elo está embutida dentro de um parágrafo. O conteúdo do elemento de elo, “iniciar o procedimento de instalação”, é especial, pois não é apenas um texto, mas também uma âncora, uma porção do documento a que um elo está ligado (DeRose \& Duran 94). No caso do clink, ele próprio é uma das pontas do elo, chamada âncora fonte.

O atributo linkend especifica a outra ponta do elo, que no exemplo acima referencia um elemento qualquer que tem um ID igual a sec1. Dessa forma, o elemento section é a âncora destino para o clink. Um sistema HyTime percebe a presença do clink e pode, se requisitado, 
usá-lo para localizar o destino. Uma aplicação deve realçar a âncora fonte e providenciar a apresentação da âncora destino caso o usuário click na âncora fonte.

\begin{tabular}{|c|c|c|c|c|}
\hline \multirow[t]{4}{*}{$\begin{array}{l}<\text { ! element } \\
<\text { ! attlist }\end{array}$} & clink & \multicolumn{2}{|c|}{ - 0 (\%HyBrid; )* } & \multirow[t]{3}{*}{$>$} \\
\hline & HyTime & NAME & clink & \\
\hline & & ID & \#IMPLIED & \\
\hline & linkend & IDREF & \#REQUIRED & $>$ \\
\hline
\end{tabular}

Figura 3.14: Especificação da forma arquitetural clink

Como discutido por Rutledge em (Rutledge 96a), a estrutura clink é muito similar a estrutura de âncora href de HTML. Um elemento clink poderia ser representado em um documento HTML como um elemento âncora com o seu atributo href destinado a localizar o objeto que o atributo linkend de HyTime localiza. A Figura 3.15 ilustra um exemplo de um código clink HyTime e uma possível conversão HTML.

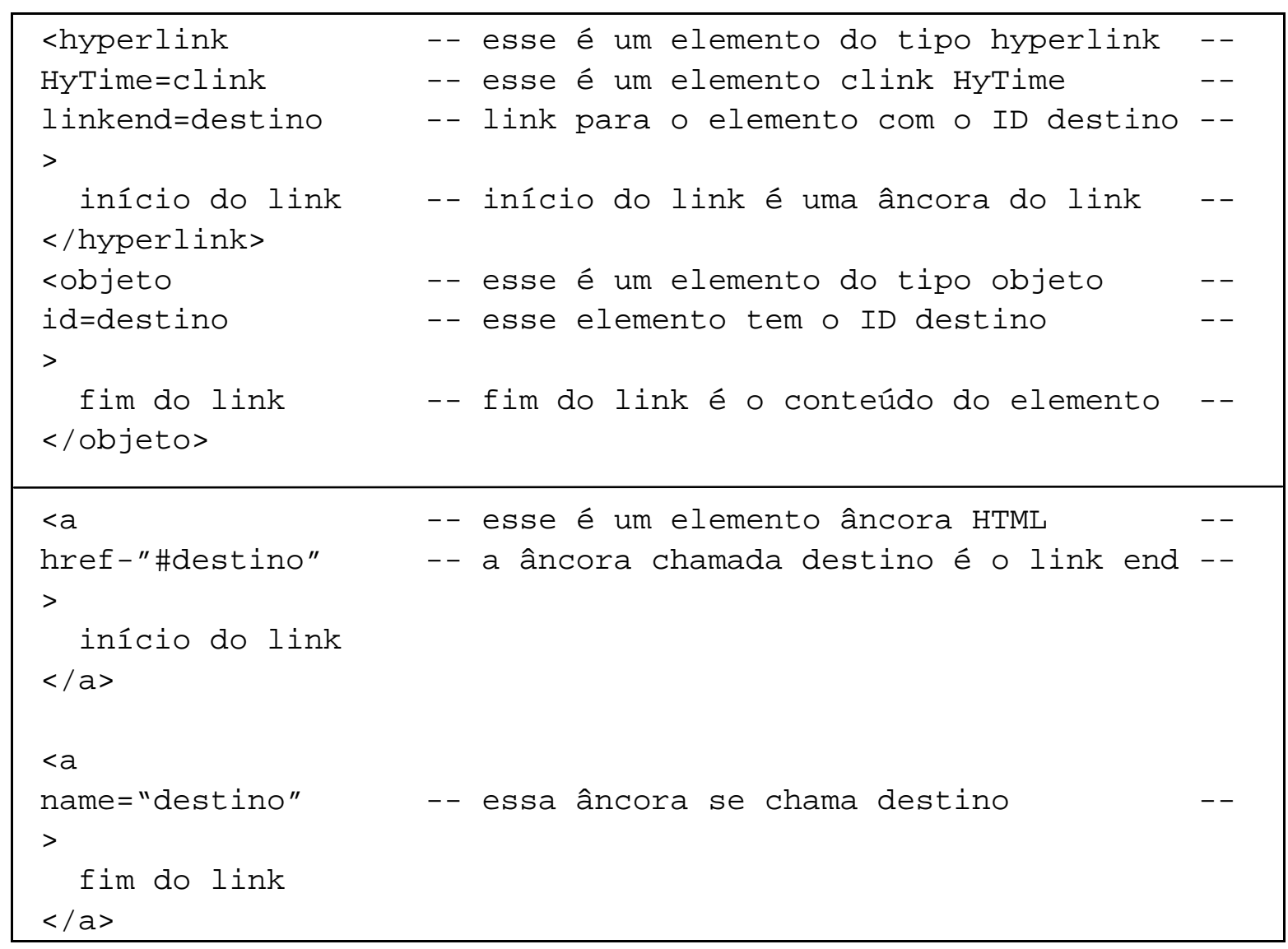

Figura 3.15: Um clink HyTime e sua conversão HTML (Rutledge 96a) 


\subsubsection{Independent Link}

O ETF ilink (independent link), mostrado na figura 3.16, é um hiper-elo cuja posição em um documento não precisa ter relação com a posição de suas âncoras. O significado da posição é determinado pela aplicação (ISO 92).

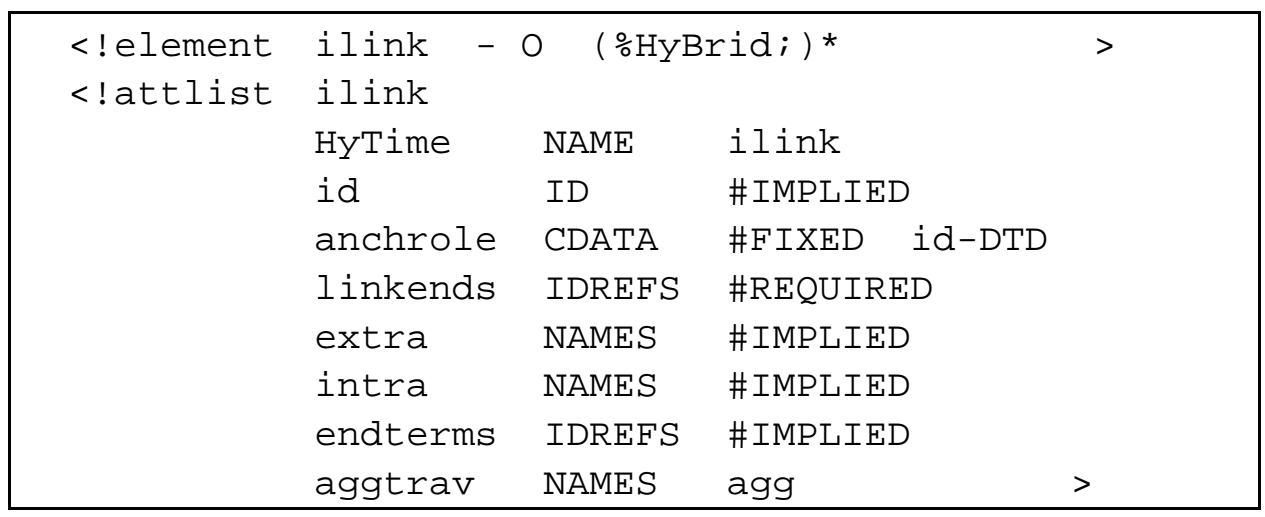

Figura 3.16: Especificação da forma arquitetural ilink

O atributo anchrole (anchor roles) é um identificador que destingue a função de uma âncora em particular (DeRose \& Duran 94).

O atributo linkends (link ends) identifica as posições que correspondem às âncoras de um elo (ISO 92).

Os atributos extra (external access traversal rule) e intra (internal access traversal rule) especificam a travessia que é permitida a partir de uma determinada âncora com respeito a ela ter sido acessada de dentro do elo ou de fora do elo (ISO 92).

O atributo endterms (link end terms) guarda informações sobre a âncora para uso da aplicação (DeRose \& Duran 94).

O atributo aggtrav (aggregate traversal) se aplica a uma âncora quando ela é um aggregate location link (ou seja, agglink e não aggloc). $\mathrm{O}$ atributo especifica se a travessia para uma âncora causa uma travessia direta para os membros do aggregate ("mem”), uma travessia para o aggregate (“agg”), ou uma travessia para um membro correspondente em um elo correspondente (“cor”). Uma dessas três palavras-chave são especificadas para cada âncora, ou uma única palavra-chave é especificada para todas as âncoras (ISO 92). A Figura 3.17 ilustra que tipos de elo são possíveis quando a âncora é um aggtrav.

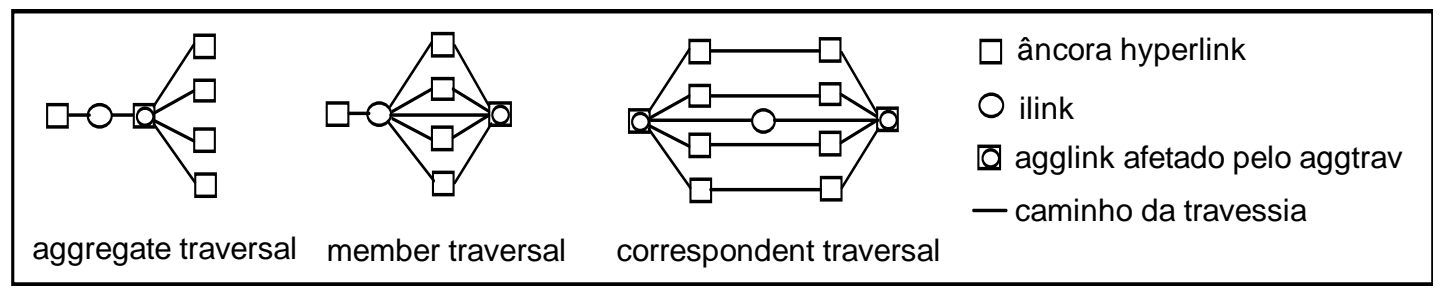

Figura 3.17: Tipos de elo a partir de uma âncora aggtrav (Rutledge 95) 
Para aplicações que necessitam de elos que conectem mais de duas posições ou posições armazenadas em documentos diferentes, HyTime provê o ilink. Um exemplo simples de um ilink conectando duas posições no mesmo arquivo seria o seguinte:



\subsection{Considerações Finais}

Nesse capítulo foram apresentadas as formas arquiteturais do base, location address e hyperlinks modules de HyTime — os quais podem ser utilizados na definição de documentos conformantes com o Minimal hyperlinking HyTime document. Esse subconjunto de HyTime provê recursos para a elaboração de formas de endereçamento sofisticadas que permitem a ligação a praticamente qualquer tipo de informação estruturada.

Foram detalhadas as AFs mais significativas desses três módulos e as que foram utilizadas na especificação das estruturas formalizadas pelo DTD CHTS, apresentado no Capítulo 5.

Para apresentar uma contextualização do trabalho reportado nesta dissertação em relação a modelos outros que o HyTime, o próximo capítulo apresenta alguns sistemas e modelos hipermídia reportados na literatura atual. 


\section{Modelos E Sistemas Hipermídia}

\subsection{Considerações Iniciais}

A tecnologia de hipermídia tem evoluído de modo a suportar hiperdocumentos cada vez mais complexos em termos de seu conteúdo e de sua estrutura. No primeiro caso, o suporte exclusivo à mídia texto deu lugar à manipulação de outras mídias, tais como informação de áudio e vídeo. No segundo caso, a estrutura básica dos hiperdocumentos passou de um grafo com ligações 1:1 para estruturas mais complexas que suportam, por exemplo, composições (Soares et al. 95c), trilhas ou guided-tours (Zellweger 89) (Soares et al. 95b), anotações e elos multi-destino (Yankelovich et al. 88).

Essa evolução tem levado à proposta de modelos de estruturação de hiperdocumentos os quais formalizam a estrutura desses hiperdocumentos - e de modelos que formalizam a estrutura de aplicações hipermídia - as quais manipulam hiperdocumentos. HyTime pertence à primeiro dessas catergorias, ao lado do Modelo Dexter (Halasz \& Schwartz 94) e NCM (Soares et al. 95c). A próxima seção desse capítulo é dedicada à apresentação dessa categoria de modelos. Com o objetivo de apresentar a outra categoria de modelos existente na área, a seção seguinte desse capítulo apresenta alguns modelos representativos da categoria que formaliza a estrutura de aplicações: HDM (Hardman et al. 94) e RMM (Isakowitz et al. 95). A seção seguinte é destinada à apresentação de sistemas hipermídia. Inicialmente são apresentados dois sistemas hipermídia desenvolvidos a partir de modelos apresentados: DHM, baseado no Modelo Dexter; HyOctane, baseado em HyTime. Finalmente, é apresentado o Microcosm, um sistema proprietário que não segue nenhum modelo em particular.

\subsection{Modelos Hipermídia para a Estruturação de Hiperdocumentos}

\subsubsection{Dexter Hypertext Reference Model}

O Dexter Hypertext Reference Model (Halasz \& Schwartz 94) provê uma terminologia hipertexto padrão juntamente com um modelo formal das abstrações importantes comumente encontradas em uma grande quantidade de sistemas hipertexto. Desse modo, o modelo Dexter pode ser utilizado como um padrão de comparação e contraste de características e funcionalidade para vários sistemas hipertexto. O modelo também pode ser utilizado como base para o desenvolvimento de padrões para interoperabilidade e intercâmbio entre sistemas hipertexto.

\section{Uma Visão Geral do Modelo}


O modelo Dexter divide um sistema hipertexto em 3 camadas: run-time layer, storage layer e within-component layer. O foco principal do modelo é a storage layer, que descreve a estrutura de rede básica de elos e nós que é a essência de documentos hipertexto. A storage layer descreve um banco de dados que é composto por uma hierarquia de componentes interconectados por elos. Componentes correspondem ao que tipicamente chamamos de nós em uma rede de hipertexto. A storage layer enfoca os mecanismos pelos quais os componentes de elo e não-elo são agrupados para formar redes de documentos hipertexto. Nessa camada os componentes são tratados como repositórios genéricos de dados. Portanto, a storage layer não faz nenhuma diferenciação entre textos e gráficos.

Em contraste, a within-component layer está voltada especificamente para o conteúdo e estrutura dentro de componentes de uma rede hipertexto. A gama de conteúdo/estrutura possíveis que podem ser incluídas em um componente não é restrita. Texto, gráficos, animações, simulações, imagens e muitos outros tipos de dados têm sido usados em sistemas hipertexto existentes. Dexter não é um modelo genérico que trata todos esses tipos de dados. Em vez disso, o modelo Dexter trata as estruturas dentro dos componentes como se elas estivessem fora do modelo hipertexto. É assumido que outros modelos de referência projetados especificamente para modelar a estrutura de aplicações particulares, documentos, ou tipos de dados serão usados em conjunto com o modelo Dexter.

Uma parte crítica do modelo Dexter é a interface entre a rede de hipertexto e o conteúdo e estrutura de within-component. Sistemas hipertexto requerem um mecanismo para endereçamento de posições ou itens dentro do conteúdo de um componente particular. No modelo Dexter, esse mecanismo é conhecido como anchoring.

Outro aspecto importante do modelo Dexter é a interface entre a storage layer e a runtime layer. No modelo Dexter, isto é resolvido usando-se a noção de especificações de apresentação. Especificações de apresentação são um mecanismo pelo qual a informação sobre como um componente deve ser apresentado ao usuário pode ser codificada na rede de hipertexto na storage layer. Portanto, a forma em que um componente é apresentado ao usuário pode não ser uma função exclusiva da ferramenta hipertexto específica que está fazendo a apresentação, mas pode também ser uma propriedade do próprio componente.

\section{Modelo de Storage Layer}

A storage layer descreve a estrutura de um hipertexto como um conjunto finito de componentes e duas funções: resolve e accessor. As funções resolve e accessor são responsáveis pela recuperação dos componentes.

A entidade fundamental e unidade básica de endereçamento na storage layer é o componente. Um componente pode ser tanto um átomo, um elo, ou um composite formado por outros componentes. Componentes atômicos podem ser comparados aos nós dos sistemas hipertexto. Elos são entidades que representam o relacionamento entre outros componentes. Composites são componentes construídos a partir de outros componentes. 


\section{Modelo Run-time Layer}

O conceito fundamental na run-time layer é a instanciação de um componente. Uma instanciação é uma apresentação do componente ao usuário. Operacionalmente, pode-se dizer que uma instanciação é um tipo de cache run-time para o componente.

Nas próximas sessões são apresentados dois sistemas baseados em Dexter que tentam expandir sua funcionalidade: HDM e AHM.

\subsubsection{NCM - Nested Context Model}

O Nested Context Model (NCM) (Soares et al. 95b), entre outras características, dá suporte a conjuntos de versões, permite a exploração e o gerenciamento de configurações alternativas, mantém as histórias do documento, suporta o trabalho cooperativo e provê a propagação automática de modificações de versão.

\section{O Nested Context Model}

A Figura 4.1 resume as classes hierárquicas básicas do NCM.

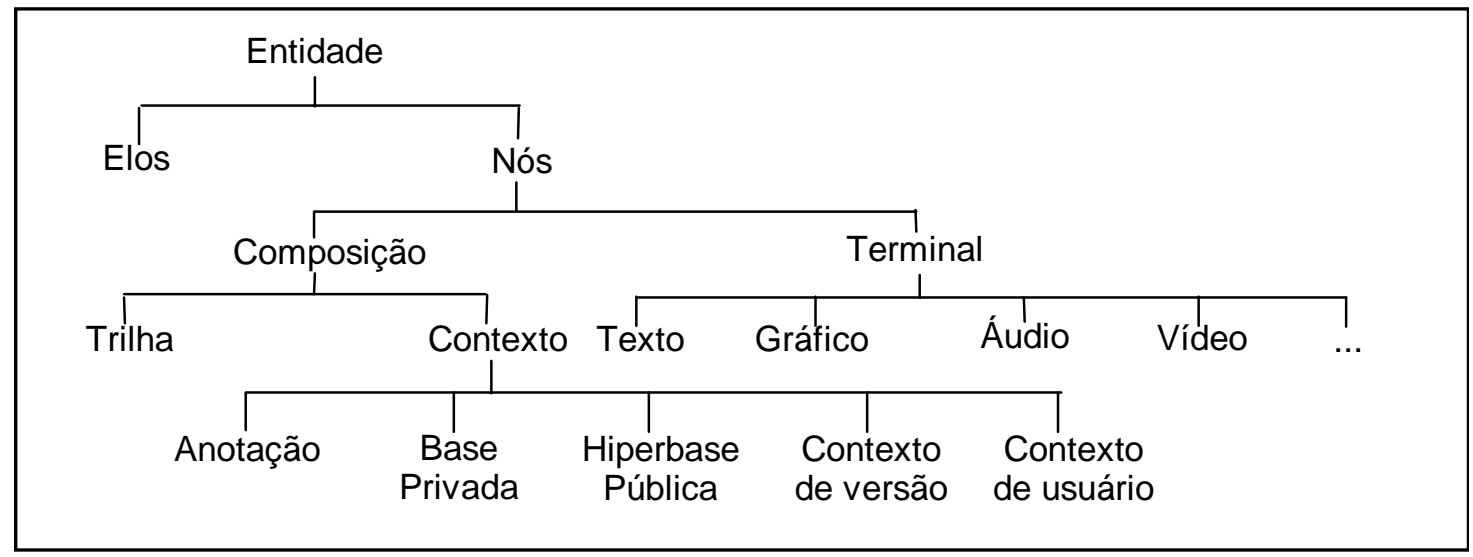

Figura 4.1: Hierarquia das classes NCM (Soares et al. 95b)

Uma entidade é um objeto que tem como atributos um identificador único, uma lista de controle de acesso e um descritor de entidade. Um nó é uma entidade que tem como atributos adicionais um conteúdo e um conjunto de âncoras. Cada elemento no conjunto de âncoras é chamado uma âncora do nó e é um objeto que tem como atributos um id, uma região e um conjunto de pares condição/ação. Um nó terminal é um nó cujo conteúdo e conjunto de âncoras são dependentes da aplicação. O modelo permite que classes de nós terminais sejam especializadas em outras classes (texto, áudio, imagem, etc.).

Um elo é uma entidade com dois atributos especiais, o source end point set e o destination ou target end point set. 
O NCM básico trata documentos hipermídia como estruturas de dados essencialmente passivas. Entretanto, um sistema hipermídia deve prover ferramentas para o usuário acessar, visualizar, manipular e navegar através da estrutura de documentos hipermídia. Esses aspectos são de responsabilidade do modelo de apresentação do NCM.

\section{Estendendo o NCM para incluir controle de versão}

O NCM básico já provê suporte a alguns mecanismos de controle de versão. Em NCM, somente os nós terminal e de contexto de usuário recebem o controle de versão. Foi introduzida a noção de estado de um nó terminal e de um nó de contexto de usuário para controlar a consistência entre nós interrelacionados, para suportar o trabalho cooperativo e para permitir a criação automática de versões.

Para resolver o problema da manutenção da história de um documento, o NCM foi estendido com a classe de nós de contexto de versão (Soares et al. 95c).

Foi definida a hiperbase pública como um tipo especial de nó de contexto que agrupa conjuntos de nós terminais e de contexto de usuário. Também foi definida uma base privada como um tipo especial de nó de contexto que agrupa qualquer entidade, exceto os nós de hiperbase pública e de contexto de versão. Uma anotação é um tipo especial de nó de contexto que agrupa conjuntos de elos, nós terminais, nós de contexto de usuário e trilhas.

O modelo NCM resolve o problema da propagação automática de versão deixando que o usuário decida se ele quer ou não essa facilidade, e limitando a propagação automática àqueles nós de contexto de usuário que pertencem à perspectiva em que a nova versão foi criada. A propagação também se limita àqueles nós de contexto de usuário que estão commited. Isto significa prover um mecanismo que suporta conjuntos de mudanças coordenadas.

\subsection{Modelos Hipermídia para a Estruturação de Aplicações}

\subsubsection{HDM - Hypertext Design Model}

Em (Garzotto \& Schwabe 93) é apresentado um modelo para authoring-in-the-large, chamado HDM (Hypertext Design Model). Authoring-in-the-large permite a especificação e projeto de aspectos gerais e estruturais de uma aplicação hipertexto. HDM prescreve a definição de um schema de aplicação, que descreve classes globais de elementos de informação em termos de suas características de apresentação comuns, suas estruturas de organização interna, e os tipos de interconexões mútuas. HDM é, principalmente, um dispositivo para modelamento, e provê meios para descrever, concisamente e de uma maneira independente da aplicação, aplicações hipertexto. Adicionalmente, HDM pode ser usado como um gerador de implementações executáveis de aplicações hipertexto; para isso, atua como a base para ferramentas de projeto que suportam diretamente o desenvolvimento de aplicações. 


\section{Um Modelo Baseado na Abordagem de Authoring-in-the-Large}

HDM é um modelo para a descrição de aplicações hipertexto. Uma aplicação HDM consiste de estruturas grandes de pedaços de informação chamadas entidades. Uma entidade denota um objeto físico ou conceitual do domínio. Entidades são agrupadas em tipos de entidades. Uma entidade é a menor porção autônoma de informação que pode ser introduzida ou removida de uma aplicação. Nesse contexto, porção “autônoma” de informação significa que sua existência não está condicionada à existência de outros objetos de informação. Em HDM, somente entidades são autônomas, enquanto componentes e unidades não o são, como discutido a seguir.

Uma entidade é uma hierarquia de componentes. Componentes são, por sua vez, compostos por unidades. Cada unidade mostra o conteúdo de um componente segundo uma perspectiva particular. As unidades são a menor porção de informação que podem ser visualizadas por uma aplicação HDM, e elas têm muito em comum com o conceito de nós hipertexto.

Estruturas de informação HDM podem ser interconectadas por elos. HDM faz distinção entre 3 categorias de elos: elos estruturais conectam componentes pertencentes à mesma entidade; elos de perspectiva conectam as diferentes unidades que correspondem ao mesmo componente; e elos de aplicação denotam relacionamentos arbitrários e conectam componentes e entidades, do mesmo tipo ou não, em padrões arbitrários definidos pelo autor.

De acordo com a terminologia HDM, uma aplicação pode ser dividida em duas porções: uma hiperbase e uma conjunto de estruturas de acesso. A hiperbase consiste em entidades, componentes, unidades e nas três categorias de elos. O usuário/leitor pode explorar o hipertexto através da travessia dos elos lá definidos. Estruturas de acesso têm o propósito de permitir ao leitor a escolha dos pontos de entrada para novas navegações.

Uma semântica de browsing tem o propósito de especificar como estruturas de informação são visualizadas pelo leitor, e como ele pode navegar pela informação. HDM provê uma semântica de browsing default simples, porém diferentes semânticas de browsing podem ser definidas para descrever efeitos de visualização mais sofisticados.

O modelo OOHDM é um modelo mais recente, proposto como uma extensão do HDM com o objetivo a explorar os recursos da orientacao a objetos no projeto de aplicações hipermídia (Schwabe et al 1996).

\subsubsection{AHM - Amsterdam Hypermedia Model}

O Amsterdam Hypermedia Model (AHM) (Hardman et al. 94) foi proposto como uma ferramenta que pode ser usada para descrever os construtores e ações básicas comuns a uma grande parte dos sistemas hipermídia. O AHM foi desenvolvido como uma extensão do modelo Dexter a fim de explorar suas contribuições para o entendimento de sistemas hipertexto. O AHM estende o modelo Dexter através da adição de noções de tempo, atributos de apresentação de alto 
nível e contexto de elo. Uma parte dessa extensão é baseada nos aspectos básicos do modelo para documentos multimídia CMIF (Bulterman et al. 91)(Bulterman 93).

\section{Componentes AHM}

Um documento hipertexto é modelado como uma rede de componentes relacionados através de um conjunto de elos. Um componente atômico contém meta-informação referente a um bloco de dados particular, enquanto que componentes compostos definem a meta-informação para um conjunto de blocos atômicos ou compostos. Os componentes compostos não dão suporte a dados, uma vez que dados só podem ser referenciados por componentes atômicos.

Os componentes atômicos AHM contêm informação de apresentação, atributos do componente, informação sobre âncora de elo e um campo de conteúdo. O acréscimo significativo ao bloco atômico é uma seção de informação de apresentação expandida. Uma parte dessa informação expandida é usada para modelar aspectos do bloco relacionados ao tempo, enquanto outros são usados para codificar atributos de apresentação de alto nível.

O composite de AHM inclui vários itens não encontrados no modelo Dexter. A diferença principal é que o composite é usado para construir a estrutura da apresentação ao invés de simplesmente coletar componentes relacionados para propósitos de navegação.

\section{Relações Temporais}

O principal mecanismo de suporte a relacionamentos temporais entre entidades é o composite. A sincronização entre componentes é suportada de duas formas: uma para sincronização de granularidade grossa e outra para sincronização de granularidade fina. Sincronização de granularidade grossa consiste em restrições definidas entre os filhos de um composite, tal como o tempo de disparo relativo de cada filho dentro do composite. Sincronização de granularidade fina consiste em restrições entre filhos irmãos e não-irmãos (aninhados) dentro do composite; essas restrições são especificadas usando-se arcos de sincronização. $\mathrm{O}$ arco de sincronização é um construtor que provê um mecanismo flexível para o estabelecimento de relacionamentos em sistemas multimídia.

Segundo os projetistas de AHM, a principal vantagem do modo com que AHM especifica relacionamentos temporais é a separação clara entre o grupo de componentes que devem ser apresentados juntos, a ordem relativa desses objetos e as restrições detalhadas de tempo que podem existir durante a apresentação de um grupo de objetos.

\section{Contexto de Elo AHM}

Os aspectos temporais da arquitetura de componentes AHM provêem um método conveniente de agrupar e sincronizar objetos relacionados. Porém, componentes compostos não provêem informação sobre como cada componente se comporta quando um elo é seguido a partir do componente ou até o componente composto. Afim de descrever esse tipo de comportamento, AHM define a noção de contexto de elo. Um contexto é um componente que contém um grupo 
de componentes atômicos ou compostos afetados por uma operação de elo. Um contexto fonte para um elo é a porção de uma apresentação hipermídia afetada pela inicialização de um elo, e um contexto destino é aquela parte da apresentação que é executada quando o destino de um elo é alcançado.

Um benefício da especificação de contexto é que apenas parte da estrutura do documento necessita ser afetada quando um elo é atravessado. Componentes da apresentação em um nível mais alto na hierarquia da composição permanecem ativos e somente aqueles que estão em níveis mais baixos são afetados.

\section{Canais AHM: Codificando Atributos de Apresentação de Alto Nível}

Tanto o modelo Dexter quanto AHM permitem que atributos de apresentação sejam especificados para componentes atômicos ou composições individuais. Esses atributos são suficientes para o controle local, mas são inadequados para especificar atributos mais globais de um documento. Esses atributos são definidos em AHM usando-se canais.

Canais são dispositivos de saída abstratos para a execução do conteúdo de um documento. Associado a cada canal estão características default do tipo mídia apresentada por esse canal, tais como fonte e estilo para um canal de texto, ou volume para um canal de áudio. O número de canais não é restrito.

O uso de canais permite que o mesmo documento seja apresentado de formas diferentes através da re-especificação de estilos ao invés de mudar a especificação da apresentação para todos os itens.

\subsubsection{RMM - Relationship Management Methodology}

O Relationship Management Methodology (RMM) foi proposto para o projeto e construção de aplicações hipermídia (Isakowitz et al. 95). A classe de aplicações para o qual RMM é mais adequado exige uma estrutura regular e volatilidade da informação.

\section{RMDM (Relationship Management Data Model)}

Modelos de dados são necessários para expressar o projeto da aplicação. É importante diferenciar sistemas hipertexto de aplicações hipertexto. O primeiro pode ser considerado como um ambiente que facilita a criação do último. Um modelo de dados para um sistema hipermídia detalha a arquitetura interna, mas é de pouco valor para a modelagem de aplicações hipermídia. RMDM provê uma linguagem para a descrição de objetos de informação e mecanismos de navegação em aplicações hipermídia.

O modelo de dados HDM é apropriado para a descrição da estrutura do domínio da aplicação, e o RMDM é baseado no modelo de dados HDM e do seu sucessor, HDM2. 
A figura 4.2 mostra as primitivas de modelagem RMDM. Na parte superior da figura estão as primitivas de domínio, que modelam a informação a respeito do domínio da aplicação. Entidades e seus atributos representam objetos abstratos ou físicos, tais como pessoas ou contas bancárias. Relacionamentos associativos, que podem ser um-para-um ou um-para-muitos, descrevem associações entre diferentes entidades.

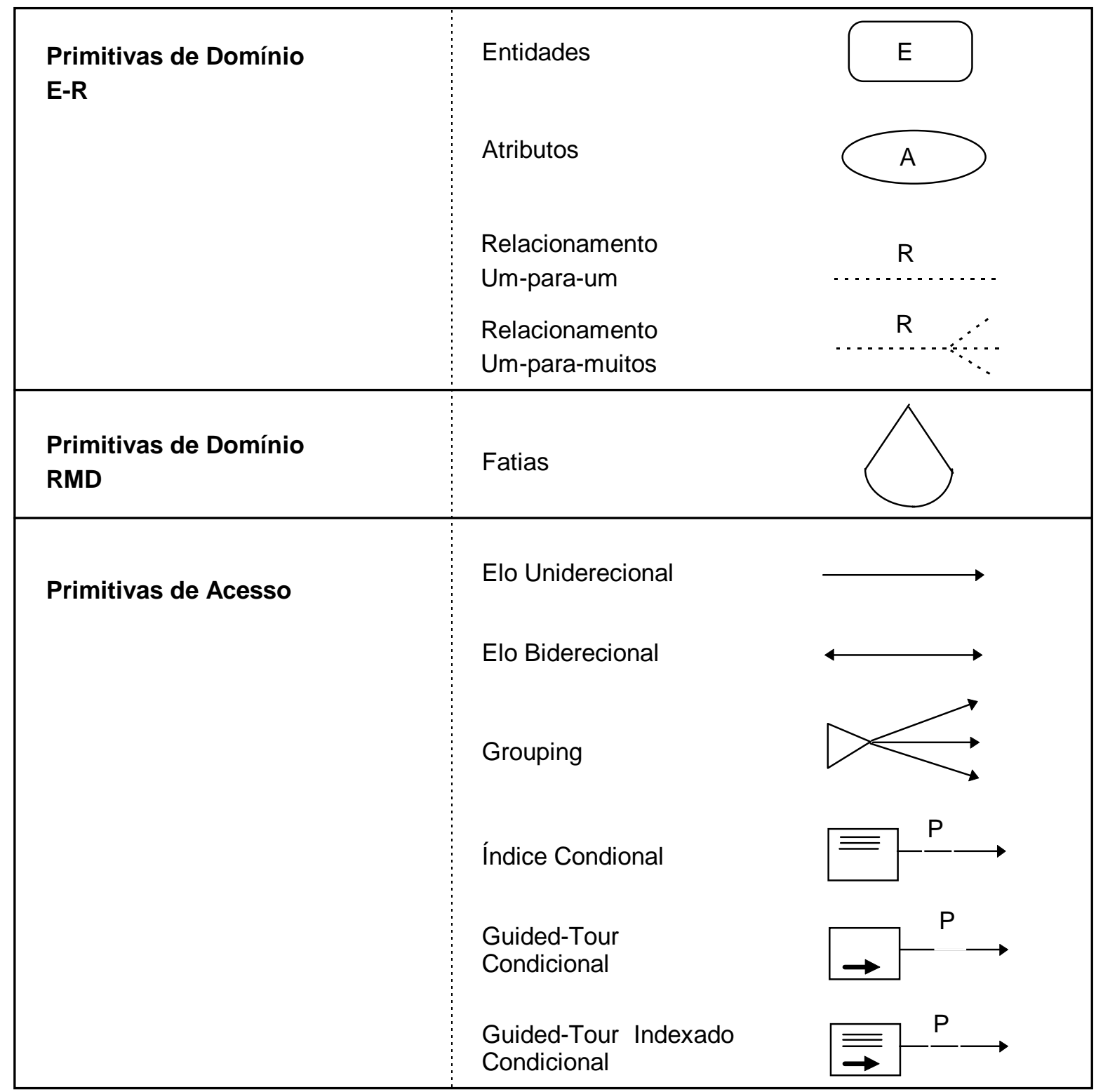

Figura 4.2: Primitivas RMDM (Isakowitz et al. 95)

Entidades podem consistir de um grande número de atributos de naturezas diferentes, por isso, pode ser impraticável ou indesejado apresentar todos os atributos de uma entidade ao mesmo tempo. Portanto, atributos são agrupados em fatias (slices).

A navegação é suportada em RMDM por seis primitivas de acesso mostradas na parte inferior da figura 4.2. Os elos unidirecionais e bidirecionais são usados para especificar o acesso 
entre fatias de uma entidade. RMDM suporta navegação entre diferentes entidades via índices, guide tour e groupings.

Um diagrama RMDM permite descrever o modo de navegação de um usuário em uma aplicação hipermídia, ao invés de representar o projeto de banco de dados como faz o diagrama de Entidade-Relacionamento.

\subsection{Sistemas Hipermídia}

\subsubsection{DHM - DeVise Hypermedia}

O DHM (DeVise Hypermedia) (Grøbæk \& Trigg 94) é um sistema baseado no modelo de referência Dexter e utilizado na plataforma Apple Macintosh. DHM dá suporte a elo e composites de browser para componentes atômicos, e um composite para capturar configurações de tela de componentes abertos. As mídias suportadas por DHM são texto, gráficos e vídeo.

Além da travessia do elo, os usuários podem editar elo ends com o auxílio de uma interface gráfica. Componentes podem ser recuperados e apresentados via uma busca pelo título. O modelo Dexter de âncoras é estendido para incluir uma distinção entre âncoras marcadas e desmarcadas. Finalmente, DHM dá suporte explícito a elos pendentes.

Uma âncora marcada é aquela em que um objeto está diretamente embutido no conteúdo do componente. Esses objetos são chamados de link marker em Dexter. DHM suporta link markers no texto de componentes mantendo uma região de contorno em volta do texto.

Uma âncora desmarcada não possui link markers. Normalmente sua localização dentro do componente deve ser calculada. Componentes de texto em DHM suportam um tipo particular de âncora desmarcada chamada keyword.

Uma diferença entre âncoras marcadas e desmarcadas é a habilidade de recuperar a âncora diretamente a partir de uma seleção no editor de componentes. Se um link marker é selecionado em uma instanciação ativa, então a instanciação é capaz de acessar diretamente a âncora marcada correspondente, em contraste com as âncoras desmarcadas, em que é necessário se fazer uma busca.

Ao contrário do modelo Dexter, no qual um elo não pode ter menos de duas âncoras, em DHM essa restrição é relaxada, ou seja, elos pendentes que têm zero ou uma âncora são perfeitamente legais.

\subsubsection{HyOctane}

HyTime e SGML provêem um meio para a definição da representação de hiperdocumentos como arquivos texto que podem ser intercambiados e processados em qualquer 
plataforma. Eles também provêem um modelo em camadas para o processamento de documentos hipermídia.

Um dos trabalhos pioneiros em relação a HyTime foi desenvolvido na Universidade de Massachussets Lowell como uma arquitetura para um MMIS (multimedia information system) que armazena documentos HyTime. Esse sistema é composto por um SGML parser dedicado, um banco de dados orientado a objetos para o armazenamento da descrição do documento, e um protótipo de um HyTime engine chamado HyOctane (Buford et al. 94a) para acessar e apresentar instâncias de documentos.

Os inicializadores do HyOctane pesquisam a camada SGML para identificar AFs HyTime e gerar estruturas correspondentes na camada HyTime. A seqüência de processamento envolve o SGML parser, o HyTime engine e a aplicação, o que implica em uma arquitetura com três camadas: camada SGML, camada HyTime e camada de aplicação. Consistentemente, o projeto da estrutura de dados para a construção da base de dados orientada a objetos é organizada em três camadas: uma para classes SGML, outra para classes HyTime e outra para classes da aplicação.

A aplicação construída comporta a apresentação de vários componentes do hiperdocumento na forma de um slide show. Uma ferramenta para apresentação multimídia previamente desenvolvida para uma aplicação comercial foi convertida para usar o protótipo do HyOctane engine para o armazenamento e recuperação da apresentação. A ferramenta controla apresentações interativas consistindo de imagens sobrepostas, áreas de interação e áudio. Pode-se definir um elo entre dois slides ou telas quaisquer, e uma determinada tela pode conter vários elos. Um grande número de ações, como por exemplo, transição automática para o próximo slide e realce automático das âncoras, podem ser associadas a um elo. Além disso, é definido um tempo de duração para cada apresentação individual na tela.

O HyOctane engine processa instâncias de oito AFs HyTime usadas por essa aplicação. Essas formas representam as utilidades básicas do base module e as facilidades de linking do hyperlinks module. As formas do measurement e scheduling modules especificam a alocação de imagens na tela da estação de trabalho.

\subsubsection{Microcosm}

O Microcosm (Davis et al. 92) (Hall et al. 93), que está sendo desenvolvido na Universidade de Southampton, pode ser visto como um conjunto de processos de comunicação autônomos que complementam as facilidades providas pelo sistema operacional. Microcosm permite ao usuário navegar por grandes corpos de informação multimídia através de uma gama de técnicas. Nenhuma marcação é imposta à informação, de tal forma que todos os dados são acessíveis e editáveis pela aplicação que os criou. Toda a informação que diz respeito a elos é armazenada em banco de dados de elos ou linkbases.

Em Microcosm o usuário interage com um viewer. Um viewer é qualquer programa que é capaz de exibir algum formato de dado e que pode se comunicar com o serviço de elo 
Microcosm. Mensagens para a execução de ações são enviadas do viewer para Microcosm, que as despacha para uma série de filtros.

Filtros particularmente importantes são os linkbases, que contêm toda a informação a respeito dos elos disponíveis. Quando uma mensagem chega ao linkbase requisitando um elo a ser seguido, o processo procura pelo destino em um arquivo de dados e, se encontrar, retorna detalhes do destino do elo, que são passados para o link dispatcher. Outros filtros incluem processos de auxílio à navegação, por exemplo, geração de guided-tours, e processos para computar elos dinâmicos.

\subsection{Considerações Finais}

Para dar suporte aos hiperdocumentos cada vez mais complexos, a literatura tem apresentado modelos destinados à especificação da estrutura de hiperdocumentos e à especificação de aplicações hipermídia — as quais manipulam esses documentos. Esse capítulo apresentou modelos representativos de ambas as categorias e, além disso, apresentou um sistema que utiliza o HyTime - foco do trabalho reportado nessa dissertação — para definir a estrutura dos hiperdocumentos tratados.

Nessa tecnologia, os padrões ainda não são largamente adotados, e o capítulo apresentou também um sistema que não segue nenhum modelo em particular. 


\section{CHTS: CLASSIC HYPERTEXT STRUCTURES EM HYTIME}

\subsection{Considerações Iniciais}

A estrutura dos hiperdocumentos suportados em sistemas clássicos tais como NoteCards (Halasz 88) e HyperCard (Williams 87) é, essencialmente, a de um grafo direcionado no qual vários tipos de ligações são representados por arestas com atributos diferentes. Tal estrutura pode ser descrita em HyTime através da AF clink, a qual atributos são associados de modo a permitir a definição dos diversos tipos de ligação. De fato, para definição de ligações com tipos distintos, o suporte ao ID-IDREF de SGML é suficiente na maioria dos casos — como o foi para HTML. Essa construção é mapeada diretamente em HyTime para a AF clink. Entretanto, as melhorias possíveis com a ilink em relação ao ID-IDREF de SGML são tão significativas que, como sugere Newcomb, a estrutura de hipertexto pode ser considerada inteiramente nova para SGML (Newcomb 95).

A AF ilink é necessária à descrição de endereçamentos mais elaborados como aqueles do Intermedia (Garret et al. 86). O atributo aggloc, por exemplo, pode ser utilizado para especificar as ligações com múltiplos destinos do Intermedia.

A literatura tem sugerido o suporte a estruturas tais como composições e contextos, particularmente para o suporte à hipermídia (Grøbæk 94) (Hardman et al. 94) (Soares et al. 95b). Em HyTime, essas estruturas demandam a combinação da AF ilink com opções de endereçamento do módulo location address. O suporte à especificação e escalonamento multimídia demanda o uso de AFs dos módulos scheduling e rendition.

Neste capítulo são apresentadas as estruturas, modeladas segundo a sintaxe de SGML e HyTime, formalizadas no DTD CHTS (Classic Hypertext Structures) para a classe de hiperdocumentos que foi definida. Essa classe de hiperdocumentos pode ser classificada como um Minimal hyperlinking HyTime document, pois utiliza AFs do base module (HyDoc e allref), location address module (nameloc, nmlist, treeloc, locsrc e mult loc) e hyperlinks module (clink e ilink).

O DTD CHTS define estruturas clássicas encontradas em vários modelos e sistemas hipermídia: anotação (Yankelovich et al. 87) (Catlin et al. 89), glossário (Brown 89b), elo multidestino (Yankelovich et al. 88) (Casanova et al. 95), elo m:n (Casanova et al. 95), guided tour (Marshall \& Irish 89) (Trigg 88) (Zellweger 89) e composição (Soares et al. 95c) (Grøbæk 94). Cada uma dessas estruturas é descrita nas próximas seções. O DTD CHTS completo encontra-se no Apêndice A dessa dissertação. 
Para maior clareza, nas próximas seções são dados alguns exemplos de como as estruturas definidas no DTD CHTS poderiam ser apresentadas por uma aplicação. Entretanto, deve ficar claro que HyTime não define a forma de apresentação de suas estruturas — esse é o papel da aplicação. A linguagem HTML é usada como formato de representação dos hiperdocumentos citados nesses exemplos devido à sua larga adoção pela comunidade da WWW, porém as estruturas definidas no DTD CHTS poderiam ser utilizadas por qualquer tipo de documento hipermídia estruturado.

\subsection{Anotação}

Uma anotação é um texto que se deseja associar a um determinado ponto de um documento, mesmo que não se seja o autor do documento e, portanto, não se possua acesso de escrita ao mesmo. Isso pode ser feito armazenando-se as anotações em um arquivo distinto, específico para esse fim, e fazendo-se o relacionamento entre o documento ao qual se deseja acrescentar anotações e essas anotações através de elos armazenados em um outro arquivo. Esse tipo de arquivo, que armazena os elos e possivelmente suas âncoras, será chamado de Web of links no decorrer dessa dissertação. Essa abordagem é ilustrada na Figura 5.1.

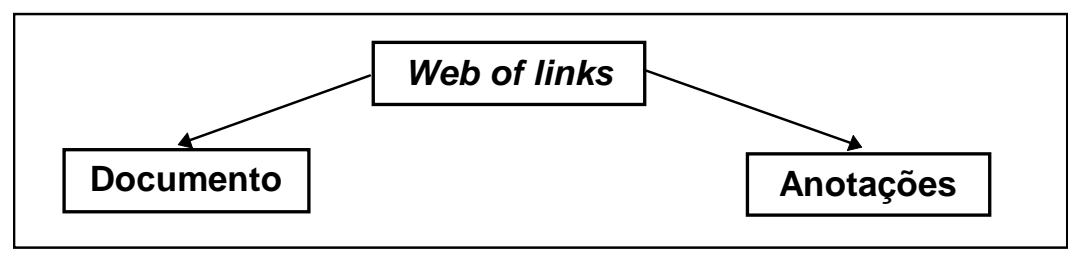

Figura 5.1: Relacionamento entre os arquivos de uma anotação

O arquivo Web of links na figura acima, é um documento pertencente à classe de documentos definida no DTD CHTS. Esse documento contém o elemento annot (annotation), mostrado na Figura 5.2, que se baseia na AF ilink de HyTime.

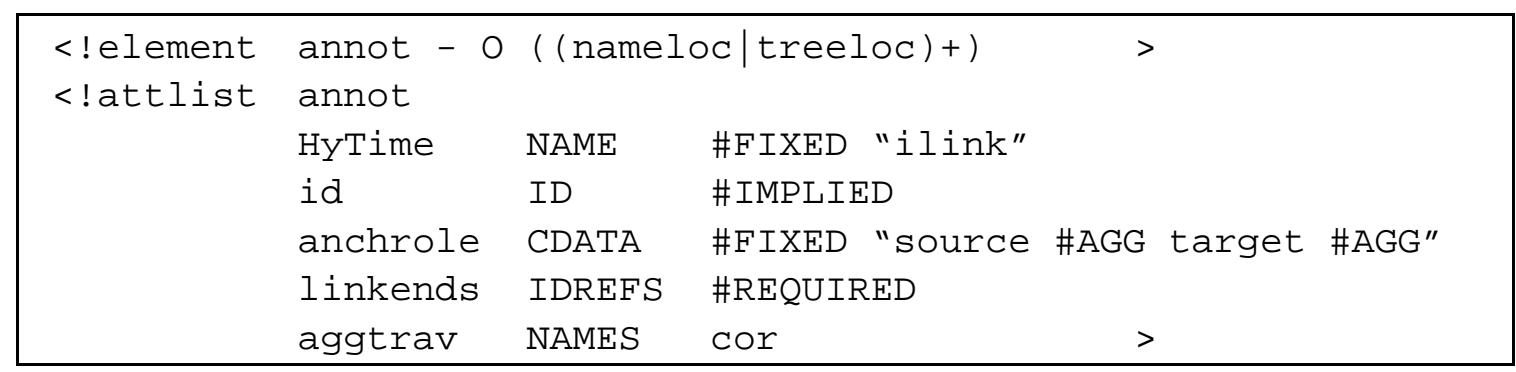

Figura 5.2: Definição do elemento annot (annotation)

Esse elemento estabelece um elo entre dois agregados, como indica o atributo anchrole. O primeiro agregado, que representa a âncora de origem do elo, contém os pontos (posições) no documento aos quais se deseja relacionar as anotações. O segundo agregado, a âncora destino do elo, contém as anotações. O número de elementos nos dois agregados é o mesmo, pois cada 
anotação no arquivo de anotações se refere a um ponto do documento ao qual deseja-se acrescentar as anotações. Dessa forma, cada membro de um dos agregados possui um membro correspondente no outro agregado. Por isto, foi utilizada a correspondent traversal (aggt $r a v=$ cor) para definir a forma de travessia entre os dois agregados.

A Figura 5.3 ilustra o exemplo de uma instância de um documento representando um arquivo do tipo Web of links. Nesse exemplo, o documento ao qual deseja-se acrescentar anotações é um arquivo HTML, chamado index.html, e é representado pela entidade doc1, enquanto o arquivo com as anotações (anot.sgml) é representado pela entidade doc2. Optouse por colocar a declaração dessas entidades no document type declaration subset do documento Web of links para que o mesmo DTD possa ser usado por várias instâncias dessa classe de documentos. Os elementos dos agregados, tanto do documento HTML usado como exemplo, quanto das anotações, são endereçados de forma indireta. $\mathrm{O}$ atributo linkends do elemento annot aponta para os identificadores únicos id1 e id2. A âncora de origem do elo definido pelo elemento annot é especificada pelo elemento nameloc com id=id1. Esse nameloc aponta para dois elementos treeloc com identificadores únicos ANCH1 e ANCH2.

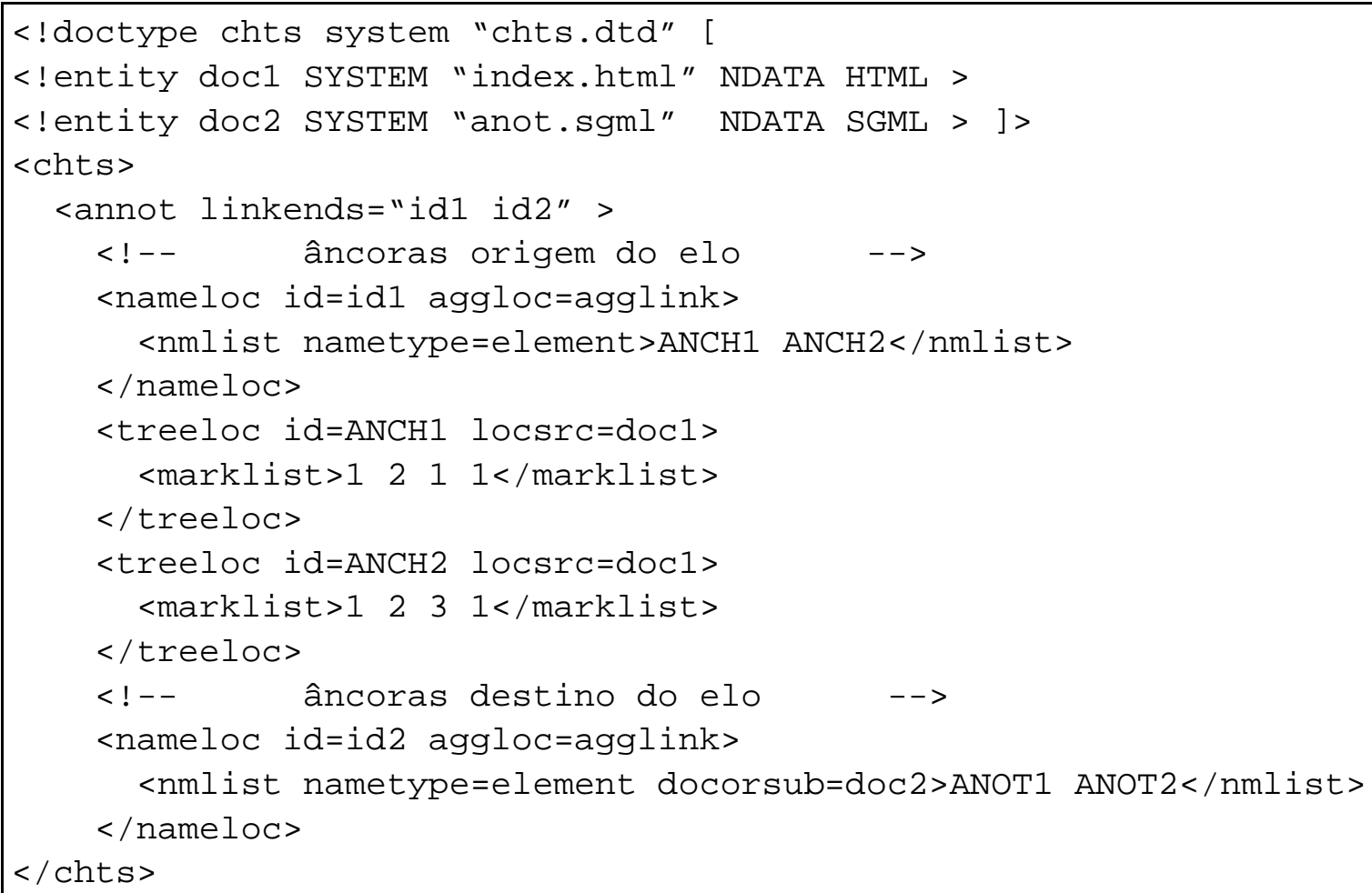

Figura 5.3: Instância de um arquivo do tipo web of links para anotações

Considerando-se a árvore de estruturas do arquivo index.html, usado no exemplo acima, como a que pode ser vista na Figura 5.4, o primeiro treeloc endereça o elemento $\mathrm{H} 2$ cujo conteúdo é sgml, e o segundo treeloc endereça o elemento H3 cujo conteúdo é ilink. 


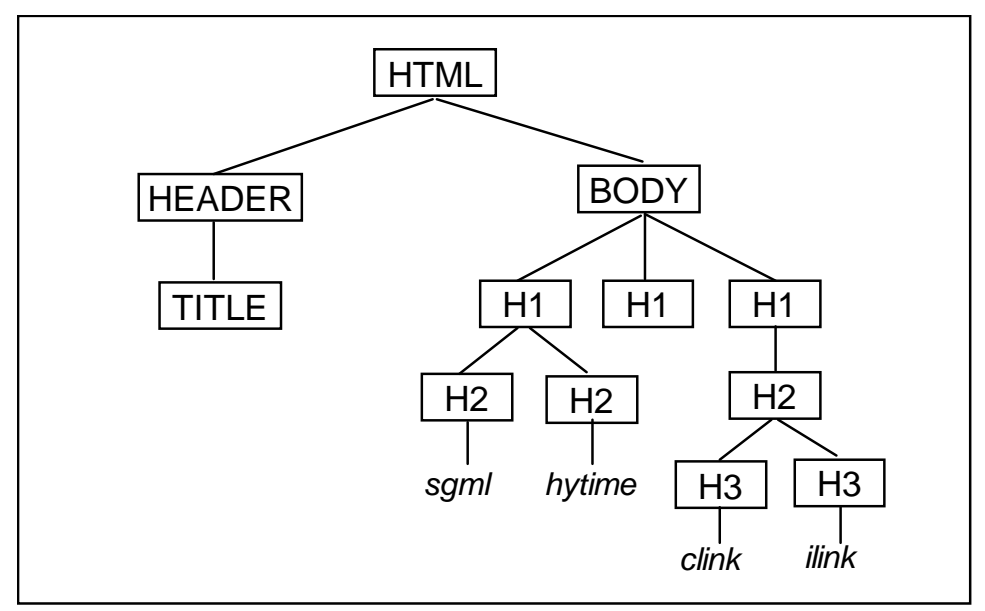

Figura 5.4: Árvore de estruturas do documento index.html

A âncora destino do elo definido na Figura 5.3 (id2) também identifica um elemento nameloc que por sua vez aponta para os elementos que contêm as anotações no arquivo anot.sgml (ANOT1 e ANOT2). Esse arquivo, como pode ser visto na Figura 5.5, é um documento SGML cujo DTD encontra-se no seu document type declaration subset.



Figura 5.5: Documento com as anotações (annot.sgml)

Observe que, seguindo essa abordagem, nenhuma marcação é imposta ao documento ao qual deseja-se acrescentar anotações, possibilitando o acréscimo de anotações em documentos aos quais não se tem permissão de escrita. Isto é possível devido às capacidades de endereçamento de HyTime providas pelo location address module, porém essas capacidades só podem ser exploradas em documentos com o mínimo de estruturação. No caso de documentos HTML, que não possuem uma estrutura rígida, o ideal seria adotar o Stricter DTD para HTML discutido na seção 6.2.4 do próximo capítulo. 


\subsection{Glossário}

Um glossário é algo que pode ser compartilhado por vários documentos, por isso, o elemento glossary, apresentado na Figura 5.6, foi modelado de tal forma que ele possa ser referenciado por vários documentos, ao invés de fazer parte da estrutura interna dos mesmos. Também é possível fazer referência a um único item do glossário e não ao glossário como um todo. Outra característica de glossários, explorada na definição desse elemento, é o fato de que mais de um termo pode possuir a mesma definição.

A especificação do elemento glossary define que ele é composto por vários elementos item, o qual, por sua vez, é composto por um elemento term e um elemento def opcional. Esses dois últimos elementos são do tipo texto (\#PCDATA) e representam um termo do glossário e sua definição respectivamente. O elemento def é opcional porque o elemento term pode possuir a mesma definição de um outro item do glossário. Quando isso ocorrer, a definição não é repetida, e sim é estabelecida uma referência à definição já existente, como ocorre no exemplo apresentado na Figura 5.7.



Figura 5.6: Definição do elemento glossary

No exemplo da Figura 5.7, um trecho extraído do glossário de (DeRose e Duran 94), o termo hypermedia possui a mesma definição do termo hypertext. Sendo assim, o primeiro faz uma referência à definição do segundo. Isto é possível porque o elemento term se baseia na AF clink de HyTime, com o detalhe de que o seu atributo linkend não é obrigatório (\#IMPLIED), pois se a definição do termo estiver contida no próprio item, a referência a essa definição é feita de forma automática pela aplicação. 


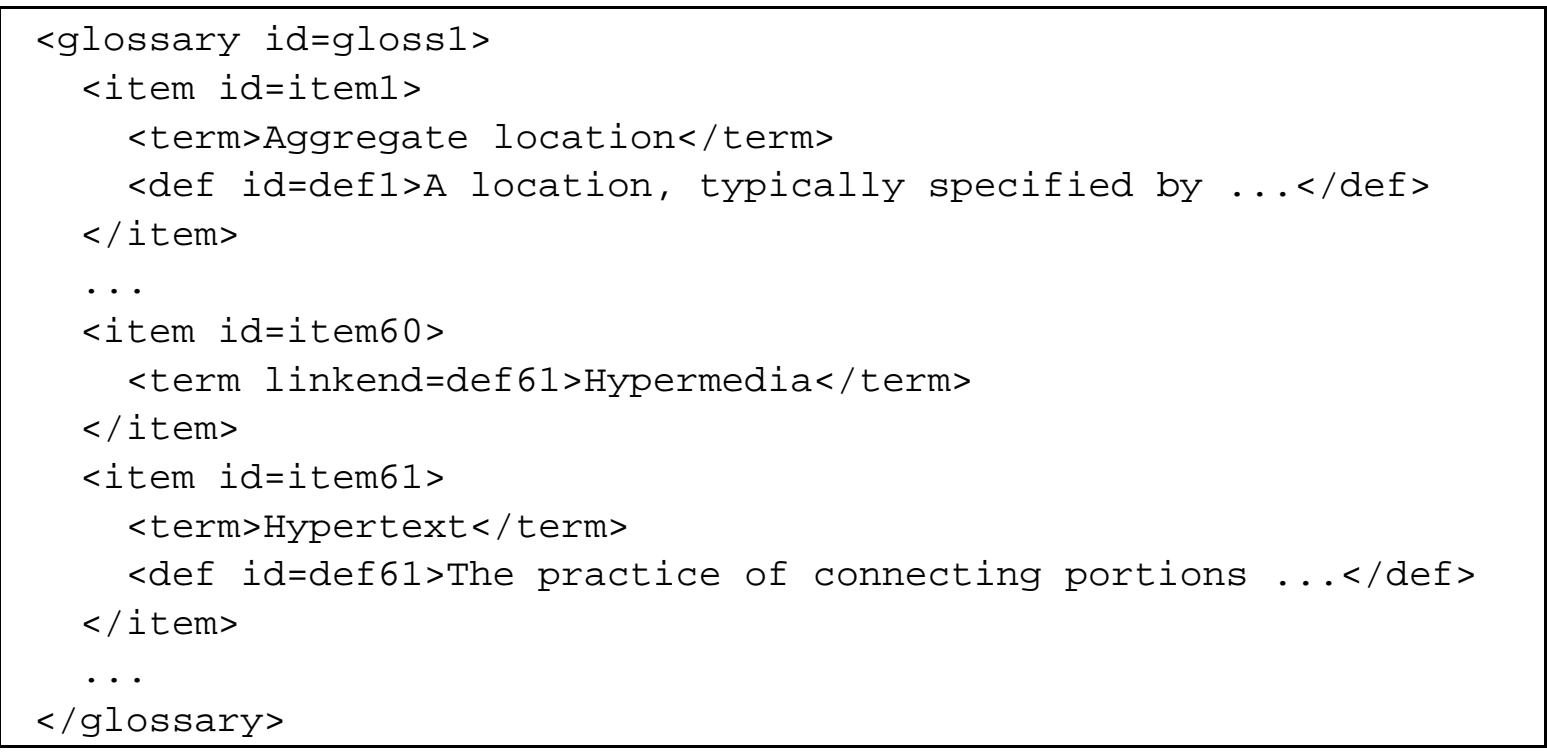

Figura 5.7: Exemplo do uso do elemento glossary

Para fazer referência ao glossário como um todo, basta referenciar o seu identificador único. Considerando o exemplo da Figura 5.7, para apontar para o glossário bastaria referenciar o ID gloss1, enquanto que para referenciar o termo “Aggregate location”, por exemplo, bastaria referenciar o ID do item no qual ele está contido, nesse caso, item1. No primeiro caso, a aplicação exibiria o glossário completo, enquanto que no segundo caso, seriam exibidos apenas o termo e a definição do item ao qual se fez referência.

Deve-se observar que essa abordagem permite que um glossário bastante genérico possa ser definido para um classe de documentos, e assim ser referenciado por várias instâncias dessa classe, seja por referência ao glossário como um todo ou a itens individuais do glossário.

\subsection{Elo multi-destino}

Um elo multi-destino é aquele que permite a especificação de vários endereços como âncora destino do elo. Nesse tipo de elo, uma aplicação pode tratar a ativação de sua âncora origem através da exibição de um pop-up menu contendo os possíveis destinos do elo, dentre os quais o usuário deve selecionar um. A Figura 5.8 mostra a estrutura de um elo multi-destino.



Figura 5.8: Estrutura de um elo multi-destino 
Um elo com essas características pode ser modelado utilizando-se a AF ilink de HyTime. Essa AF foi usada para especificar o elemento mtarglnk (multi-target link), apresentado na Figura 5.9. Esse elemento é composto por elementos conformantes com as AFs nameloc e treeloc, que são usados para referenciar de forma indireta as âncoras do elo, além de vários elementos text, usados para descrever os elementos que compõem a âncora destino do elo.

\begin{tabular}{|c|c|c|c|c|}
\hline \multirow[t]{8}{*}{$\begin{array}{l}<\text { ! element } \\
<\text { ! attlist }\end{array}$} & $\begin{array}{l}\text { mtarglnk } \\
\text { mtarglnk }\end{array}$ & \multicolumn{3}{|c|}{$--(($ nameloc $\mid$ treeloc $)+$, text +$)>$} \\
\hline & HyTime & NAME & \#FIXED “ilink" & \\
\hline & id & ID & \#IMPLIED & \\
\hline & anchrole & CDATA & \#FIXED "source target & \#AGG" \\
\hline & linkends & IDREFS & \#REQUIRED & \\
\hline & endterms & IDREFS & \#REQUIRED & \\
\hline & reftype & CDATA & \#FIXED "endterms text" & \\
\hline & aggtrav & NAMES & agg & $>$ \\
\hline \multirow{2}{*}{\multicolumn{4}{|c|}{$\begin{array}{l}<\text { lelement text - } 0 \text { (\#PCDATA) } \\
<\text { ! attlist text id ID \#REOU }\end{array}$}} & $>$ \\
\hline & & & & $>$ \\
\hline
\end{tabular}

Figura 5.9: Definição do elemento mtarglnk

A âncora destino de um mtarglnk é um agregado, dessa forma, pode-se especificar um número qualquer de elementos como destino do elo. $\mathrm{O}$ atributo endterms aponta para elementos text que contêm uma descrição de cada um dos elementos que compõem esse agregado, é essa descrição que é exibida no pop-up menu mostrado quando se ativa a âncora origem do elo. A forma de travessia, definida pelo atributo aggtrav=agg, especifica uma travessia direta ao agregado. Os elementos que compõem o agregado são referenciados pelas AFs nameloc e/ou treeloc que, como foi visto em seções anteriores, podem endereçar praticamente qualquer tipo de informação estruturada.



Figura 5.10: Trecho de um documento HTML (index.html) 
Dado o trecho do documento HTML (index.html) mostrado na Figura 5.10, a marcação necessária para definir um elo multi-destino com origem no texto "6.3.2 A Linguagem Java", tendo como âncoras destino um documento contendo um curso sobre a linguagem Java (course.html) e outro documento contendo um tutorial sobre o mesmo assunto (tutorial.html), é apresentada no exemplo da Figura 5.11.

Nesse exemplo, o elemento mtarglnk é usado para definir o elo multi-destino. Esse elemento estabelece um elo com origem em um elemento com id=source, e destino em um elemento com id=target. A localização da âncora origem é especificada pelo par nameloc/treeloc. O nameloc identifica um elemento com id=chapt6 no arquivo index.html; como trata-se de um documento HTML, o nameloc identifica na realidade um elemento $a$ HTML com um atributo name=chapt6. Já o elemento treeloc identifica o segundo nó do terceiro elemento hierárquico de chapt6, portanto o segundo H3 contido no terceiro H2.

A âncora destino do mtarglnk é identificada pelo elemento nameloc com id=target. Esse nameloc especifica um agregado (aggloc=agglink) composto por duas entidades externas: doc2, representando o arquivo course.html, e doc3, representando o arquivo tutorial.html. Os elementos text, com ids iguais a text1 e text2, descrevem as duas entidades que compõem a âncora destino do elo.

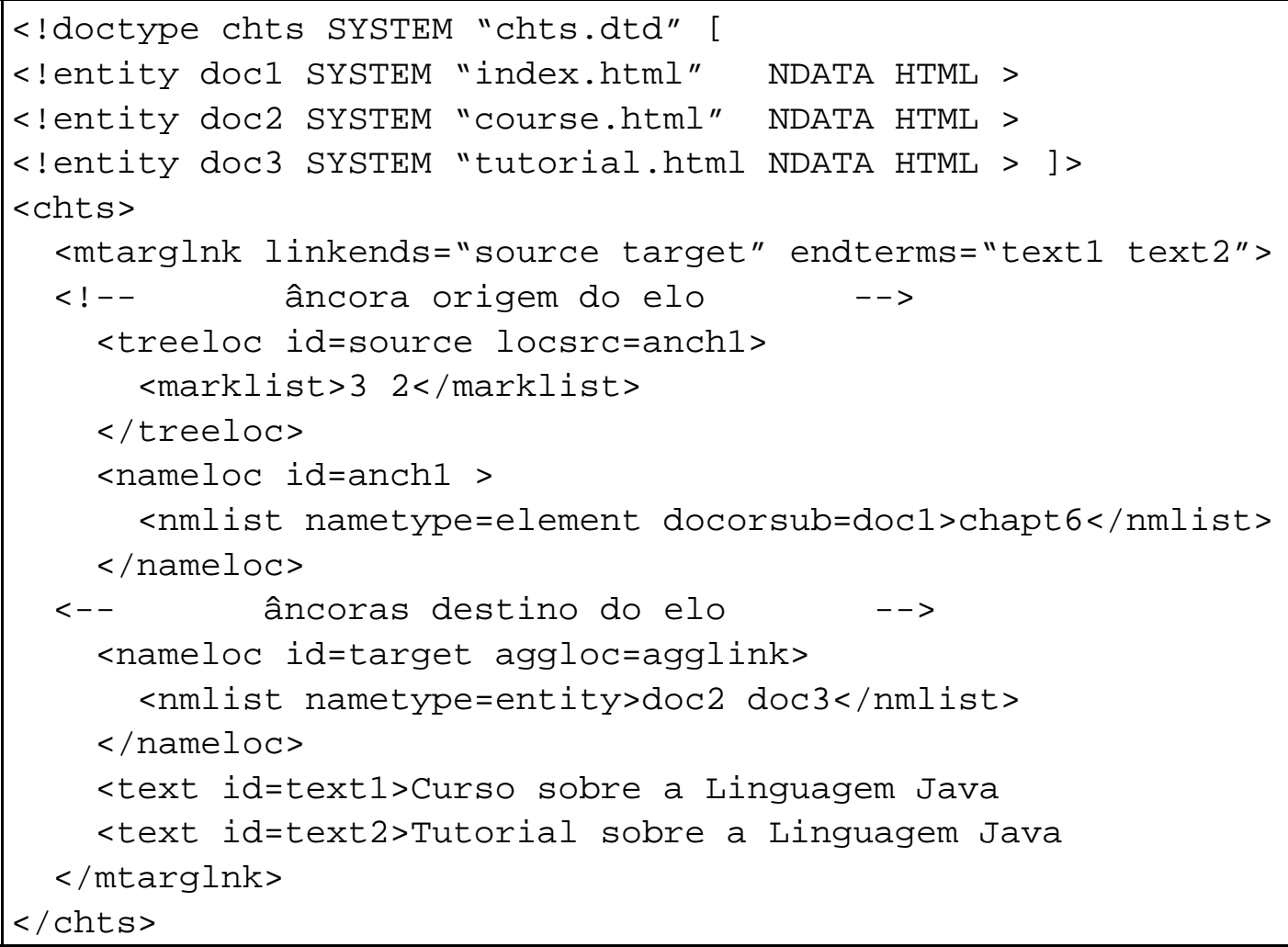

Figura 5.11: Exemplo do uso do elemento mtarglnk

Uma aplicação poderia interpretar a marcação especificada na Figura 5.11 e gerar uma apresentação como a mostrada na Figura 5.12 quando o usuário selecionasse o texto "6.3.2 A Linguagem Java”. 




Figura 5.12: Apresentação de um elo multi-destino

No exemplo da Figura 5.11, pode-se notar algumas das características de endereçamento e ligação de HyTime incorporadas pelo elemento mtarglnk:

- o elemento mtarglnk pode estar em um arquivo do tipo web of links, separado daquele aonde se encontram as âncoras de origem e destino, que por sua vez, também podem estar contidas em documentos distintos;

- o endereçamento de elementos com múltiplas posições (agregados) através do uso da AF ilink juntamente com o atributo aggloc=agglink da AF nameloc;

- o endereçamento de elementos estruturais hierárquicos de um documento, como no caso da âncora origem do elo, onde a AF treeloc é utilizada;

- a referência a entidades externas, como no caso das âncoras destino do elo.

\subsection{Elo $M: N$}

Em um elo m:n podem ser definidas várias âncoras origem e várias âncoras destino. A seleção de qualquer uma das $m$ âncoras origem leva a todas as $n$ âncoras destino simultaneamente. A Figura 5.13 ilustra a estrutura de um elo m:n.



Figura 5.13: Estrutura de um elo $m: n$

O elemento m-nlnk (m:n link), apresentado na Figura 5.14, especifica um elo m:n. A modelagem em HyTime desse tipo de elo é semelhante a adotada nas anotações e elos multidestino. São definidos dois agregados: um para as âncoras origem e outro para as âncoras destino. É estabelecida uma ligação entre esses dois agregados através do elemento $\mathrm{m}$ - $\mathrm{n} l n k$, que se baseia na AF ilink. Nesse caso, a travessia do elo é feita de acordo com a member traversal (aggtrav=mem), ou seja, a ativação de qualquer uma das âncoras origem leva a uma travessia direta aos membros do agregado que contém as âncoras destino. Não foram considerados os aspectos de sincronização na definição do elemento m-nlnk. Os aspectos de sincronização de estruturas HyTime são discutidas em (Pimentel et al. 97c). 


\begin{tabular}{|llll|}
\hline$<$ element & m-nlnk & - & $>$ \\
$<$ !attlist & m-nlnk & & \\
& HyTime & NAME & \#FIXED “ilink" \\
& id & ID & \#IMPLIED \\
& anchrole & CDATA \#FIXED “source \#AGG target \#AGG" & \\
& linkends & IDREFS \#REQUIRED & $>$ \\
& aggtrav & NAMES mem & \\
\hline
\end{tabular}

Figura 5.14: Definição do elemento m-nlnk

Novamente foi aplicado o conceito de um arquivo do tipo web of links para armazenar os elementos de elo. A Figura 5.14 ilustra o exemplo de um elo m:n, e a instância do documento web of links contendo o elemento $\mathrm{m}$ - nlnk que modela esse elo é mostrado na Figura 5.15. Nesse exemplo, as âncoras origem do elo estão contidas no arquivo tutorial.html, e as âncoras destino correspondem aos arquivos applet1.html, applet2.html e applet3.html. Esses arquivos estão definidos no document type declaration subset do arquivo web of links como as entidades doc1, doc2, doc3 e doc4 respectivamente.

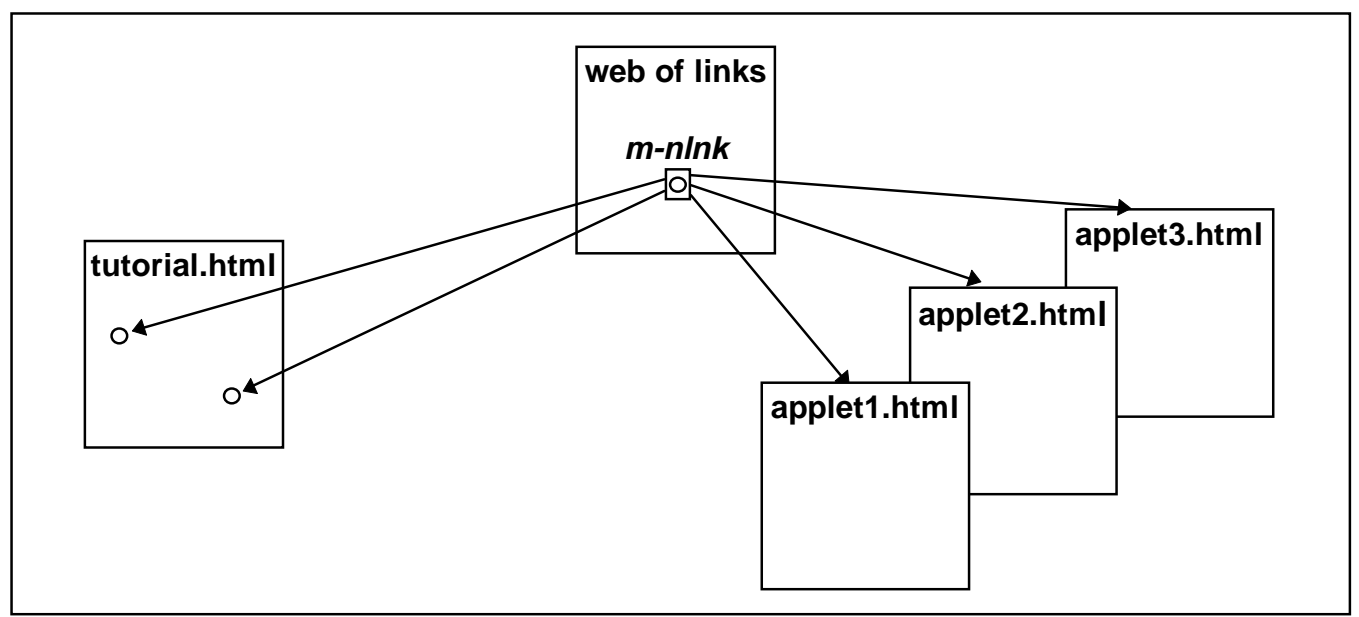

Figura 5.15: Exemplo de um elo m:n

As âncoras origem do elo apresentado na Figura 5.15 são endereçadas pelo nameloc com id=source. Esse nameloc especifica um agregado com dois elementos: ORIG1 e ORIG2. Esses elementos são baseados na AF treeloc, e endereçam dois nós da árvore do arquivo tutorial.html tendo como location source um elemento a com o atributo name igual a sect3 especificado pelo nameloc com id=applet. 


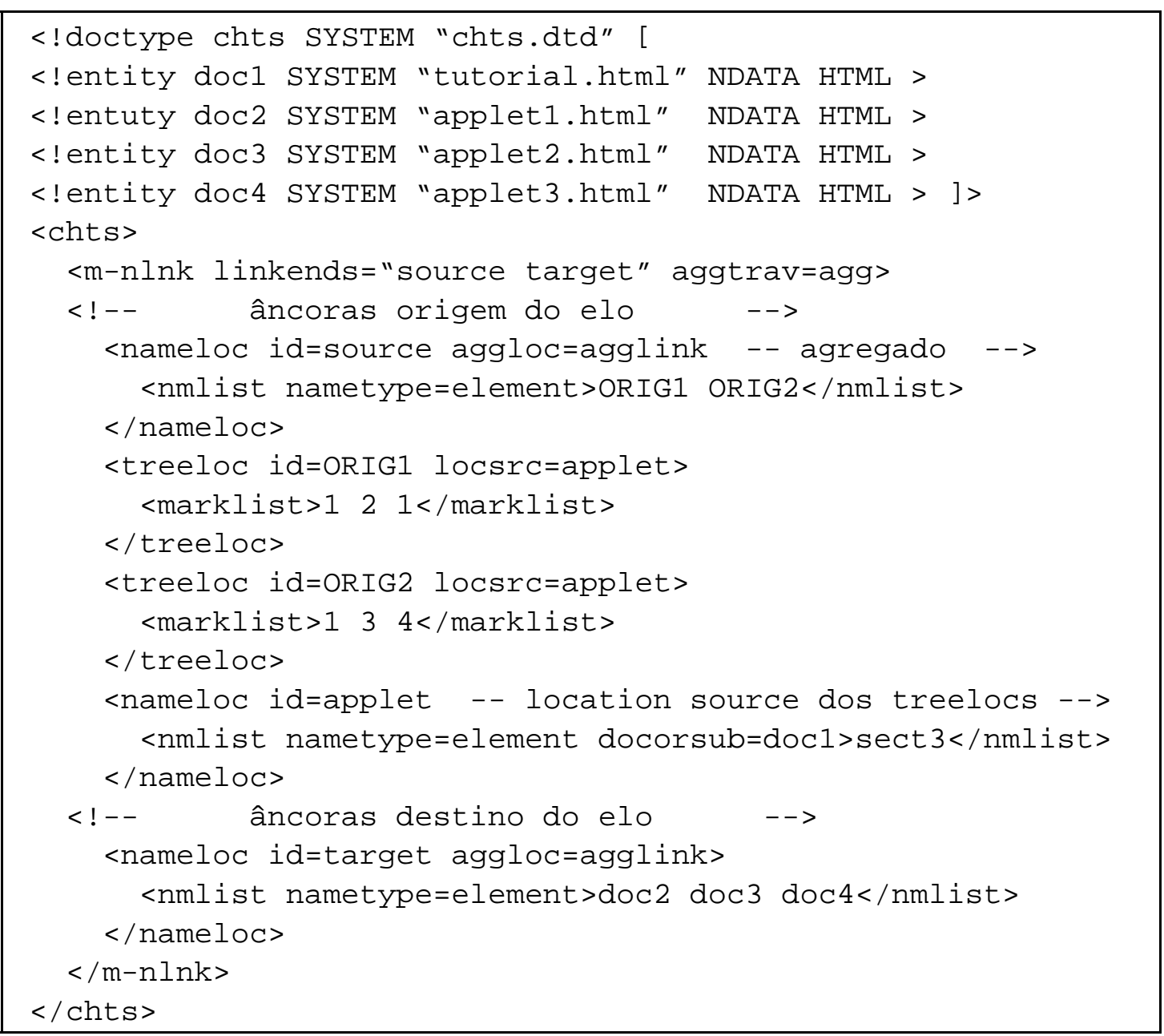

Figura 5.15: Instância de um web of links contendo um elemento m-nlnk

As âncoras destino do elo são endereçadas pelo nameloc com id=target. Ele especifica um agregado com três entidades: doc2, doc3 e doc4. Uma aplicação pode apresentar simultaneamente os três arquivos representados por essas entidades quando qualquer uma das duas âncoras origem contidas no documento tutorial. html for ativada.

A definição do elemento $m$ - nlnk permite a referência a arquivos contendo qualquer tipo de mídia, e não apenas a arquivos do tipo texto, como foi mostrado nos exemplos dessa seção. Portanto, este elemento pode ser usado potencialmente para dar suporte a apresentações multimídia, para isso basta que ele seja estendido, incorporando aspectos de sincronismo providos pelos módulos scheduling e rendition de HyTime.

\subsection{Guided Tour}

Um guided tour implementa um caminho linear através de uma coleção de itens, permitindo ao usuário mover-se para frente e para trás nesse caminho. Há algumas variações úteis em guided tours. Por exemplo, um guided tour circular interliga o último elemento ao 
primeiro; um guided tour com volta ao principal possui um nó distinto que contém informação sobre a própria guided tour e é tanto o ponto de início e de término do tour; e um guided tour com entrada e saída possui diferentes pontos de entrada e saída (Isakowitz et al. 95).

Uma especificação SGML/HyTime para guided tours é apresentada na Figura 5.16. O elemento gtour permite a modelagem de guided tours circulares e com volta ao principal. Esse elemento possui como atributos um identificador único (id) e uma referência opcional ao item inicial do tour (home). Um gtour pode ser composto por vários elementos item. Cada elemento item possui como atributos um identificador único (id), uma referência ao seu conteúdo (content), uma referência opcional ao próximo item do tour (next) e uma referência opcional ao item anterior (previous). Esse elemento pode conter uma combinação dos elementos nameloc e treeloc, os quais são conformantes com as AFs de mesmo nome e podem ser usados para especificar de forma indireta o conteúdo de cada elemento item.

\begin{tabular}{|lllll|}
\hline$<$ !element & gtour - - (item+) & & $>$ \\
$<$ !attlist & gtour & ID & \#REQUIRED \\
& id & ID & \\
& home & IDREF & \#IMPLIED & \\
$<$ !element & item -0 & $\left.(\text { (nameloc|treeloc })^{*}\right)$ & $>$ \\
$<$ !attlist & item & & & \\
& id & ID & \#IMPLIED & \\
& content & IDREF & \#REQUIRED & \\
& next & IDREF & \#IMPLIED & $>$ \\
& previous & IDREF & \#IMPLIED & $>$ \\
\hline
\end{tabular}

Figura 5.16: Especificação de um guided tour

Um exemplo de uso do elemento gtour é mostrado na Figura 5.17. Nesse exemplo, é implementado um guided tour circular com quatro itens. O conteúdo de um item do guided tour pode ser referenciado diretamente pelo atributo content do elemento item quando se deseja fazer uma referência a uma entidade, como nos casos do primeiro e do último item do tour; ou pode fazer referências mais refinadas com o auxílio dos elementos nameloc e treeloc, como nos casos do segundo e terceiro item do tour.

Se os atributos next e previous do elemento item forem omitidos, como ocorreu no exemplo da Figura 5.17, uma aplicação deve considerar a ordem em que os elementos foram especificados no elemento gtour para se determinar quais são os itens anterior e posterior de um determinado item. O mesmo ocorre com o atributo home do elemento gtour, que caso seja omitido, é considerado o item inicial do tour aquele que foi especificado primeiro. 




Figura 5.17: Exemplo do uso do elemento gtour

A principal vantagem de se usar esse tipo de estrutura é que um documento pode pertencer a vários guided tours ao mesmo tempo, o que não seria possível se a ligação entre os itens do tour fossem especificadas internamente nos próprios documentos.

\subsection{Composição}

A modelagem de nós de composição através de construtores SGML e HyTime foi baseada no modelo NCM (Soares et al. 95b) discutido na seção 4.2.2. Um nó de composição, definido pelo elemento composit, pode conter nós de contexto e/ou nós terminais, e sua especificação é apresentada na Figura 5.18. 


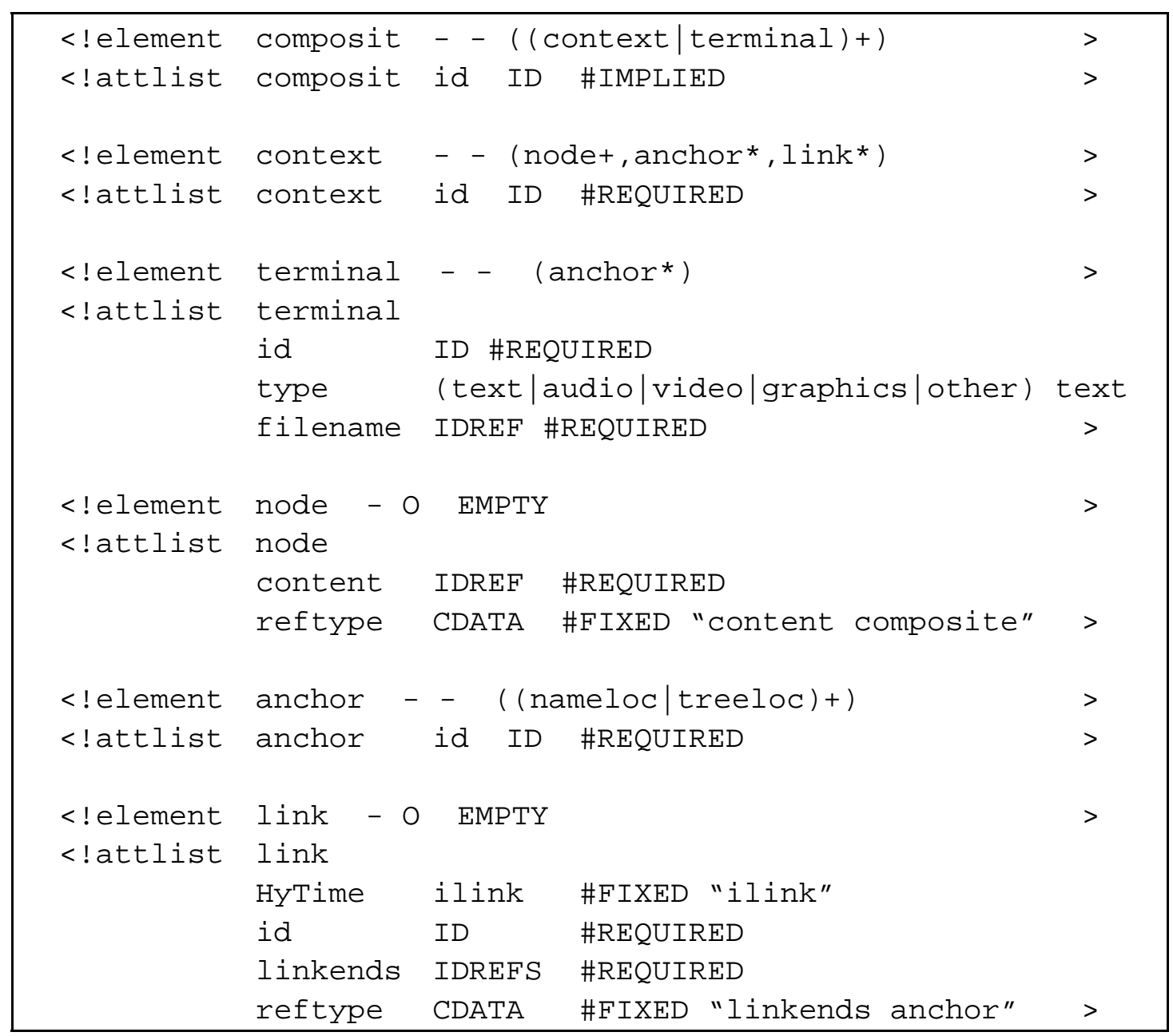

Figura 5.18: Especificação do elemento composit

Um nó de contexto (elemento context), pode conter outros nós e um conjunto de âncoras e elos. O elemento node representa os nós que podem estar contidos em um contexto. Esse elemento é, na verdade, uma referência a um nó terminal ou a um nó de contexto. Dessa forma, um nó de contexto pode possuir nós de contexto aninhados.

Um nó terminal (elemento terminal), pode conter um conjunto de âncoras e seu conteúdo é definido pelo atributo filename, que é uma referência (IDREF) a um arquivo externo. $\mathrm{O}$ atributo type especifica o tipo desse arquivo: texto, áudio, vídeo, gráfico ou outro.

As âncoras são representadas pelo elemento anchor, que usa as AFs nameloc e treeloc para especificar sua posição em um nó de contexto ou terminal. Esse elemento possui um atributo do tipo ID que será referenciado pelos elos de um contexto. Esses elos são representados pelo elemento link, que é baseado na AF ilink de HyTime.

Na Figura 5.19 é ilustrado um exemplo de um nó de composição. Essa composição consiste em um nó de contexto $A$, que é composto pelo nó de contexto $B$ e pelo nó terminal $E$. $O$ contexto $B$ é formado pelos nós terminais $C$ e $D$, e o elo $L 1$ que liga a âncora $a 1$ do nó $C$ à âncora $a 2$ do nó $D$. O nó de contexto $A$ possui ainda um elo $L 2$ que interliga a âncora $a 3$ do nó $D$ à âncora $a 4$ do nó $E$. 


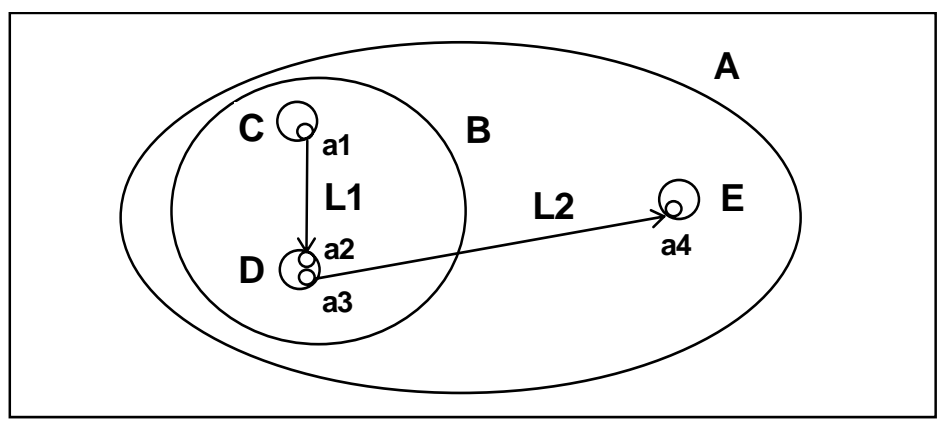

Figura 5.19: Ilustração de um nó de composição

A marcação do nó de composição apresentado na Figura 5.19 é mostrada na Figura 5.20. Nesse exemplo a especificação da posição das âncoras nos nós foi omitida para simplificar o exemplo. O elemento composit permite a estruturação exata do nó de composição em questão.



Figura 5.20: Especificação do nó de composição mostrado na Figura 5.19

A definição desse elemento ilustra a capacidade de SGML/HyTime de representar estruturas complexas e definição de elos tipados através do uso do atributo reftype definido pela ALF all - ref do base module de HyTime (seção 3.2.5). 


\subsection{Considerações Finais}

Nesse capítulo foi especificado o DTD CHTS, que define algumas estruturas clássicas encontradas em vários sistemas e modelos hipermídia. Nessas especificações foram utilizados construtores HyTime, principalmente aqueles encontrados nos módulos location address e hyperlinks desse padrão; portanto o DTD é conformante com a classe Minimal hyperlinking HyTime documents de HyTime. Esses construtores HyTime permitiram a especificação de estruturas com recursos de endereçamento e ligação sofisticados, que suportam a referência a qualquer tipo de informação estruturada.

Dessa forma, ficou demostrada a capacidade de HyTime de especificar estruturas clássicas hipermídia que atendem aos requisitos dos ambientes hipermídia modernos.

No próximo capítulo são apresentados dois trabalhos em desenvolvimento para dar suporte às estruturas descritas nesse capítulo. 


\section{IMPLEMENTAÇÕES}

\subsection{Considerações Iniciais}

Nesse capítulo é apresentado um sistema básico hipermídia, em desenvolvimento no contexto deste trabalho, que inclui ferramentas para edição (HyperPena) e navegação (HyperJangada) de hiperdocumentos que adotam o DTD HTML, além de um SGML parser (nsgmls).

É apresentada ainda a arquitetura de um ambiente baseado na apresentação das estruturas definidas no DTD CHTS através de applets escritas na linguagem Java. Uma versão inicial desse ambiente está implementada e é descrita nesse capítulo.

\subsection{Sistema Básico Hipermídia}

O ambiente descrito neste capítulo está sendo desenvolvido como parte da proposta do projeto SMmD (Teixeira et al. 95). Esse projeto inclui a modelagem de um sistema básico hipermídia que permita a autoria e apresentação de documentos que contenham objetos multimídia conformantes ao HyTime, e a implementação de um protótipo para esse sistema (Pimentel et al. 96) (Pimentel \& Leiva 97).

A linguagem HTML foi escolhida como referência para a modelagem e implementação inicial desse sistema, devido a dois fatores principais. Primeiramente, devido à estreita relação do HTML com o SGML e HyTime (Rutledge et al. 95), pois HTML é definido por um DTD SGML. Desse modo, um hiperdocumento HTML pode ser considerado, em termos práticos, como conformante a HyTime.

O segundo fator é a popularidade obtida por HTML durante o andamento do projeto SMmD. Tal popularidade permitiu que os conceitos de estruturação de hiperdocumentos propostos por SGML e HyTime fossem disseminados, e que uma série de ferramentas de suporte a HTML surgissem. Além disso, ficou patente a importância do suporte a hiperdocumentos hipermídia estruturados em sistemas abertos hipermídia distribuídos. Finalmente, é também importante notar que, estando o trabalho associado com HTML, os resultados obtidos podem ser melhor e mais abrangentemente disseminados - uma vez que a comunidade de pesquisadores e usuários HTML é maior que a de usuários de HyTime.

Desse modo, a abordagem adotada para a realização das atividades de modelagem e implementação de um sistema hipermídia no projeto SMmD foi a de tomar como sistema básico 
hipermídia um sistema que suportasse o HTML e, a partir desse, suportar documentos mais estruturados e complexos.

\subsubsection{A Arquitetura do Sistema}

A arquitetura de um sistema básico hipermídia para autoria e apresentação de hiperdocumentos HyTime, que inclui as ferramentas de edição, navegação, um SGML parser e um HyTime engine é mostrada na Figura 6.1.



Figura 6.1: Arquitetura do sistema (Pimentel et al. 96)

Nesse ambiente, as ferramentas Editor e Navegador tratam documentos estruturados de acordo com um DTD fornecido. Desse modo, tanto o DTD quanto a instância do documento são submetidos, pelas ferramentas, ao SGML parser para validação e obtenção de informações tais como elementos e atributos associados. Essas informações são armazenadas em uma base de dados para serem posteriormente utilizadas pelo HyTime engine quando requisitado pelo Navegador.

O Editor provê suporte à atividade de autoria ao apresentar os elementos estruturados definidos em um DTD especificado. Em uma primeira fase, apenas o Navegador interage com o HyTime engine, o qual contém as funções necessárias ao reconhecimento das AFs e resolução dos elos suportados. É através do HyTime engine que o Navegador acessa as funções do SGML parser.

\subsubsection{O Editor HyperPena}

O editor HyperPena (Pimentel et al. 97a) manipula arquivos ASCII que adotam o DTD HTML. Sua interface gráfica ${ }^{4}$ orientada a menus, botões e formulários (vide a Figura B.1 no apêndice B) foi implementada na linguagem Tcl na sua extensão Tk (Ousterhout 94) (Welch 95),

\footnotetext{
${ }^{4}$ As figuras correspondentes à interface gráfica do HyperPena encontram-se no Apêndice B desta dissertação.
} 
um toolkit utilizado na construção de interfaces gráficas. A utilização do Tcl-Tk toolkit permite a implementação dos eventos em linguagem C, além de garantir a portabilidade para as plataformas UNIX, Macintosh e o ambiente MS-Windows.

Comportando sensibilidade a contexto e função de validação com formato HTML, o editor tem a finalidade de impedir a construção de hiperdocumentos com erros sintáticos. A sensibilidade a contexto provoca a desabilitação de botões e menus conforme a posição do cursor de edição no hiperdocumento (vide a Figura B.2).

O editor possui dois modos de edição: um onde os tags não são mostrados e outro onde os tags são visíveis e aos quais são aplicadas formas de apresentação especiais para facilitar a separação entre tags e texto. Um style sheet é aplicado aos hiperdocumentos apresentados, de forma que a visualização sem os tags se aproxime da forma de apresentação no browser Netscape Navigator .

As funções de edição, implementadas na linguagem C, incluem seleção, cópia, eliminação, undo e procura (vide a Figura B.3). Também está disponível um módulo de tratamento dos caracteres acentuados em português (vide a Figura B.4).

Na fase atual de implementação desse projeto, o HyperPena adota o parser nsgmls (Clark 96) para analisar os documentos HTML manipulados. Nesse ambiente, o parser faz a validação através de um DTD determinado no próprio hiperdocumento carregado no HyperPena (vide a Figura B.5), sendo que o DTD default consiste no DTD HTML Stricter (Leiva 96), discutido na seção 6.2.4.

\subsubsection{O Navegador HyperJangada}

O HyperJangada (Pimentel et al. 97b) é uma ferramenta para a navegação em hiperdocumentos estruturados, no qual a estrutura é especificada através de um DTD. A versão do protótipo atual suporta documentos estruturados de acordo com a linguagem HTML, e a proposta é a evolução da ferramenta para permitir a visualização de documentos estruturados de acordo com outros DTDs, notadamente aqueles que incorporam as estruturas definidas no DTD CHTS.

A interface gráfica do HyperJangada (vide Figura B.6 ${ }^{5}$ ), também implementada em Tcl/Tk, foi baseada na interface do Netscape Navigator, familiar a muitos usuários.

As funções básicas desse navegador são:

- Back e Forward: possibilitam ir e voltar dentro de um hiperdocumento dentre as páginas já visitadas;

- Reload: se uma página veio defeituosa ou foi modificada, pode-se chamá-la novamente através dessa função;

\footnotetext{
${ }^{5}$ Encontrada no Apêndice B dessa dissertação.
} 
- History: permite que se tenha um histórico das páginas já visitadas, ou seja, uma lista das páginas visitadas;

- Open File: permite que sejam vistas as páginas gravadas em disco.

- Guided-Tour: possibilita a especificação de um guided tour através de documentos que podem ser especificados pelo usuário em um arquivo texto.

A versão atual do HyperJangada não está integrada ao parser nsgmls, ao invés dele, o navegador baseia-se na biblioteca Hippo (Uhler 95), desenvolvida em Tcl/Tk, para a exibição de arquivos HTML. A estrutura dos documentos não é, portanto, validada. Essa limitação deve ser eliminada na próxima versão (Pimentel \& Leiva 97).

\subsubsection{O Stricter DTD}

Os DTDs para HTML atualmente disponíveis não impõem estrutura aos documentos HTML, dificultando a implementação de um HyTime engine que permite, por exemplo, oferecer o recurso de ligação entre quaisquer trechos de quaisquer hiperdocumentos. O primeiro passo em direção à criação de documentos hierárquicos e estruturados foi a elaboração de um DTD baseado no nível 2 do DTD para HTML. As alterações básicas foram a limitação no contexto dos headings (elementos H1...H6) e a inclusão de novos elementos representando seções (elementos D1...D6) que contêm obrigatoriamente um dos headings acima. Os documentos HTML atuais que adotarem este DTD, sem modificação alguma de seu conteúdo, são validados com sucesso por um SGML parser porque o DTD aceita os elementos de heading e respeita a estrutura dos mesmos. A hierarquia existe entre as seções, o que possibilita compatibilidade com os hiperdocumentos já existentes na WWW. Contudo, através do Stricter DTD é possível criar documentos com seções (elementos $\mathrm{Di}$ ) que englobam um título (elemento $\mathrm{Hi}$, correspondente à seção), seguido por um ou mais parágrafos delimitados pelas marcações $<$ P $>$ e $<$ P $>$ (Pimentel \& Leiva 97).

O DTD completo está disponível, juntamente com sua documentação, em (Leiva 96).

\subsection{Um Ambiente Baseado em Applets Java}

Java não é uma linguagem para formatação de documentos hipermídia e sim uma linguagem de programação para a criação de apresentações portáveis usando uma GUI (Graphical User Interface) particular. Entretanto, as funcionalidades e interfaces de apresentação providas por Java possuem aspectos inerentes ao processamento hipermídia (Rutledge 96b). Dessa forma, a linguagem Java foi utilizada para que documentos conformantes com o DTD CHTS possam ser apresentados por um browser HTML. Para que isso seja possível foi modelado o ambiente descrito na próxima seção. 


\subsubsection{Arquitetura do Ambiente}

A arquitetura do ambiente modelado para permitir a apresentação das estruturas definidas no DTD CHTS através de um browser HTML é apresentada na Figura 6.2. A abordagem utilizada foi a de converter tais estruturas em inclusões de applets Java responsáveis pela apresentação das mesmas.



Figura 6.2: Arquitetura do ambiente baseado em applets Java

Nesse ambiente, um HyTime engine recebe um documento que inclui as estruturas definidas no DTD CHTS e processa seus elementos HyTime. O engine se encarrega do tratamento das âncoras dos elos estabelecidos pelas estruturas definidas no DTD CHTS. As âncoras destino são transformadas, se necessário, em elementos a HTML com atributo name para que, desse modo, possam ser endereçados através da notação URL. As âncoras origem são identificadas com uma tag especial indicando que naquele ponto há uma âncora origem de um elo estabelecido por uma das estruturas definidas no DTD CHTS. A seguir, o documento é submetido a um Tradutor, que converte a marcação das âncoras origem na inclusão das applets Java específicas para cada tipo de estrutura.

As applets incluídas no local das âncoras origem dos elos exibem um botão nessa posição, que quando pressionado ativa uma interface específica para cada tipo de estrutura. Atualmente, a maioria dessas applets já estão implementas, porém o HyTime engine e o Tradutor ainda não. Portanto, é necessário que se inclua manualmente as applets nos documentos HTML, tarefa que será do Tradutor, e só podem ser feitas referências a documentos HTML ou a elementos $a$ HTML com o atributo name nesses documentos. Portanto, formas de endereçamento como a proporcionada pela AF treeloc não são suportadas, o que será possível com a implementação do HyTime engine.

Na próxima seção a linguagem Java é brevemente comentada. 


\subsubsection{A Linguagem Java}

Java é uma linguagem de propósito geral, orientada a objetos, concorrente e portável. As características de orientação a objetos de Java são essencialmente as mesmas de $\mathrm{C}++$, com extensões de Objective $\mathrm{C}$ para a resolução de métodos dinâmicos. Java é multithreading e possui o conjunto sofisticado de primitivas de sincronização baseadas no uso de monitores. Um programa escrito em Java pode ser executado em diferentes plataformas sem a necessidade de alterações.

Uma applet Java é um pequeno programa escrito em Java, transferido dinamicamente através da rede Internet, da mesma forma que uma imagem, arquivo de som ou clip de vídeo e apresentado através de browsers que implementem o Java Virtual Machine. A diferença é que uma applet corresponde ao código de programa, não apenas uma animação ou um arquivo de formato de mídia. Em outras palavras, é um programa que pode reagir a ações do usuário e modificar-se dinamicamente (Naughton 96). Uma referência a uma applet é embutida em um documento HTML usando-se uma tag especial. Quando um leitor, usando um browser que suporte Java, carrega um documento que possui uma applet, o browser transfere essa applet do servidor e a executa no cliente (aquele em que o browser está sendo executado).

Aplicações Java são programas Java stand-alone que podem ser executados através de um interpretador Java, por exemplo, a partir da linha de comando. Devido ao fato de que applets Java são executadas a partir de um browser, elas têm acesso aos mesmos recursos do browser: pacotes de processamento sofisticados para gráficos, desenhos e imagens; elementos de interface; networking; e manipulação de eventos.

As vantagens que as applets têm sobre as aplicações em termos de recursos gráficos e de interface são, entretanto, dificultadas por restrições em o que uma applet pode fazer. Dado o fato de que applets Java podem ser transferidas de qualquer lugar e serem executadas em um sistema cliente, são necessárias restrições para prevenir que uma applet não cause danos ou quebra de segurança ao sistema. Sem essas restrições, applets poderiam conter vírus ou “cavalos de Tróia”, ou serem usadas para comprometer a segurança do sistema que as executar (Naughton 96).

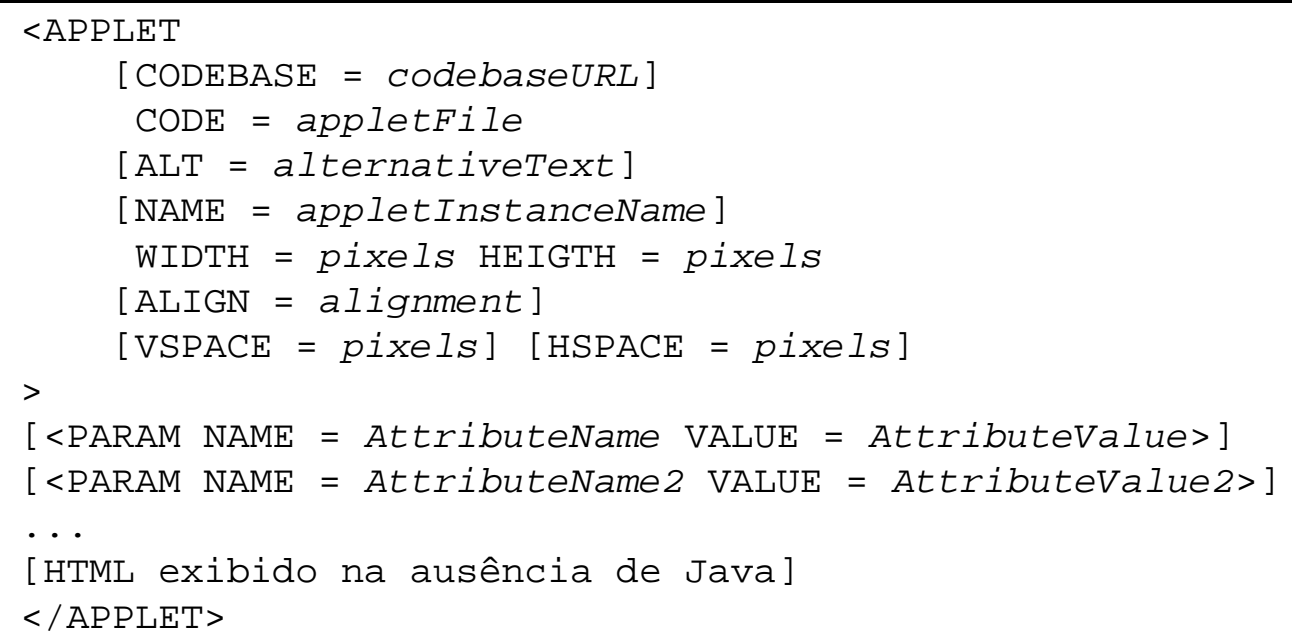

Figura 6.3: Sintaxe da tag <applet> (Naughton 96) 
A tag <applet> é usada para inicializar uma applet em um documento HTML, e sua sintaxe é mostrada na Figura 6.3.

A tag <applet> possui como atributos obrigatórios o nome do arquivo compilado que contém a applet (CODE), e o comprimento (WIDTH) e a altura (HEIGTH) iniciais da janela em que a applet será exibida. Outro atributo importante é o codebase, que especifica uma URL onde o arquivo executável da applet é procurado. É possível passar parâmetros para uma applet através do elemento PARAM.

\subsubsection{Applets Implementadas}

Nesta seção, são apresentadas implementações e as propostas de implementações de applets Java que codificam a apresentação dos construtores SGML e HyTime definidos no DTD CHTS. A implementação dessas applets é o primeiro passo na construção do ambiente discutido na seção 6.3.1. Nesse ambiente, uma applet Java é responsável pela apresentação de uma única estrutura definida no DTD CHTS. O documento HyTime contendo uma dessas estruturas é passado como parâmetro para a applet responsável pela sua apresentação. A applet interpreta a informação contida no documento e gera uma apresentação ${ }^{6}$ para a estrutura.

Para apresentar os construtores HyTime através de applets são necessárias algumas alterações no DTD CHTS, pois o ambiente completo para a apresentação das suas estruturas baseado em applets Java ainda não está completo. O DTD alterado foi chamado de chtsjava.dtd. A primeira alteração foi feita no content model do elemento chts que originalmente permite que todas as estruturas estejam presentes no mesmo documento simultaneamente. Como cada applet é responsável pela apresentação de um único construtor, um documento não pode conter mais do que um elemento; desse modo, a definição do elemento chts para a apresentação através de applets é a seguinte:

$$
<\text { !element chts - - (annot+|glossary|mtarglnk|gtour|composit)> }
$$

As demais alterações são apresentadas nas próximas seções e devem-se principalmente a limitações de endereçamento de HTML, causadas pelo uso da notação URL. Nessas seções são descritas as applets desenvolvidas e em desenvolvimento responsáveis pela apresentação de cada uma das estruturas definidas no DTD CHTS, com exceção do elemento m-nlnk (m:n link), cuja implementação está sendo realizada com o uso JavaScript (Lemay \& Moncur 96).

\footnotetext{
${ }^{6}$ Os screen dumps das applets implementados estão no apêndice C dessa dissertação.
} 


\subsubsection{Applet para anotações}

A applet responsável pela apresentação do elemento annot definido no DTD exibe um botão que quando pressionado leva à exibição de um janela com as seguintes funções:

- new: permite o acréscimo de uma nova anotação ao documento;

- edit: permite a edição de uma anotação;

- exit: fecha a janela responsável pelo controle das anotações.

A Figura C.1 mostra a interface gráfica da applet para anotações. Um documento HTML que contenha essa applet deve possuir uma marcação semelhante à mostrada na Figura 6.4.



Figura 6.4: Inclusão da applet para anotações em um documento HTML

Annot . class é o nome do arquivo Java compilado que contém a applet para anotações, e annot.hyt é um arquivo conformante com HyTime que contém os elementos annot. A definição do elemento annot pôde ser bastante simplificada para a apresentação através de applets, pois, nesse caso, as anotações se referem a um documento como um todo e não a porções do documento como na definição original do elemento. Por isso, foi incluído um atributo para que seja especificado o assunto da anotação (subject). Portanto, a definição do elemento annot foi alterada e pode ser vista na Figura 6.5 .

\begin{tabular}{|llll|}
\hline$<$ !element & annot - O EMPTY & \\
$<$ !attlist & annot & & \\
& HyTime & NAME & \#FIXED “ilink" \\
& id & ID & \#REQUIRED \\
& anchrole & CDATA & \#FIXED "source target" \\
& linkends & IDREFS & \#REQUIRED \\
& subject & CDATA & \#REQUIRED> \\
\hline
\end{tabular}

Figura 6.5: Elemento annot alterado para a apresentação através de uma applet

Com as alterações, o elemento annot estabelece um relacionamento entre duas entidades externas: um documento HTML e um arquivo contendo suas anotações. Na Figura 6.6 é dado um exemplo de um arquivo do tipo annot.hyt contendo elementos annot. Um único arquivo annot . hyt é utilizado para estabelecer o relacionamento entre os documentos HTML e suas anotações. Esse arquivo fica alocado no diretório "WWW/Annot” do diretório raiz de cada usuário. Nesse mesmo diretório ficam alocados os arquivos com as anotações do usuário. O arquivo que contém as anotações é um documento SGML semelhante ao apresentado na Figura 5.5 do capítulo anterior. 


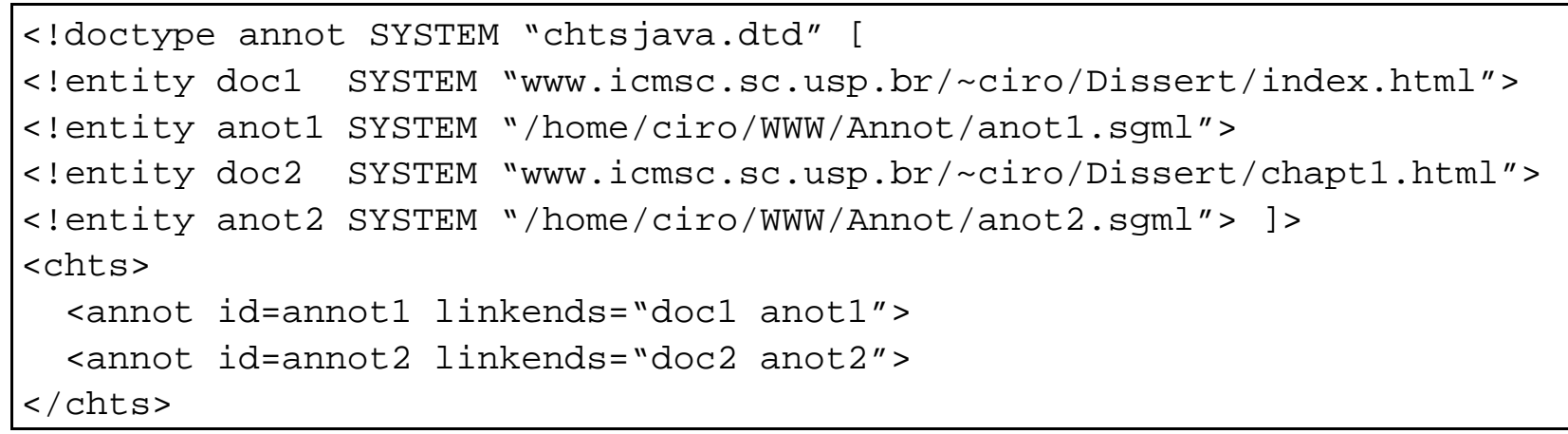

Figura 6.6: Exemplo de um arquivo annot . hyt

\subsubsection{Applet para glossários}

A applet responsável pela exibição de um glossário exibe um botão contendo o texto atribuído ao parâmetro com atributo name=button da applet. O arquivo contendo o glossário é passado para a applet através do parâmetro com atributo name=hytime, e o parâmetro com atributo name=id especifica o identificador único do glossário ou de apenas um de seus itens. A Figura 6.7 mostra um exemplo da marcação para a inclusão da applet para glossários em um documento HTML.



Figura 6.7: Inclusão da applet para glossários em um documento HTML

No exemplo da Figura 6.7, a applet faz referência ao item com id=item61 do glossário mostrado na Figura 5.7 do capítulo anterior. A Figura C.2 mostra a apresentação gerada pela applet para a marcação mostrada na Figura 6.7.

Quando a referência é feita ao glossário como um todo, através da referência ao seu identificador único, uma janela do tipo scrollbar é exibida com o conteúdo do glossário quando o botão da applet é pressionado. Se a referência é feita a apenas um item do glossário, através da referência ao identificador único do item (como ocorreu no exemplo da Figura 6.7), uma janela é exibida com a definição do termo referenciado quando o botão da applet é pressionado.

Diferentemente do elemento annot, o elemento glossary não precisou ser alterado para a apresentação através de uma applet. 


\subsubsection{Applet para elos multi-destino}

O elemento mtarglnk é baseado na AF ilink de HyTime, portanto é independente da posição de suas âncoras. Porém, sua apresentação através de uma applet é feita utilizando-se a AWT (Abstract Windowing Toolkit) choice de Java, o que acarreta em perda de semântica, pois a AWT choice é apresentada como um botão, que nesse caso representa a âncora origem do elo. Com isso, o elo torna-se contextual e não independente. Ilink pode representar um elo contextual atribuindo-se uma âncora a menos ao atributo linkends que o número estabelecido pelo atributo anchrole.

Além disso, Java usa a notação URL, portanto, as applets Java só suportam esse tipo de notação para endereçamento de objetos. Para refletir esse aspecto, o elemento mtarglnk sofreu uma pequena alteração em relação à definição original e é mostrado abaixo:

$$
<\text { !element mtarglnk - - (nameloc }+ \text {, text }+)>
$$

A alteração realizada foi a exclusão da AF treeloc do content model do elemento, pois a notação URL não permite a forma de endereçamento provida por essa AF. Na Figura 6.8 é mostrado um exemplo da marcação necessária para incluir a applet para elos multi-destino em um documento HTML.

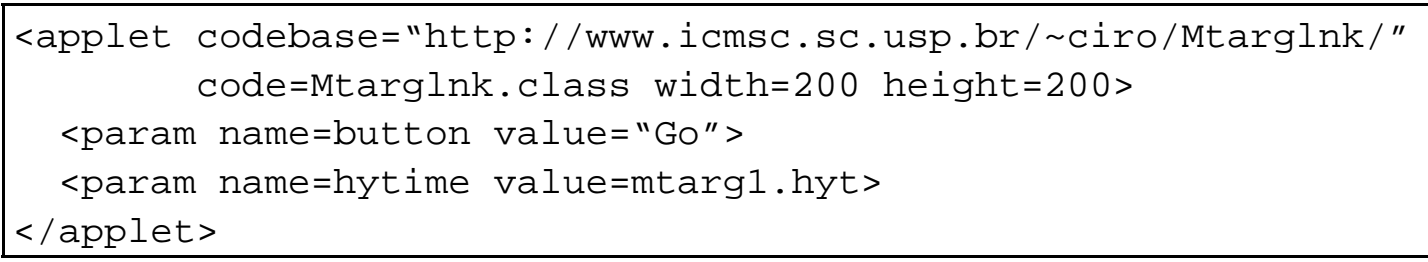

Figura 6.8: Inclusão da applet para elos multi-destino em um documento HTML

O parâmetro com atributo name=but ton da applet especifica o texto exibido no botão da applet e que faz o papel da âncora origem do elo. O parâmetro com atributo name=hytime especifica o documento conformante com HyTime que possui um elemento mtarglnk. Um exemplo desse arquivo é mostrado na Figura 6.9 e sua apresentação através da applet implementada é mostrada na Figura C.3.

No exemplo mostrado na Figura 6.9, o elo possui três âncoras destino: um arquivo HTML (index.html); um elemento $a$ com atributo name=chapt1 nesse arquivo e; um outro elemento $a$ desse arquivo com atributo name $=$ chapt 2 . 


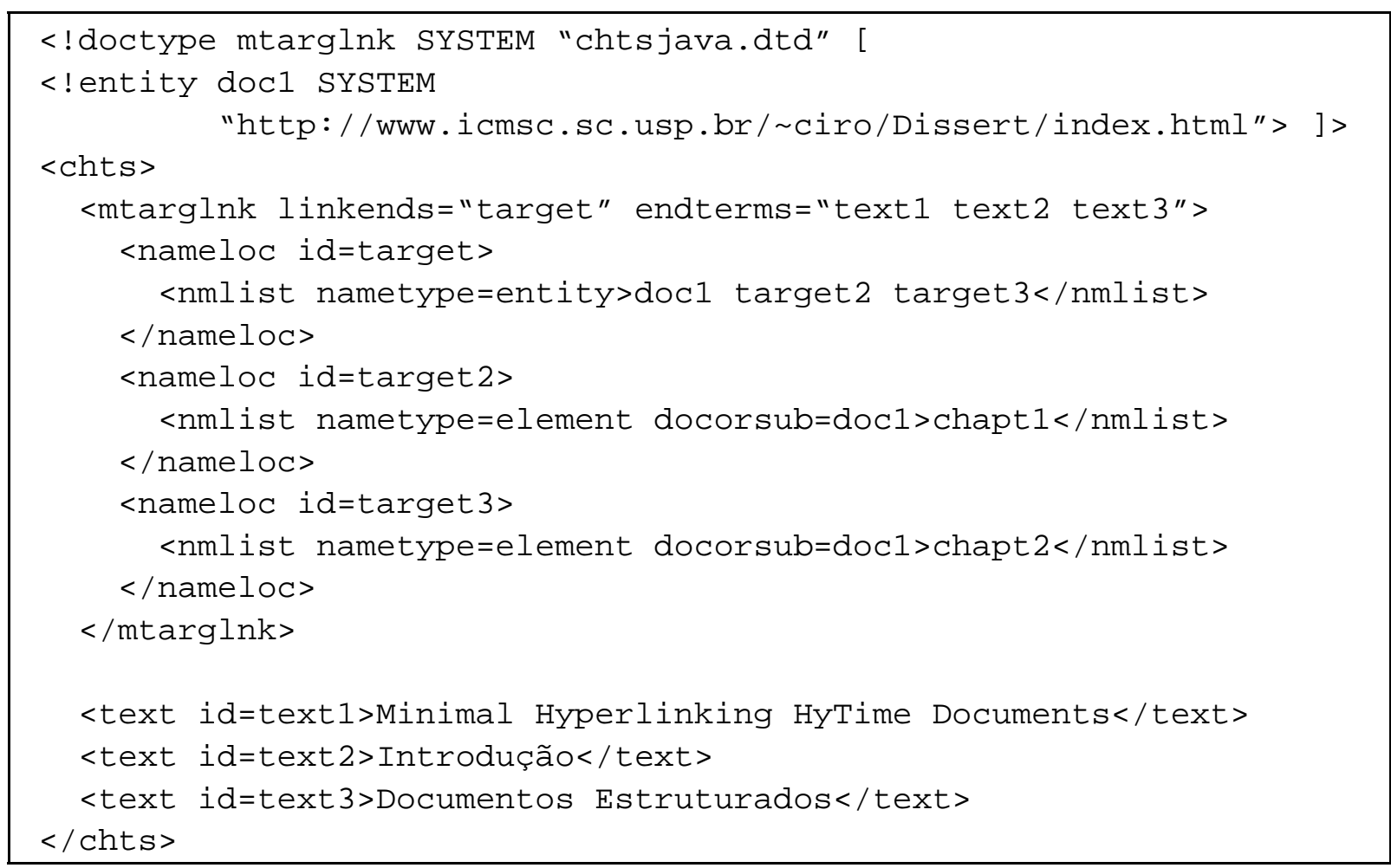

Figura 6.9: Exemplo de um documento com o elemento mtarglnk

\subsubsection{Applet para guided tours}

A applet implementada para guided tours exibe um botão que quando pressionado ativa uma janela de controle com as seguintes funções:

- first: vai para o primeiro item do tour;

- last: vai para o último item do tour;

- next: exibe o próximo item do tour;

- previous: volta para o item anterior do tour;

- exit: abandona o tour e fecha a janela de controle.

Para que o guided tour seja exibido, uma nova instância do browser HTML usado é aberta. A marcação para a inclusão da applet em um documento HTML é semelhante à mostrada na Figura 6.10. O parâmetro com atributo name=but ton especifica o texto exibido no botão que ativa a applet e o parâmetro com atributo name=hytime especifica o arquivo conformante com HyTime que contém a definição do guided tour. 


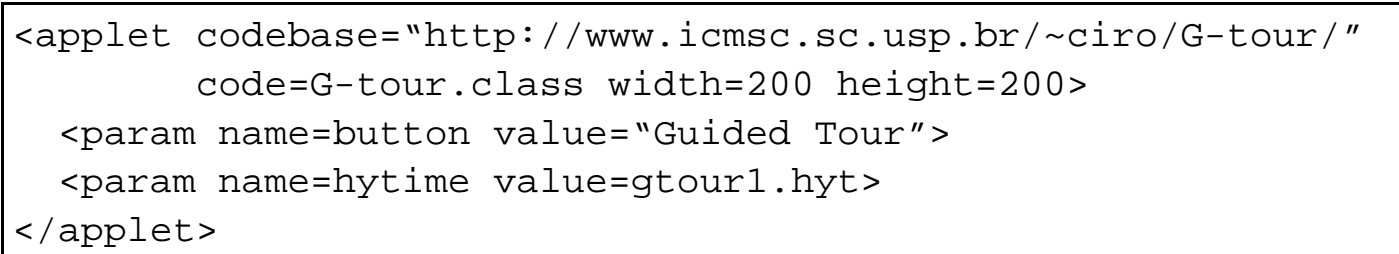

Figura 6.10: Inclusão da applet para guided tours em um documento HTML

Pelo mesmo motivo que o elemento mtarglnk foi alterado - uso da notação URL para o endereçamento de objetos por parte dos documentos HTML - o elemento gtour também necessitou de uma pequena alteração na sua definição. A AF treeloc foi excluída do content model do elemento item e sua definição ficou como mostrado abaixo:

$$
<\text { !element item - - }(\text { nameloc* })>
$$

O exemplo de um arquivo contendo a definição de um guided tour é mostrado na Figura 6.11 e sua apresentação através da applet é ilustrada na Figura C.4. No exemplo da Figura 6.11, é definido um guided tour com sete itens, todos esses itens são referências a elementos $a$ HTML com atributos name iguais a chapt1, chapt2, ..., chapt7 de um mesmo arquivo HTML (index.html).

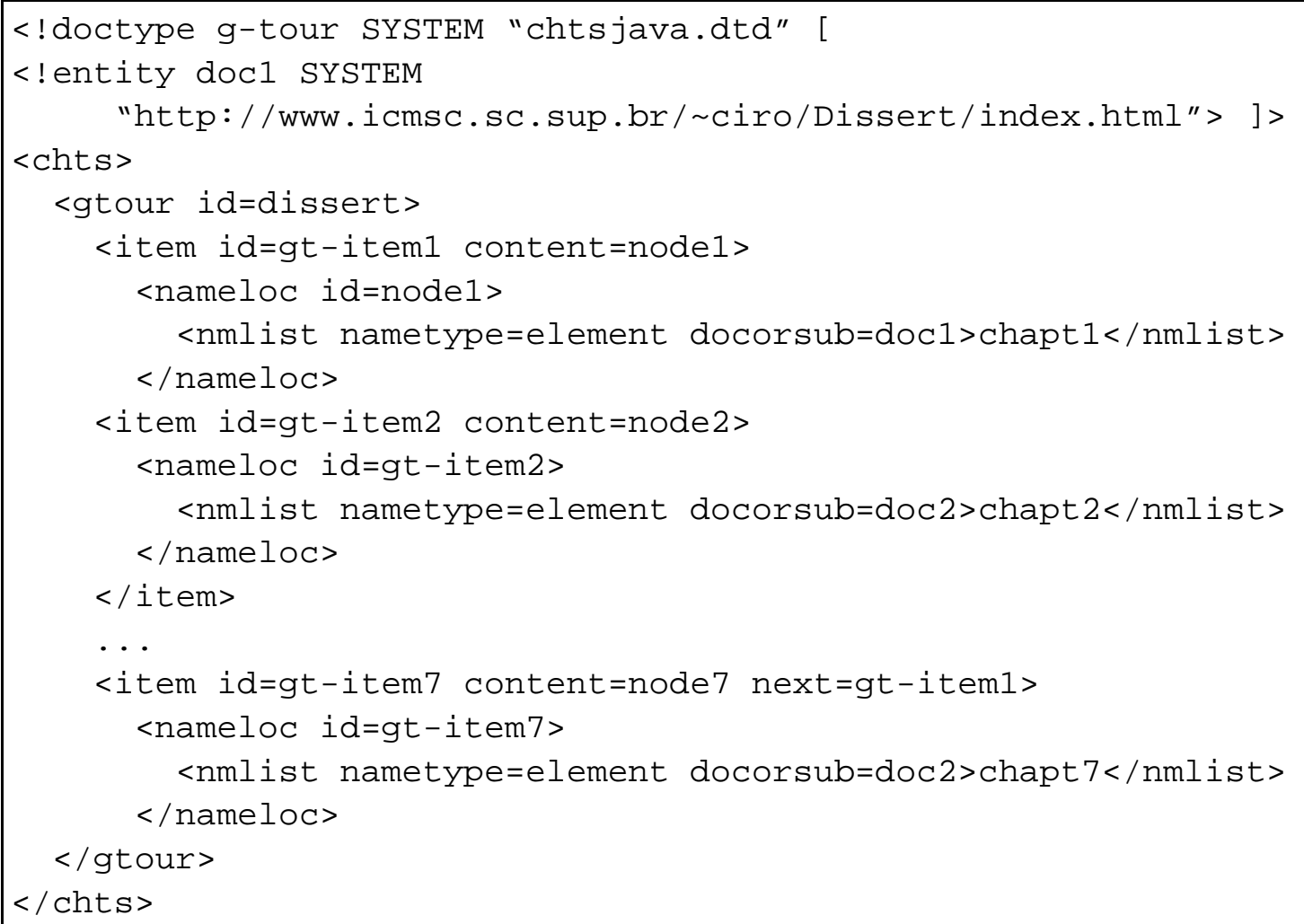

Figura 6.11: Exemplo de um arquivo contendo o elemento $g$-tour 


\subsubsection{Applet para composições}

A applet para composições encontra-se atualmente em fase de implementação. Não está prevista nenhuma mudança no elemento composit definido no DTD CHTS. A forma de apresentação desse elemento ainda está em estudo, mas em sua versão inicial a interface gráfica definida pode ser vista na Figura C.5. Nessa figura, é apresentada a composição mostrada na Figura 5.20 do capítulo anterior.

Uma referência a uma composição será feita através de um click do mouse sobre o botão da applet de composições, que exibirá uma janela de controle para a composição com funções para informar o número de nós de contexto e terminais da composição, informar quais são as âncoras e elos de um determinado nó, e um menu para a navegação dentro da composição.

A inclusão dessa applet é feita através de uma marcação semelhante à apresentada na Figura 6.12.



Figura 6.12: Inclusão da applet para composições em um documento HTML

\subsection{Considerações Finais}

Neste capítulo foram apresentados dois ambientes para a manipulação de documentos conformantes com o padrão HyTime. No primeiro, ferramentas de autoria e apresentação estão sendo implementadas em um ambiente que inclui ainda um SGML parser e um HyTime engine, como pode ser visto na Figura 6.1. Está previsto que nesse ambiente sejam suportadas várias classes de documentos definidas através de DTDs, inclusive os DTDs HTML e CHTS.

No segundo ambiente, os recursos hipermídia da linguagem Java são explorados na codificação da apresentação das estruturas formalizadas no DTD CHTS. A possibilidade de inclusão de applets Java em páginas HTML permite que esses construtores sejam disponibilizados aos usuários da WWW. Porém, as limitações impostas pela notação URL e pela pouca estruturação de HTML não permitem formas de endereçamento mais sofisticadas, como as providas pelos padrões SGML e HyTime. Por isso, é necessário um processamento como o ilustrado na Figura 6.2 e discutido na seção 6.3.1. para que as formas de endereçamento e ligação de HyTime sejam suportadas.

Uma proposta de apresentação de construtores HyTime na WWW através de sua tradução para HTML é discutida em (Rutledge 96a), porém, essa proposta não permite que estruturas não definidas por HTML sejam suportadas. 
A implementação de applets Java para a codificação da apresentação de construtores SGML e HyTime é válida, pois torna disponível a todos os usuários da WWW estruturas clássicas no ambiente hipermídia definidas segundo esses padrões.

No próximo capítulo são discutidas as contribuições e as propostas de continuidade desse trabalho. 


\section{Conclusão e TrabalHos Futuros}

\subsection{Considerações iniciais}

Alguns autores têm explorado a relação entre HyTime e HTML de modo a processar documentos HTML afim de torná-los conformantes ao padrão HyTime (Rutledge et al. 95) (DeRose \& Duran 94) e para permitir a apresentação de documentos HyTime na WWW (Rutledge 96a).

O trabalho reportado nesta dissertação teve como objetivo investigar como o padrão HyTime pode ser utilizado na especificação de hiperdocumentos que admitem estruturas clássicas e, ao mesmo tempo, possam ser manipulados por aplicações similares àquelas encontradas hoje na WWW.

Esta dissertação apresentou uma visão geral dos padrões ODA, SGML e HTML — o HyTime foi detalhado em relação aos construtores suportados em um Minimal hyperlinking HyTime document. Foram apresentados também outros modelos reportados na literatura atual modelos que formalizam a estruturação de hiperdocumentos e de aplicações hipermídia.

A seguir foi apresentado o DTD CHTS (Classic Hypertext Structures) proposto, a partir de HyTime, para suportar estruturas clássicas encontradas em sistemas hipermídia. Foi apresentada também a arquitetura de dois ambientes que permitem a manipulação de documentos conformantes com o DTD CHTS.

O trabalho aqui reportado se insere diretamente no contexto dos projetos SMmD (Teixeira et al. 95) e HyperProp (Soares et al. 95a), os quais demandam a especificação, manipulação e apresentação de hiperdocumentos em ambientes abertos. Assim, se fez necessária a investigação de um padrão que garanta o intercâmbio de documentos não apenas entre os projetos, mas de modo geral — requisitos esses atendidos por HyTime.

\subsection{Contribuições}

As contribuições mais significativas deste trabalho são apresentadas a seguir:

- Não é de conhecimento do autor a realização, no Brasil, de trabalho similar em relação à investigação dos recursos hipermídia e multimídia dos padrões SGML e HyTime. Como um dos resultados dessa investigação, produziu-se um material de grande utilidade para aqueles que desejam iniciar-se nos padrões SGML e HyTime. Parte desse material foi, ainda, disponibilizado à comunidade científica (Pimentel et al. 96). 
- A modelagem da arquitetura do Sistema Básico Hipermídia apresentado na seção 6.2 dessa dissertação. Nessa modelagem foram definidos os módulos desse sistema e o relacionamento entre eles. A definição e implementação desse sistema é um dos objetivos do projeto SMmD.

- A especificação do DTD CHTS utilizando construtores SGML e HyTime para estruturas clássicas encontradas em vários sistemas hipermídia. No Capítulo 5 desta dissertação, o DTD CHTS é apresentado e cada uma de suas estruturas é detalhada. Na elaboração desse DTD, foram explorados principalmente os recursos de endereçamento e ligação de HyTime, que são a essência de um Minimal hyperlinking HyTime document. Parte desse material foi submetido à avaliação pela comunidade científica (Trindade \& Pimentel et al. 97).

- A implementação de applets Java para a apresentação das estruturas definidas no DTD CHTS, o que permite a disponibilização dessas estruturas para toda a comunidade de usuários da WWW. Essas applets são o primeiro passo para a construção do ambiente ilustrado na Figura 6.2 desta dissertação.

\subsection{Trabalhos Futuros}

Alguns dos projetos que podem dar continuidade ao trabalho apresentado, vários dos quais estam em andamento, são:

- A implementação da tradução automática de documentos HyTime, que contenham as estruturas definidas no DTD CHTS, para documentos HTML, onde essas estruturas são substituídas pelas applets Java implementadas. Esse trabalho é descrito em (Nuruki \& Pimentel 97) e tem como objetivo a implementação do HyTime engine e do Tradutor descritos na seção 6.3.1 desta dissertação.

- A extensão do DTD CHTS para que sejam incluídas estruturas que dêem suporte à construção de material voltado para o ensino: cursos, tutoriais, planos de aula e exercícios práticos. Este trabalho está tendo início como reportado em (Macedo \& Pimentel 97).

- A extensão das implementações em Java para que possam ser referenciados arquivos contendo qualquer tipo de mídia - atualmente somente arquivos texto são suportados. Isso não requer nenhuma modificação nas estruturas definidas no DTD CHTS, cujas definições já suportam esse tipo de referência - apenas as aplicações, neste caso as applets Java, precisam ser estendidas (Silva \& Pimentel 97).

- Devido à sua complexidade e, portanto, dificuldade de entendimento, é interessante a realização da modelagem dos construtores HyTime utilizando o paradigma da orientação a objetos. Este trabalho está em fase inicial, conforme proposto em (Scott \& Pimentel 97).

- Os documentos disponibilizados na WWW são simples dada a estrutura imposta por HTML. Entretanto, alguns autores advogam que essa simplicidade é uma das causas do sucesso da WWW. Um estudo de interesse, nesse contexto, é a verificação do grau de dificuldade encontrado pelos usuários durante a navegação em documentos que possuam as estruturas propostas no DTD CHTS. 
- Similarmente ao item anterior, um estudo sobre as dificuldades de autoria e a qualidade da autoria de hipertextos que possuam as estruturas definidas no DTD CHTS pode ser realizado, e seus resultados comparados com os obtidos ao utilizar-se o DTD HTML.

\subsection{Considerações Finais}

Embora seja um padrão internacional ISO, HyTime ainda não atingiu uma grande aceitação por parte da comunidade envolvida com o desenvolvimento de hipermídia. Isso se deve, em parte, à complexidade do padrão e, mais recentemente, à larga adoção de HTML como formato de representação dos documentos disponibilizados na WWW. A grande questão é se HyTime vai se estabelecer como um padrão hipermídia de fato, ou HTML, que define uma estrutura simples e sem muita rigidez, vai continuar monopolizando a WWW.

Eliot Kimber, em mensagem postada no newsgroup comp. text. sgml, defende que o surgimento das Intranets dará um impulso aos padrões SGML e HyTime, pois somente com o uso desses padrões todo o potencial das Intranets será explorado. Ele argumenta que HyTime tem que fazer parte do ambiente das Intranets porque, por um lado, esse tipo de rede envolve a ligação dinâmica entre bancos de dados heterogêneos em um ambiente descentralizado e, por outro lado, o método de endereçamento direto baseado em arquivos usado pelos protocolos HTTP (URL, URN, etc.) não são robustos o suficiente para suportar esse ambiente. Além disso, as estruturas de representação de ligação em HTML limitam a habilidade de representar bancos de dados com relacionamentos arbitrários, um ponto chave nos sistemas de suporte à decisão que deveriam ser capazes de interligar qualquer informação em qualquer local em uma empresa (Kimber 96).

Outro ponto importante é o fato de HyTime especificar apenas a estrutura e não a forma de apresentação de hiperdocumentos; isso não implica que não existam esforços no sentido de permitir a padronização de apresentações hipermídia. O padrão DSSSL, por exemplo, provê uma linguagem padrão para a descrição tanto dos style sheets quanto das transformações em um documento hipermídia descrito em SGML/HyTime. Outro padrão que também permite definir a forma de apresentação de documentos multimídia e hipermídia é o MHEG (ISO 95), que tem como objetivo definir a representação e codificação de objetos multimídia e hipermídia, visando o intercâmbio entre aplicações.

O que se pode concluir é que a investigação dos padrões SGML e HyTime para a descrição da estrutura de documentos hipermídia e multimídia, realizada nesta dissertação, foi proveitosa. Além disso ficou demonstrado, através da formalização das estrutras do DTD CHTS, que esses padrões se adequam à definição de estruturas hipermídia as quais podem ser disponibilizadas em ambientes abertos tais com a WWW.

Finalmente, pode-se ter um indicativo da importância das contribuições desta dissertação pela qualidade e quantidade de trabalhos futuros gerados. 


\section{REFERÊNCIAS BIBLIOGRÁFICAS}

(Berners-Lee et al. 94) Berners-Lee, Tim; Cailliau, Robert; Luotonen, Ari; Nielsen, Henrik; Secret, Arthur. The World Wide Web. Communications of the ACM, no. 8, vol. 37 (1994), pp. 76-82.

(Brown 89a) Brown, Heather. Standards for Structured Documents. The Computer Journal, no. 6, vol. 32, (1989), pp. 505-514.

(Brown 89b) Brown, Peter J.. A Hypertext System for UNIX. Computing Systems, no. 1, vol. 2 (1989), pp. 37-53.

(Buford et al. 94a) Buford, John; Rutledge, Lloyd; Keskin, C.. HyOctane: a HyTime Engine for an MMIS. Multimedia Systems, no. 4, vol. 1 (1994), pp. 173-185.

(Buford et al. 94b) Buford, John; Rutledge, Lloyd; Rutledge, John. Integrating Object-Oriented Scripting Languages with HyTime. Proceedings of IEEE International Conference on Multimedia Computing and Systems, Maio, 1994, http://www.cwi.nl/ lloyd/Papers.

(Buford et al. 94c) Buford, John; Rutledge, Lloyd; Rutledge, John. Toward Automatic Generation of HyTime Applications. Proceedings of Eurographics Multimedia'94, Junho, 1994, http://www.cwi.nl/ lloyd/Papers.

(Buford 96) Buford, John. Evaluating HyTime: An Examination and Implementation Experience. Proceedings of ACM Hypertext'96, Washington, Março, 1996, pp. 105-115.

(Bulterman et al. 91) Bulterman, D. C. A.; van Rossum, G.; van Liere, R.. A Structure for Transportable, Dynamic Multimedia Documents. Proceedings of the Summer 1991 USENIX Conference, Nashville, Julho, 1991, pp.137-155.

(Bulterman 93) Bulterman, D. C. A.. Specifying and Support of Adaptable Networked Multimedia. Springer-Verlag/ACM Multimedia Systems, no. 2, vol. 1 (1993), pp. 68-76.

(Catlin et al. 89) Catlin, T.; Bush, P.; Yankelovich, N.. InterNode: Extending a Hypermedia Framework to Support Annotative Collaboration. Proceedings of the ACM Hypertext'89, Pittsburg, Novembro, 1989, pp. 365-378.

(Casanova et al. 95) Casanova, Marco A.; Soares, Luiz F. G.; Souza, Guido L.. Anchors and Links for Composite Nodes. Relatório Técnico do Departamento de Informática da PUCRio, Rio de Janeiro, Setembro, 1995.

(Clark 96) Clark, James. SP. Junho, 1996, disponível em http://www.jclark.com/sp. 
(Davis et al. 92) Davis, H.; Hall, W.; Heath, I.; Hill, G.; Wilkins, R.. Towards an Integrated Information Environment with Open Hypermedia Systems. Proceedings of the ACM on Hypertext’92, Milão, Dezembro, 1992, pp. 181-190.

(DeRose \& Duran 94) DeRose, Steven J.; Duran, David G.. Making Hypermedia Work: A Users’s Guide to HyTime. Kluwer Academic Publishers, Massachusetts, 1994.

(Fujitsu \& TechnoTeacher 95) Fujitsu Open Systems Solutions; TechnoTeacher, Inc. HyTime Application Development Guide, Versão 1.2, Maio, 1995.

(Garret et al. 86) Garret, P. K.; Smith, K. E.; Meyrowitz, N. K.. Intermedia: Issues, Strategies, and Tactics in the Design of a Hypermedia Document System. Proceedings of Conference on Computer-Supported Cooperative Work, Local, Mês, 1986, pp. 163-174.

(Garzotto \& Schwabe 93) Garzotto, Franca; Schwabe, Daniel. HDM - A Model-Based Approach to Hypertext Application Design. ACM Transactions on Information Systems, no. 1, vol. 11 (1993), pp. 1-26.

(Garzotto et. al. 94) Garzotto, Franca; Mainetti, Luca; Paolini, Paolo. Adding Multimedia Collections to the Dexter Model. Proceedings of the ECTH'94, Edinburgh, Setembro, 1994, pp. 70-80.

(Goldfard 95) Goldfard, Charles F.. The SGML Handbook. Oxford University Press, Oxford, 1995.

(Grøbæk 94) Grøbæk, Kaj. Composites in a Dexter-Based Hypermedia Framework. Proceedings of the ECTH'94, Edinburgh, Setembro, 1994, pp. 59-69.

(Grøbæk \& Trigg 94) Grøbæk, Kaj; Trigg, Randall H.. Design Issues for a Dexter-Based Hypermedia System. Communications of the ACM, no. 2, vol. 37 (1994), pp. 41-49.

(Halasz 88) Halasz, Frank. Reflections on NoteCards: Seven Issues for the Next Generation of Hypermedia Systems. Communications of the ACM, no. 7, vol. 31 (1988), pp. 836-852.

(Halasz \& Schwartz 90) Halasz, Frank; Schwartz, Mayer. The Dexter Hypertext Reference Model. Proceedings of the Hypertext Standardization Workshop, Gaitherburg, Janeiro, 1990, pp. 95-133.

(Halasz \& Schwartz 94) Halasz, Frank; Schwartz, Mayer. The Dexter Hypertext Reference Model. Communications of the ACM, no. 2, vol. 37 (1994), pp. 30-39.

(Hall et al. 93) Hall, W.; Davis, H.; Pickering, A.; Hutchings, G... The Microcosm Link Service: An Integrating Technology. Proceedings of the ACM Hypertext'93, Nova York, Novembro, 1993, pp. 256-259. 
(Hardman et al. 94) Hardman, Linda; Bulterman, Dick; Rossun, Guido. The Amsterdam Hypermedia Model: Adding Time and Context to the Dexter Model. Communications of the ACM, no. 2, vol. 37 (1994), pp. 50-62.

(Herwijnen 94) Herwijnen, Eric van. Pratical SGML. Kluwer Academic Publishers, Massachusetts, $2^{\text {a }}$ ed., 1994.

(Isakowitz et al. 95) Isakowitz, Tomás; Stohr, Edward A.; Balasubramanian, P. RMM: A Methodology for Structured Hypermedia Design. Communications of the ACM, no. 8, vol. 38 (1995), pp. 34-44.

(ISO 86) International Standards Organization. ISO/IEC IS 8879. Information Processing Text and Office Systems — Standard Generalized Markup Language (SGML). 1986.

(ISO 87) International Standards Organization. ISO 8632. Information Processing Systems Computer Graphics — Metafile for the Storage of Description Information. 1987.

(ISO 89) International Standards Organization. ISO 8613. Information Processing — Text and Office Systems — Office Document Architecture (ODA) and Interchange Format. 1989.

(ISO 92) International Standards Organization. ISO/IEC IS 88744. Hypermedia/Time-Based Structuring Language (HyTime). 1992.

(ISO 95) International Standards Organization. ISO/IEC DIS 13522-1. Information Tecnology - Coding of Multimedia and Hypermedia Information, Part 1: MHEG Object Representation and Base Notation (ASN.1), 1995.

(ISO 96) International Standards Organization. ISO/IEC IS 10179. Document Style Semantics and Specification Language (DSSSL). 1996.

(Kimber 96) Kimber, W. Eliot. Report on the HyTime'96/SGML and the Web Conference. Postado no newsgroup comp.text.sgml, Agosto, 1996.

(Leiva 96) Leiva, Willie D.. HTML Stricter Level 2 DTD. ICMSC/USP, São Carlos, Novembro, 1996, disponível em http://www.intermidia.icmsc.sc.usp.br/ wdl/rightml.

(Lemay \& Moncur 96) Lemay, Laura; Moncur, Michael G.. JavaScript. Sams.net Publishing, Indianapolis, 1996.

(Macedo \& Pimentel 97) Macedo, Alessandra; Pimentel, Maria G. C.. Exploração da Estrutura Clássica de Hipertextos na Criação de Hiperdocumentos Adaptativos. Projeto de Mestrado, ICMSC/USP, em preparação.

(Marshall \& Irish 89) Marshall, C. C.; Irish, P. M.. Guided Tours and On-Line Presentations: How Authors Make Existing Hypertext Intelligible for Readers. Proceedings of the ACM Hypertext'89, Pittsburg, Novembro, 1989, pp. 15-26. 
(Moreira et al. 95) Moreira, Edson S.; Nunes, Maria G. V.; Pimentel, Maria G. C.. Design Issues for a Distributed Hypermedia-based Tutoring System (HyDTS). Proceedings of the International Conference on Computer Application in Industry, Dezembro, 1995.

(Naughton 96) Naughton, Patrick. The Java Handbook. Osborne McGraw-Hill, Berkeley, 1996.

(Newcomb et al. 91) Newcomb, Steven; Kipp, Neil; Newcomb, Victoria. The "HyTime" Hypermedia/Time-Based Document Structuring Language. Communications of the ACM, no. 11, vol. 34 (1991), pp. 67-83.

(Newcomb 95) Newcomb, Steven R.. Multimedia Interchange Using SGML/HyTime. IEEE Multimedia, (1995), pp. 86-89.

(Nuruki \& Pimentel 97) Nuruki, Laura; Pimentel, Maria G. C.. Tradução e Resolução de Endereçamentos HyTime para HTML. Projeto de Graduação, ICMSC/USP, em preparação.

(Ousterhout 94) Ousterhout, John K.. Tcl and teh Tk Toolkit. Addison-Wesley, Massachusetts, 1994.

(Pimentel 95) Pimentel, Maria G. C.. O HyTime no contexto do projeto SMmD. Anais do I Workshop em Sistemas Hipermídia Distribuídos, São Carlos, Julho, 1995 , pp. 67-77.

(Pimentel et al. 96) Pimentel, Maria G. C.; Trindade, Ciro C.; Leiva, Willie D.. Hyperlinking Segundo HyTime: Overview e Suporte. Anais do II Workshop em Sistemas Hipermídia, Fortaleza, Maio (1996), pp. 1-10.

(Pimentel et al. 97a) Pimentel, Maria G. C.; Silva, Richard F.; Chorfi, Marcos A.. Projeto HyperPena: um Editor para Hiperdocumentos no padrão HTML. ICMSC/USP, São Carlos, Janeiro, 1997, disponível em http://www.icmsc.sc.usp.br/ richard/proj/proj.html.

(Pimentel et al. 97b) Pimentel, Maria G. C.; Nitta, Fábio A.; Faria, Gustavo B.. HyperJangada: um Navegador HTML. ICMSC/USP, São Carlos, Janeiro, 1997, disponível em http://www.intermidia.icmsc.sc.usp.br/ chaves/hj.

(Pimentel et al. 97c) Pimentel, Maria, G. C.; Baldochi, Laércio A.; Fagundes, Fabiano; Teixeira, Cesar A. C.. Relações Temporais em Objetos Multimídia: Especificação HyTime e Apresentação. Submetido ao III Workshop em Sistemas Multimídia e Hipermídia.

(Pimentel \& Leiva 97) Pimentel, Maria G. C.; Leiva, Willie D.. Projeto e Desenvolvimento para Manipulação de Hiperdocumentos em Ambientes Abertos Distribuídos. Submetido ao III Workshop em Sistemas Multimídia e Hipermídia.

(Rutledge 93) Rutledge, Lloyd. A HyTime Engine for Hypermedia Document Presentation. Dissertação de Mestrado, Universidade de Massachusetts Lowell, 1993. 
(Rutledge et al. 95) Rutledge, Lloyd; Buford; John F.; Rutledge, John L.. Applying HyTime to HTML. Proceedings of IASTED/ISMM Distributed Multimedia Systems and Applications, Agosto, 1995, http://www.cwi.nl/ lloyd/Papers.

(Rutledge 95) Rutledge, Lloyd. Introduction to HyTime. Notas do Tutorial no ACM Multimedia'95, Novembro, 1995, http://www.cwi.nl/ lloyd/Papers.

(Rutledge 96a) Rutledge, Lloyd. Presenting HyTime Documents with HTML. Proceedings of EdMedia, Boston, Julho, 1996, http://www.cwi.nl/ lloyd/Papers.

(Rutledge 96b) Rutledge, Lloyd. Evaluations of and Extensions to a Second Generation Hypermedia Model. Tese de Doutorado. University of Massachusetts Lowell, 1996.

(Scott \& Pimentel 97) Scott, Luis Paulo; Pimentel, Maria G. C. Uma visão orientada a objetos do padrão HyTime. A ser submetido ao SBES’97, em preparação.

(Silva \& Pimentel 97) Silva, Richard; Pimentel, Maria G. C. Tratamento de mídias áudio e vídeo em hiperdocumentos CHTS estruturados. Projeto de Iniciação Científica, ICMSC/USP, em preparação.

(Soares et al. 95a) Soares, Luiz F. G. et alli. O Projeto HyperProp: uma visão geral. Anais do I Workshop em Sistemas Hipermídia Distribuídos, São Carlos, Julho, 1995, pp. 1-12.

(Soares et al. 95b) Soares, Luiz F. G.; Rodriguez, Noemi L. R.; Casanova, Marco A.. NCM: A Conceptual Model for Hyperdocuments Anais do I Workshop em Sistemas Hipermídia Distribuídos, São Carlos, Julho, 1995, pp. 40-46.

(Soares et al. 95c) Soares, Luiz F. G.; Rodriguez, Noemi L. R.; Casanova, Marco A.. Nested Composites Nodes and Version Control in a Open Hypermedia System. IEEE Transactions on Information Systems, Special Issue on Multimedia Information System, no. 6, vol. 20 (1995), pp. 501-519.

(Sun 97) Sun Microsystems. JavaSoft Home Page. Fevereiro, 1997, disponível em http://www.javasoft.com.

(Teixeira et al. 95) Teixeira, Cesar A. C.; Vieira, Marina T. P.; Araujo, Regina B.; Trevelin, Luis C.; Pimentel, Maria G. C.; Sena, Carlos V. G.. A arquitetura do projeto SMmD. Anais do I Workshop em Sistemas Hipermídia Distribuídos, São Carlos, Julho, 1995, pp. 30-39.

(Trigg 88) Trigg, R. H.. Guided Tours and Tabletops: Tools for Communicating in a Hypertext Environment. ACM Transactions on Information Systems, no. 4, vol. 6 (1988), pp. 398414.

(Trindade \& Pimentel 97) Trindade, Ciro C.; Pimentel, Maria G. C.. Especificação HyTime de Estruturas Hipertexto. Submetido ao III Workshop em Sistemas Multimídia e Hipermídia.

(Uhler 95) Uhler, S. HTML display library, release 0.3 alpha. Sun Laboratories, Mountain View, Novembro, 1995, ftp://ftp.smli.com/pub/tcl/html-library-0.3.tar.gz. 
(Welch 95) Welch, Brent B.. Practical Programming in Tcl and Tk. Prentice Hall PTR, New Jersey, 1995.

(Williams 87) Williams, Gregg. Hypercard. Byte, no. 12, vol. 12 (1987), pp. 109-117.

(Yankelovich et al. 87) Yankelovich, N.; Landow, G. P.; Cody, D.. Creating Hypermedia Materials for English Literature Students. ACM SIGCUE Outlook, no. 3-4, vol. 19 (1987), pp. 12-25.

(Yankelovich et al. 88) Yankelovich, N.; Haan, B. J.; Meyrowitz, N. K.; Drucker, S. M.. Intermedia: The Concept and the Construction of a Seamless Information Environment. IEEE Computer, no. 1, vol. 21 (1988), pp. 81-96.

(Zellweger 89) Zellweger, P. T.. Scripted Documents: a Hypermedia Path Mecanism. Proceedings of the ACM Hypertext'89, Pittsburg, Novembro, 1989, pp. 1-14. 


\section{APÊNDICE A: O DTD CHTS}

<!-- DTD CHTS (Classic Hypertext Structures) para uma classe de documentos que utilizam HyTime para o estabelecimento de ligações hipermídia. Universidade de São Paulo Instituto de Ciências Matemáticas de São Carlos Autor: Ciro Cirne Trindade

Data: Janeiro, 1997

<!-- CHTS (Classic Hypertext Structures) é o elemento que contém todo os demias elementos que compõem o documento. Ele pode conter anotações, glossários, elos com múltiplos destinos, elos m:n, guided tours e composições. Esse elemento é conformante com a AF HyDoc.

$<$ !element chts - - ((annot|glossary|mtarglnk|m-nlnk|gtour|composit)+)

$>$

$<$ !attlist chts HyTime NAME \#FIXED "HyDoc"

<-- ANNOT (annotation) é um elemento que permite a inserção de anotações em qualquer tipo de documento, mesmo que não se tenha permissão de escrita no mesmo. Esse elemento é conformante com a AF ilink de HyTime.

$<$ !element annot - O ( (nameloc|treeloc $)+)$

$<$ !attlist annot

$\begin{array}{lll}\text { HyTime } & \text { NAME } & \text { \#FIXED “ilink" } \\ \text { id } & \text { ID } & \text { \#IMPLIED } \\ \text { anchrole } & \text { CDATA } & \text { \#FIXED “source \#AGG target \#AGG" } \\ \text { linkends } & \text { IDREFS } & \text { \#REQUIRED } \\ \text { aggtrav } & \text { NAMES } & \text { cor }\end{array}$

<!-- GLOSSARY (glossary) é um elemento que define um glossário, sendo que pode-se fazer referência ao glossário como um todo ou a apenas um item do glossário. Esse elemento pode conter termos e suas definições.

$<$ !element glossary - - (item+)

$<$ !attlist glossary id ID \#REQUIRED 
<! - - ITEM (glossary item) é um elemento que define um item do glossário. Um item pode conter um termo e uma definição opcional. A definição é um elemento opcional porque mais termo podem possuir a mesma definição, se isto ocorrer, é feita apenas uma referência a definição já existente.

$<$ !element item - - (term, def?)

$<$ !attlist item id ID \#REQUIRED

<! - - TERM (glossary term) é um elemento cujo conteúdo é o um termo do glossário. Ele é conformante com AF clink de HyTime.




<!-- M-NLNK (m:n link) é um elemento que permite a definição de elos com múltiplas origems e múltiplos destinos. Esse elemento é conformante com AF ilink de HyTime.

$<$ ! element m-nlnk

$<$ !attlist m-nlnk

HyTime

id

anchrole

linkends

aggtrav
- $(($ nameloc, treeloc* $)+)$

NAME \#FIXED “ilink"

ID \#IMPLIED

CDATA \#FIXED "source \#AGG target \#AGG"

IDREFS \#REQUIRED

NAMES mem

<!-- GTOUR (guided tour) é um elemento que permite a definição de um guided tour. Ele pode conter vários itens.

$<$ !element gtour - - (item+)

$<$ !attlist gtour

id ID \#REQUIRED

home IDREF \#IMPLIED

$<$ ! - - ITEM (guided tour item) é um elemento que representa um nó do tour. Ele pode conter uma combinação de elementos nameloc e treeloc.

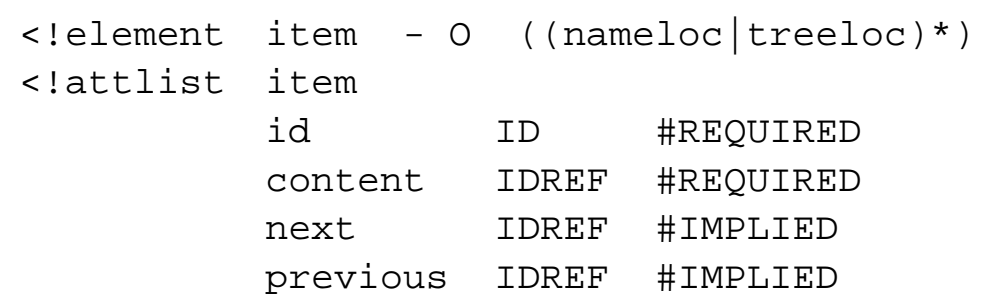

<!-- COMPOSIT (composition) é um elemento que permite a definição de nós compostos. Ele pode conter nós de contexto e/ou nós terminais.

$<$ !element composit - - ((context|terminal $)+)>$

$<$ !attlist composit id ID \#IMPLIED

<!-- CONTEXT (context node) é um elemento que pode conter vários nós, âncoras e elos.

$<$ !element context - - (node+, anchor*, link*)

$<$ !attlist context id ID \#REQUIRED

<! - - TERMINAL (terminal node) é um elemento que referencia um arquivo externo. Ele pode conter várias âncoras.

$<$ !element terminal - - (anchor*)

$<$ !attlist terminal

id ID

type (text|audio|video|graphics|other)

filename IDREF
\#REQUIRED

text

\#REQUIRED 
<! - - NODE (node) é um elemento que contém uma referência a um nó de contexto ou a nó terminal.

$<$ ! element node - 0 EMPTY

$<$ !attlist node

content IDREF \#REQUIRED

reftype CDATA \#FIXED "content composit"

<! - - ANCHOR (anchor) é um elemento que representa uma âncora de de um nó terminal ou de contexto. A posição da nesses nós é definida por elementos conformantes com as AFs nameloc e treeloc.

$<$ !element anchor - - ((nmeloc|treeloc $)+)$

$<$ !attlist anchor id ID \#REQUIRED

<!-- LINK (link) é um elemento que representa um elo em um nó de contexto. Esse elemento é conformante com a AF ilink de HyTime.

$<$ ! element link - 0 EMPTY

$<$ !attlist link

$\begin{array}{lll}\text { HyTime } & \text { ilink } & \text { \#FIXED “ilink" } \\ \text { id } & \text { ID } & \text { \#REQUIRED } \\ \text { linkends } & \text { IDREFS } & \text { \#REQUIRED } \\ \text { reftype } & \text { CDATA } & \text { \#FIXED “linkends anchor" }\end{array}$

<!-- NAMELOC (named location address) é um elemento usado para a especificação de endereços através do nome do elemento (seu id) ou entidade. Ele é conformante com a AF nameloc de HyTime.

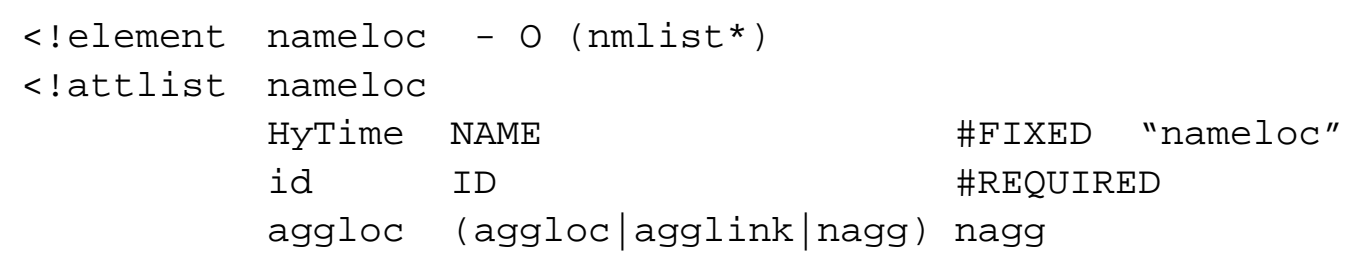

<!-- NMLIST (named list specification) é um elemento que contém os ids dos elementos ou nomes de entidades. Ele é conformante com a AF nmlist de HyTime.

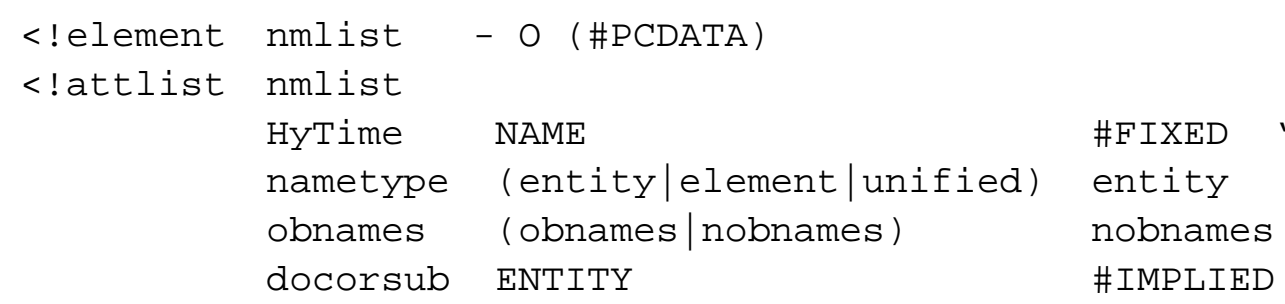


<! - - TREELOC (tree location address) é um elemento usado para o endereçamento de um nó da árvore do documento. Ele é conformante com a AF treeloc de HyTime.

$<$ ! element

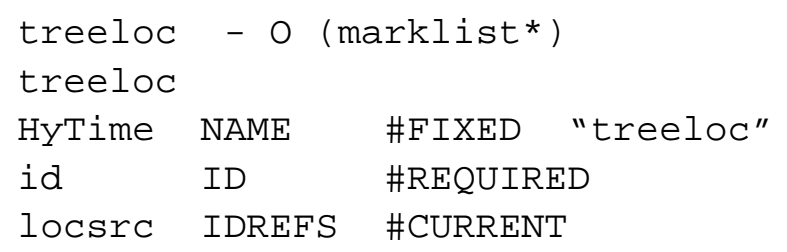

<!-- MARKLIST (axis marker list) é um elemento que contém uma lista de números que especificam a posição de um nó em uma árvore. Ele é um elemento definido por HyTime.

$<$ !element marklist 00 (marklist|\#PCDATA)

<!-- Essa classe de documentos requer o suporte aos seguintes módulos de HyTime: base, measurement e hyperlinks.

$<$ ?HyTime module base refctl >

$<$ ?HyTime module measure >

$<$ ?HyTime module links multloc $>$ 


\section{APÊNDICE B: TELAS DO HYPERPENA E HYPERJANGADA}

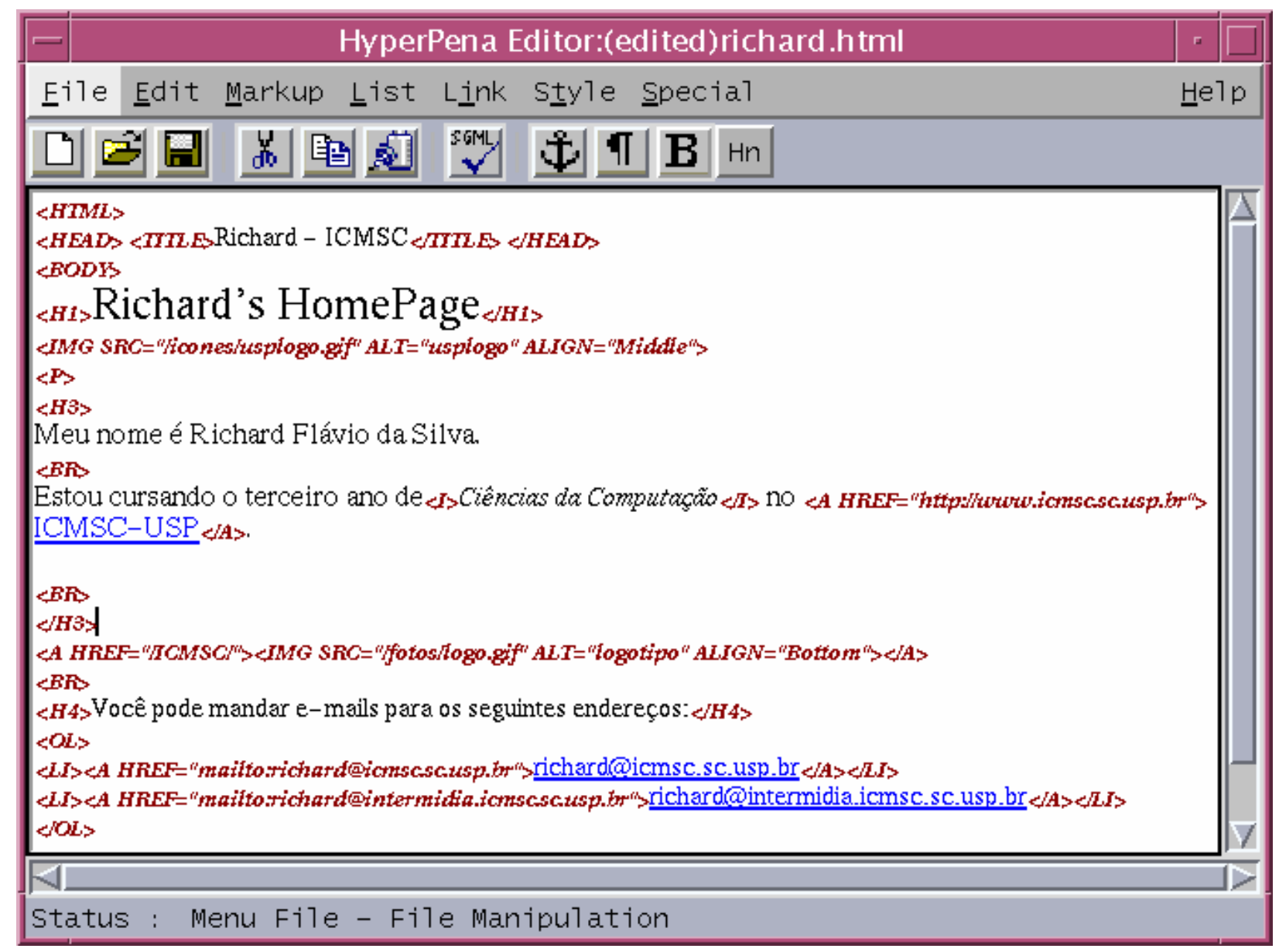

Figura B.1: Interface gráfica do HyperPena 


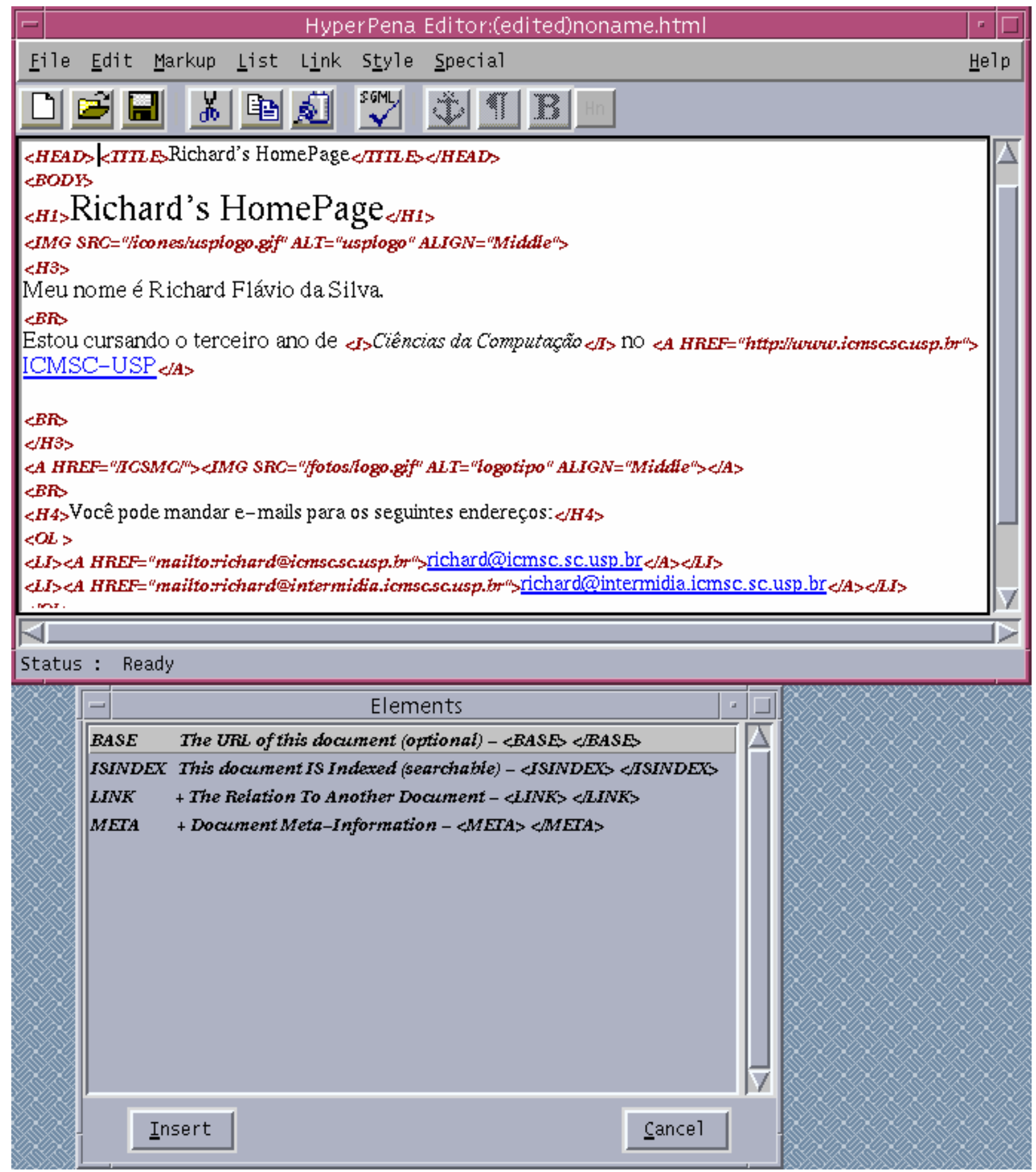

Figura B.2: Sensibilidade a contexto no HyperPena 




Figura B.3: O menu edit do HyperPena

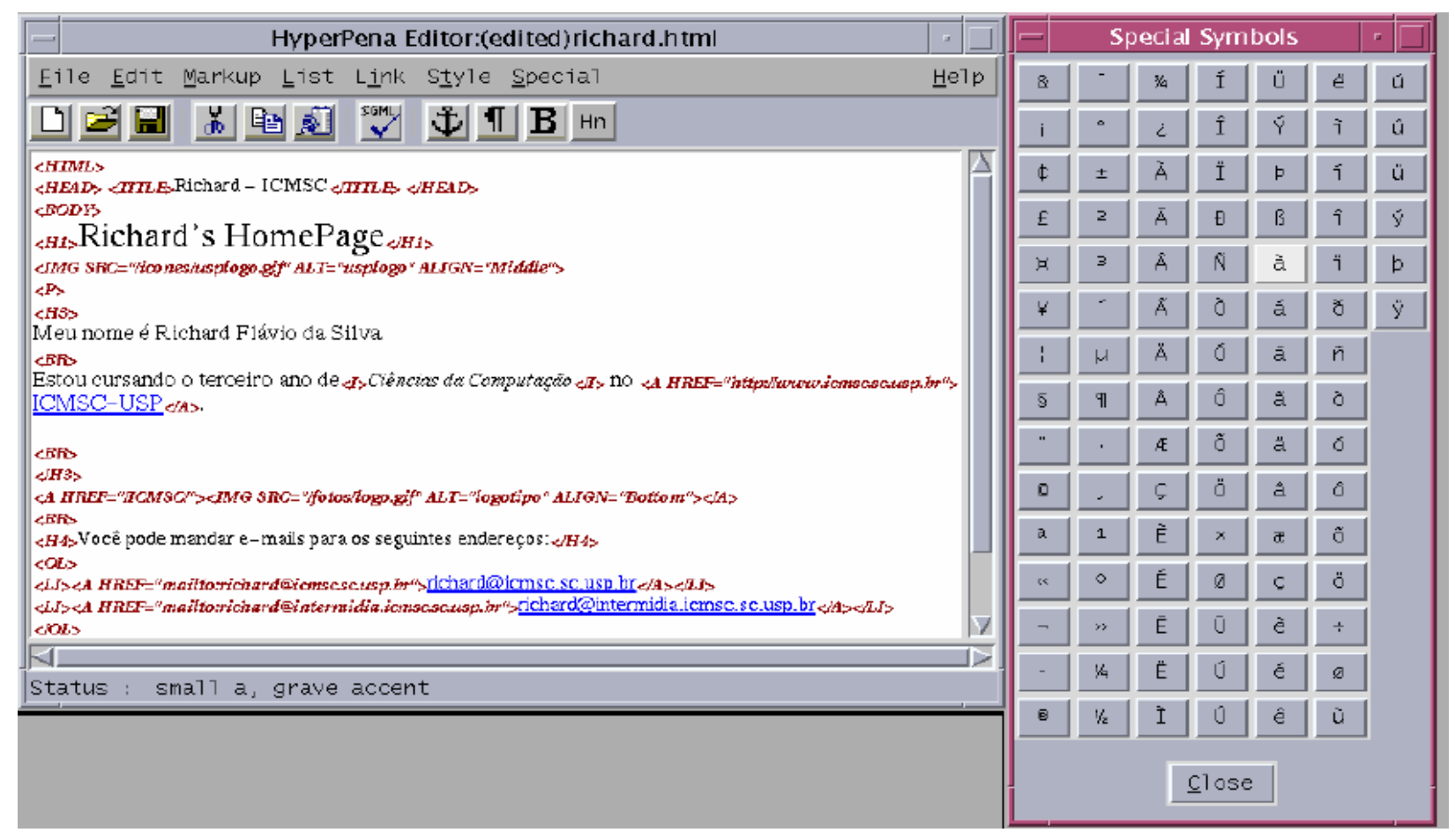

Figura B.4: Tratamento dos caracteres acentuados no HyperPena 


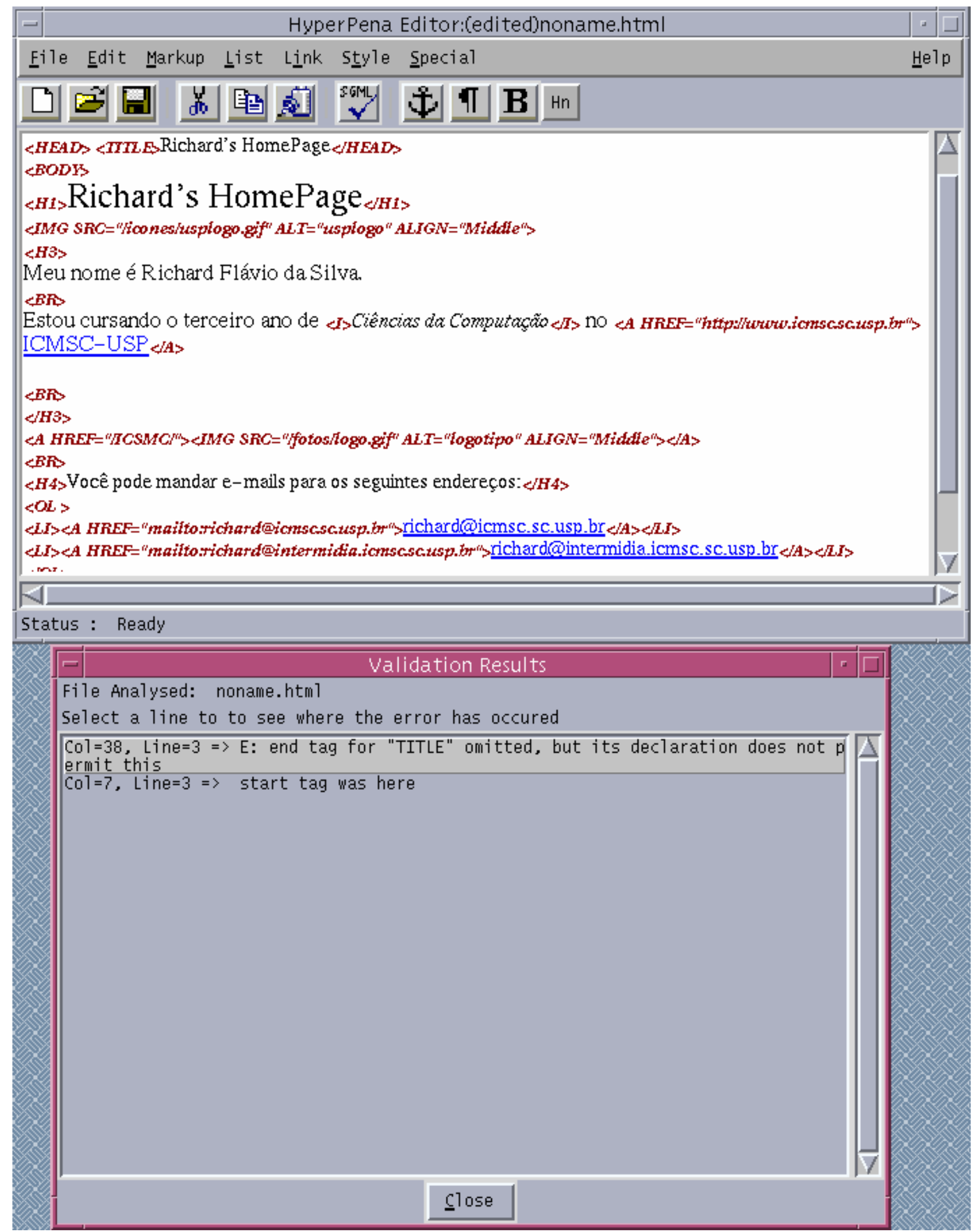

Figura B.5: Validação de um hiperdocumento no HyperPena 


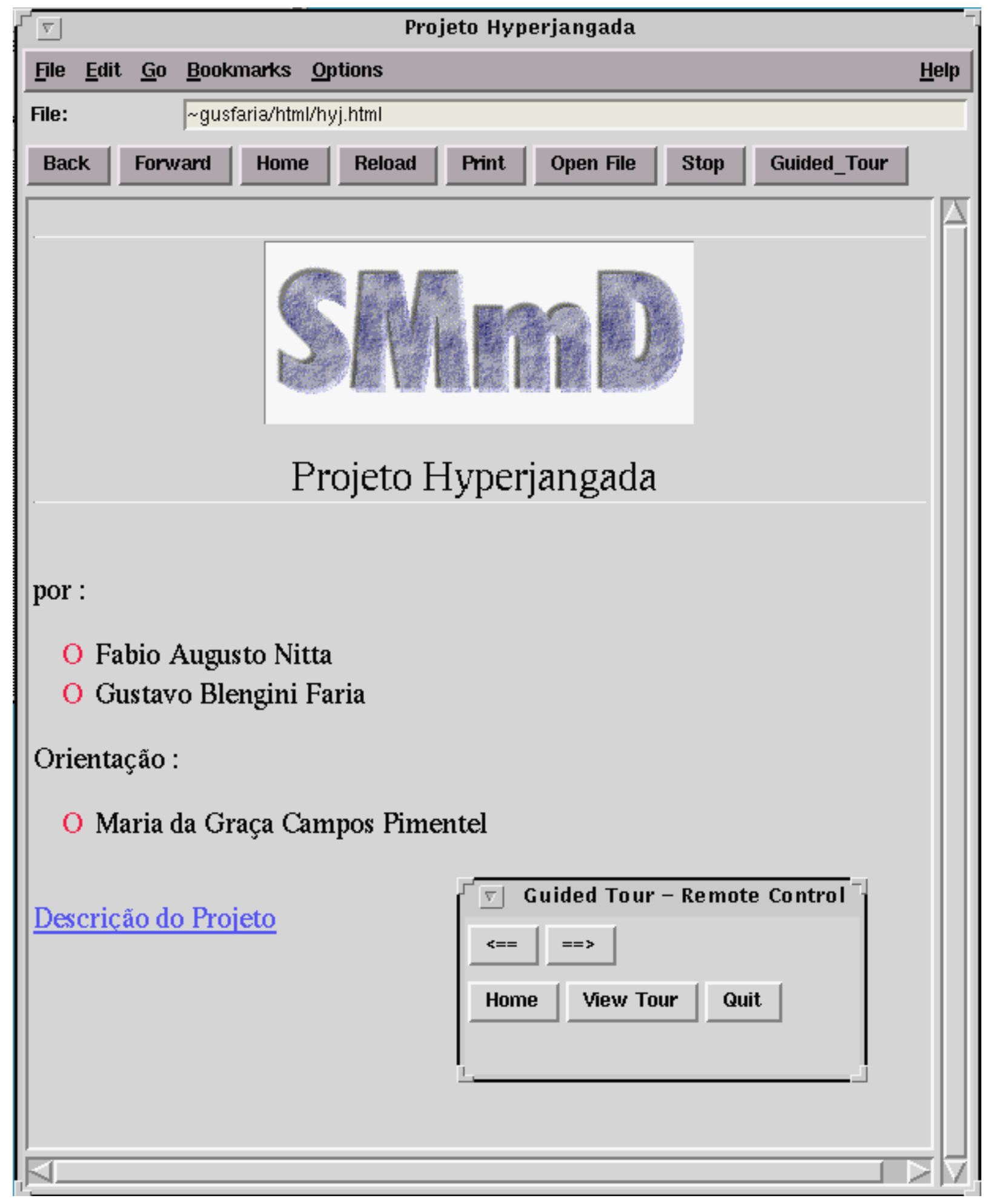

Figura B.6: Interface gráfica do HyperJangada 


\section{APÊNDICE C: SCREEN DUMPS DAS APPLETS IMPLEMENTADAS}

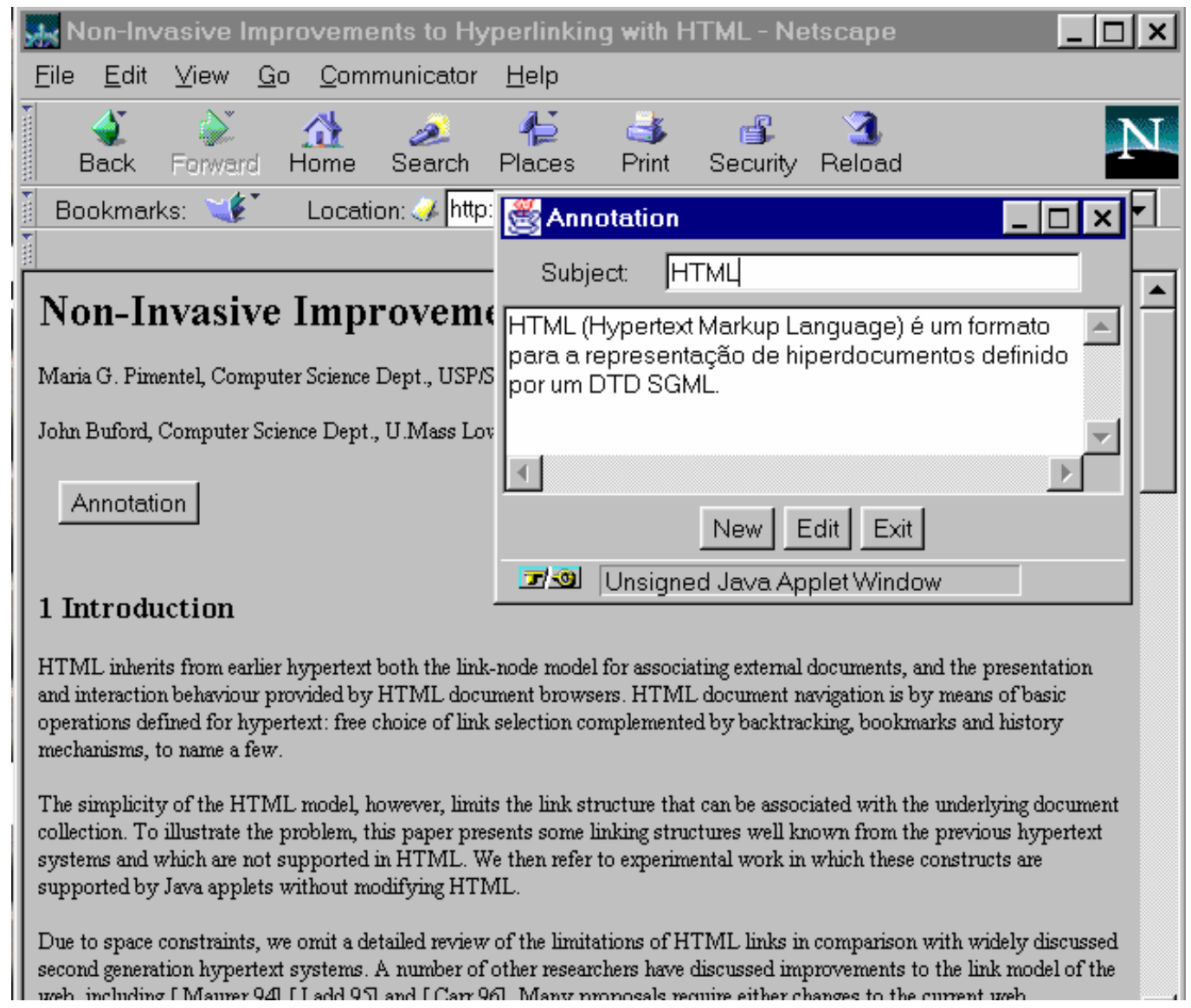

Figura C.1: Interface gráfica da applet para anotações 


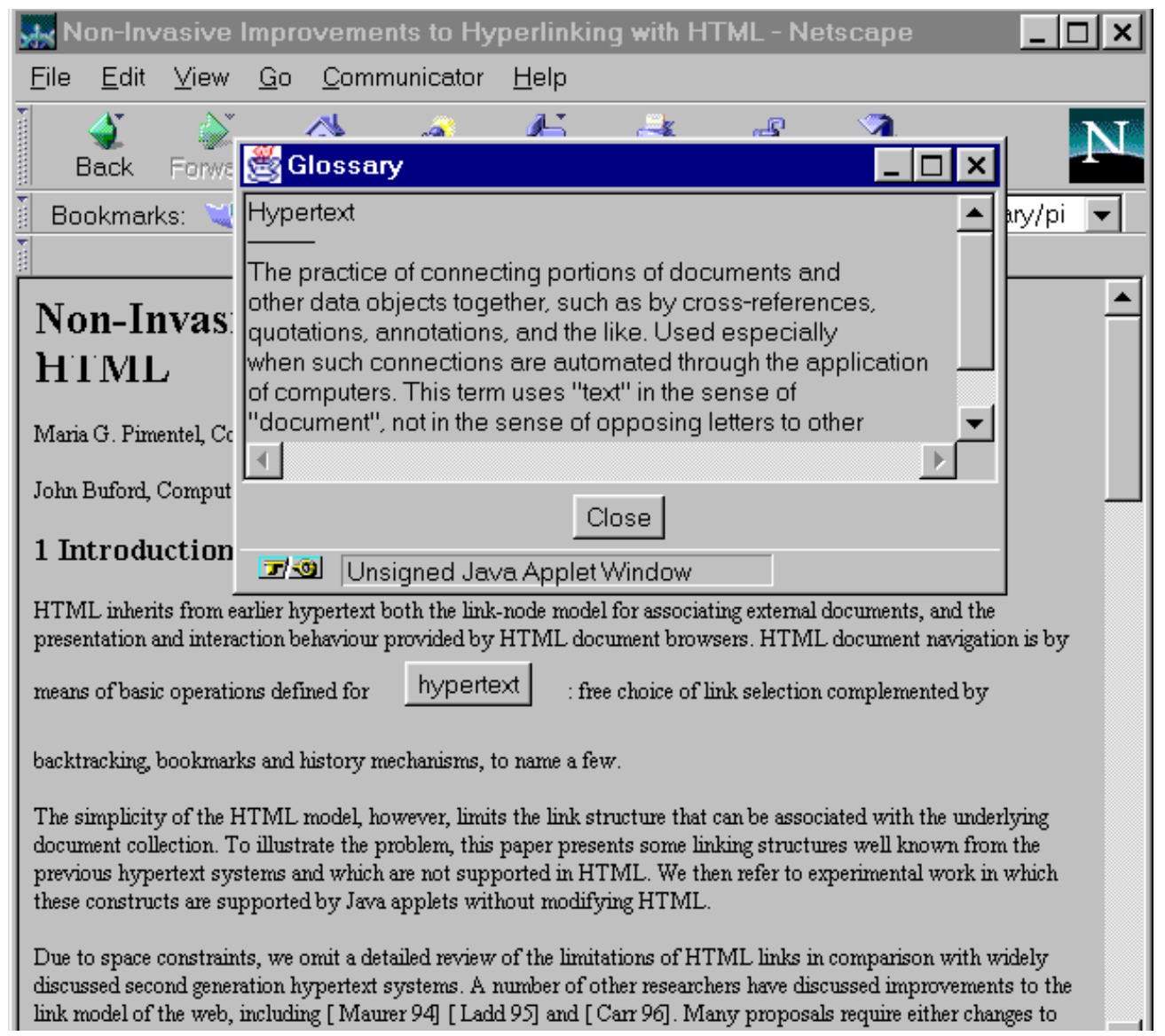

Figura C.2: Interface gráfica da applet para glossários 


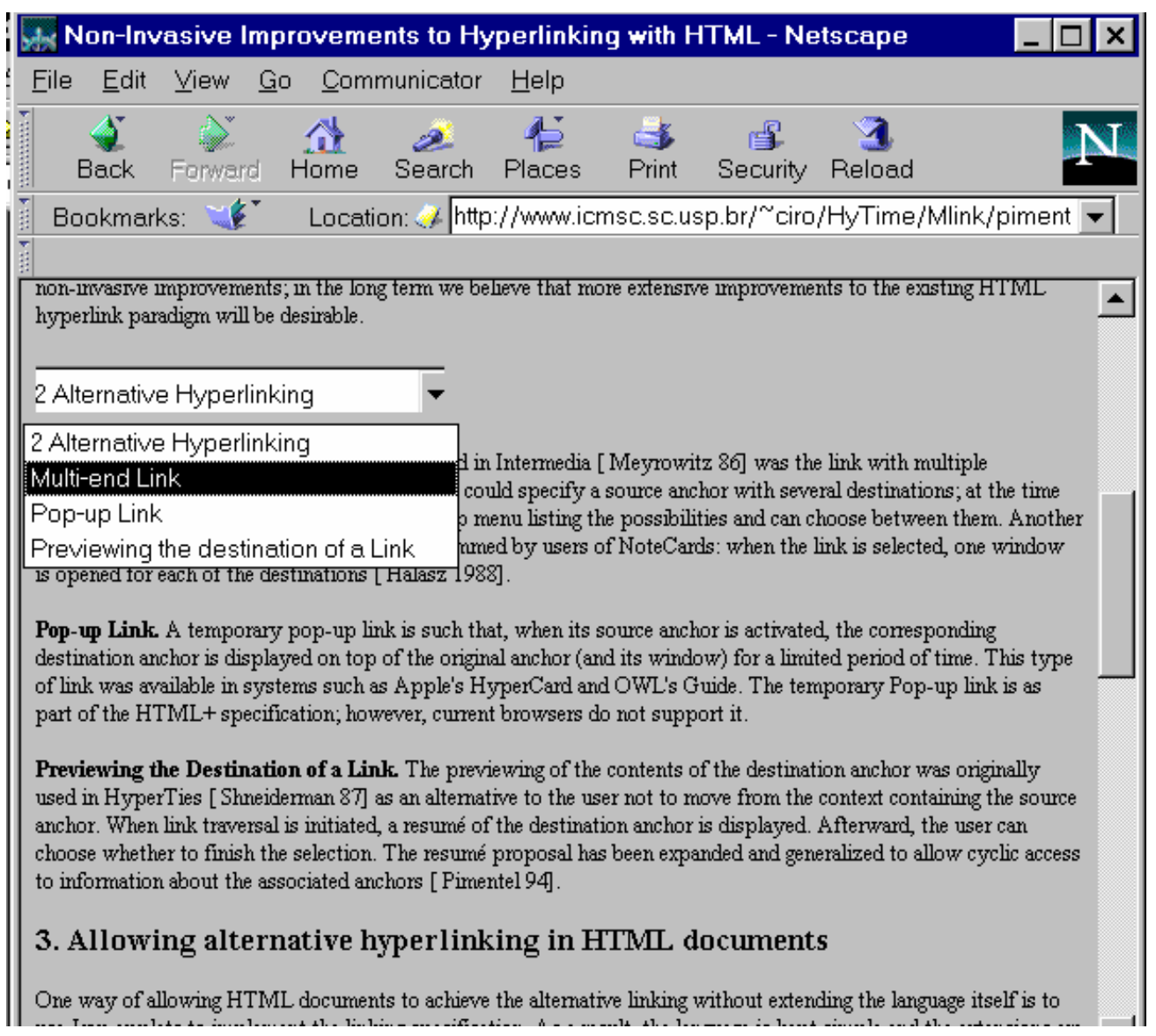

Figura C.3: Interface gráfica da applet para elos multi-destino 


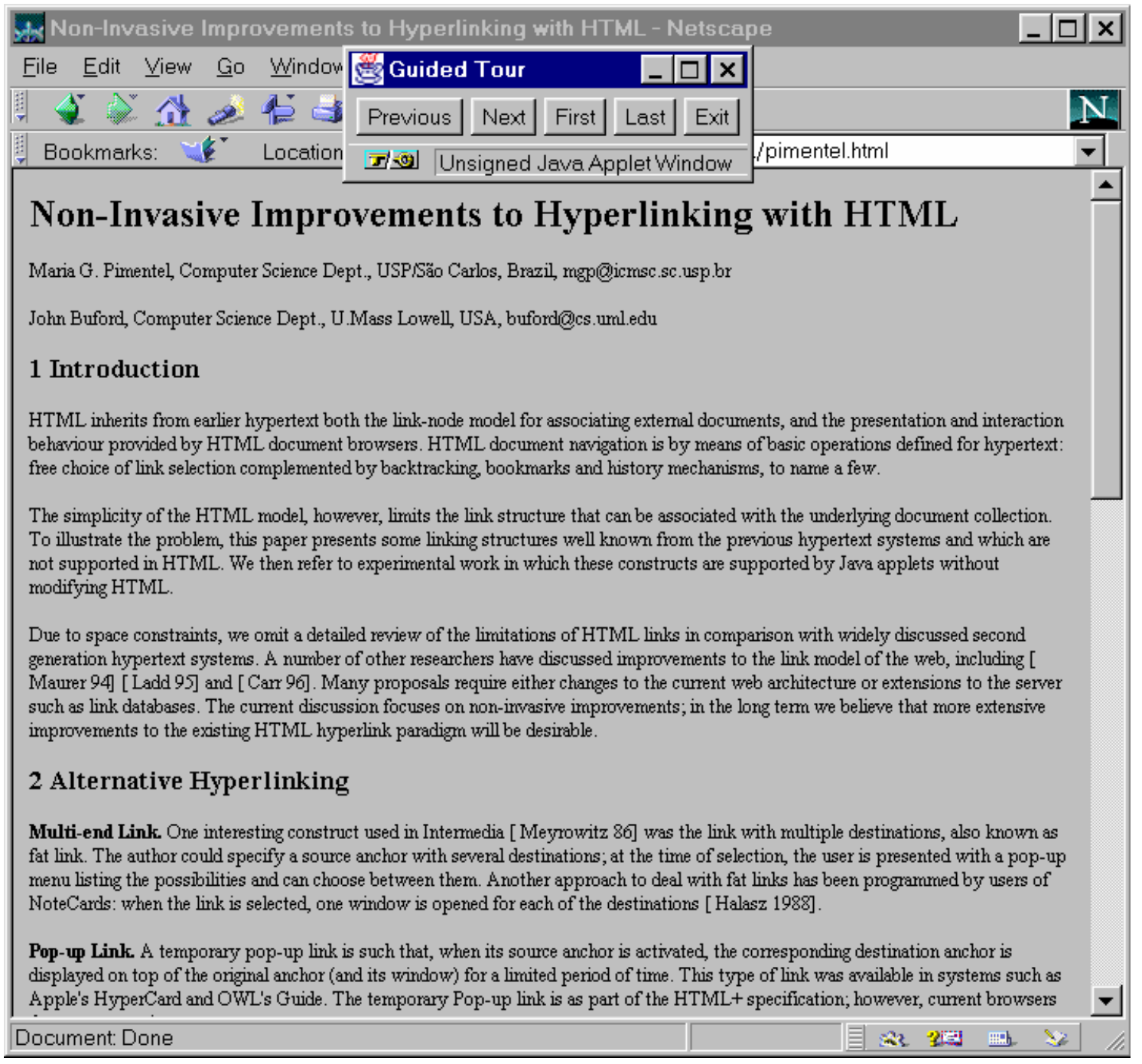

Figura C.4: Interface gráfica da applet para guided tours

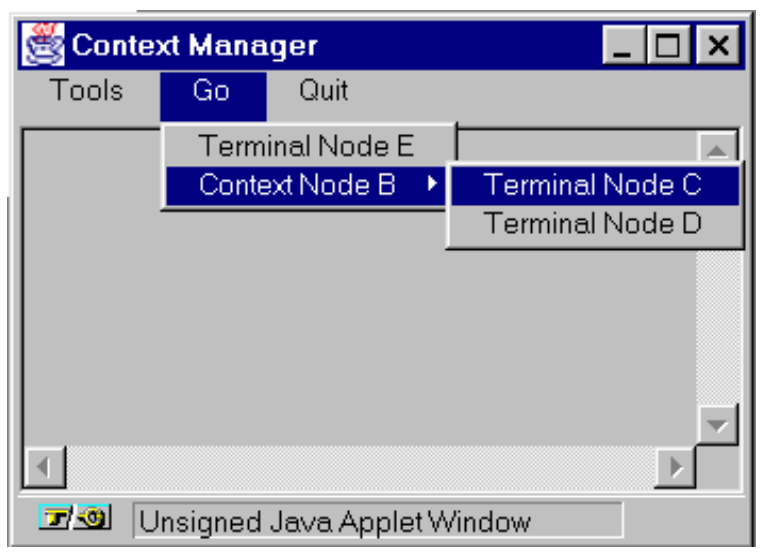

Figura C.5: Interface gráfica da applet para composições 